
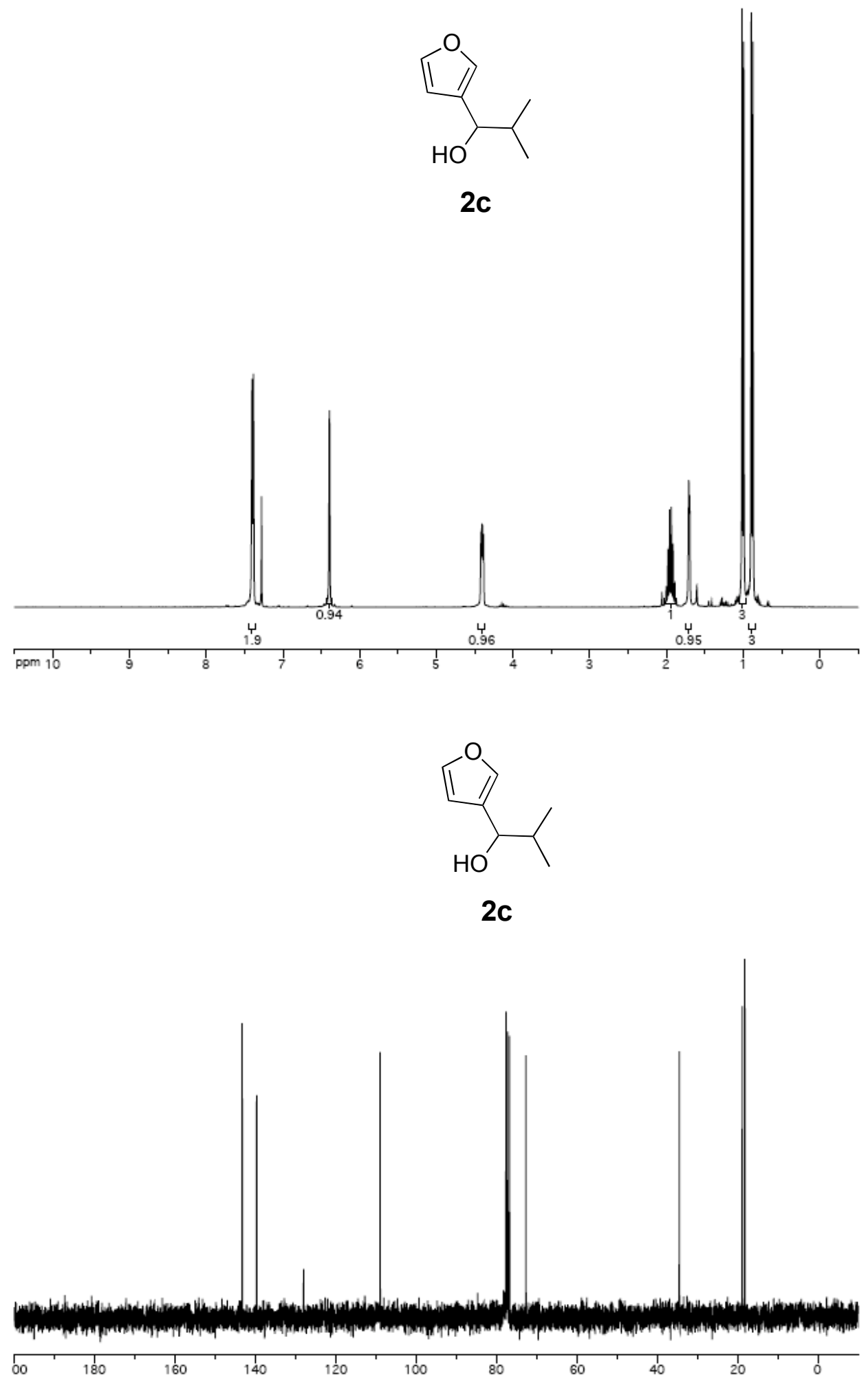

$360 \mathrm{MHz}{ }^{1} \mathrm{H}$ and $90 \mathrm{MHz}{ }^{13} \mathrm{C}\left\{{ }^{1} \mathrm{H}\right\}$ NMR in $\mathrm{CDCl}_{3}$ 


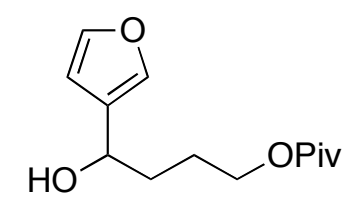

2d
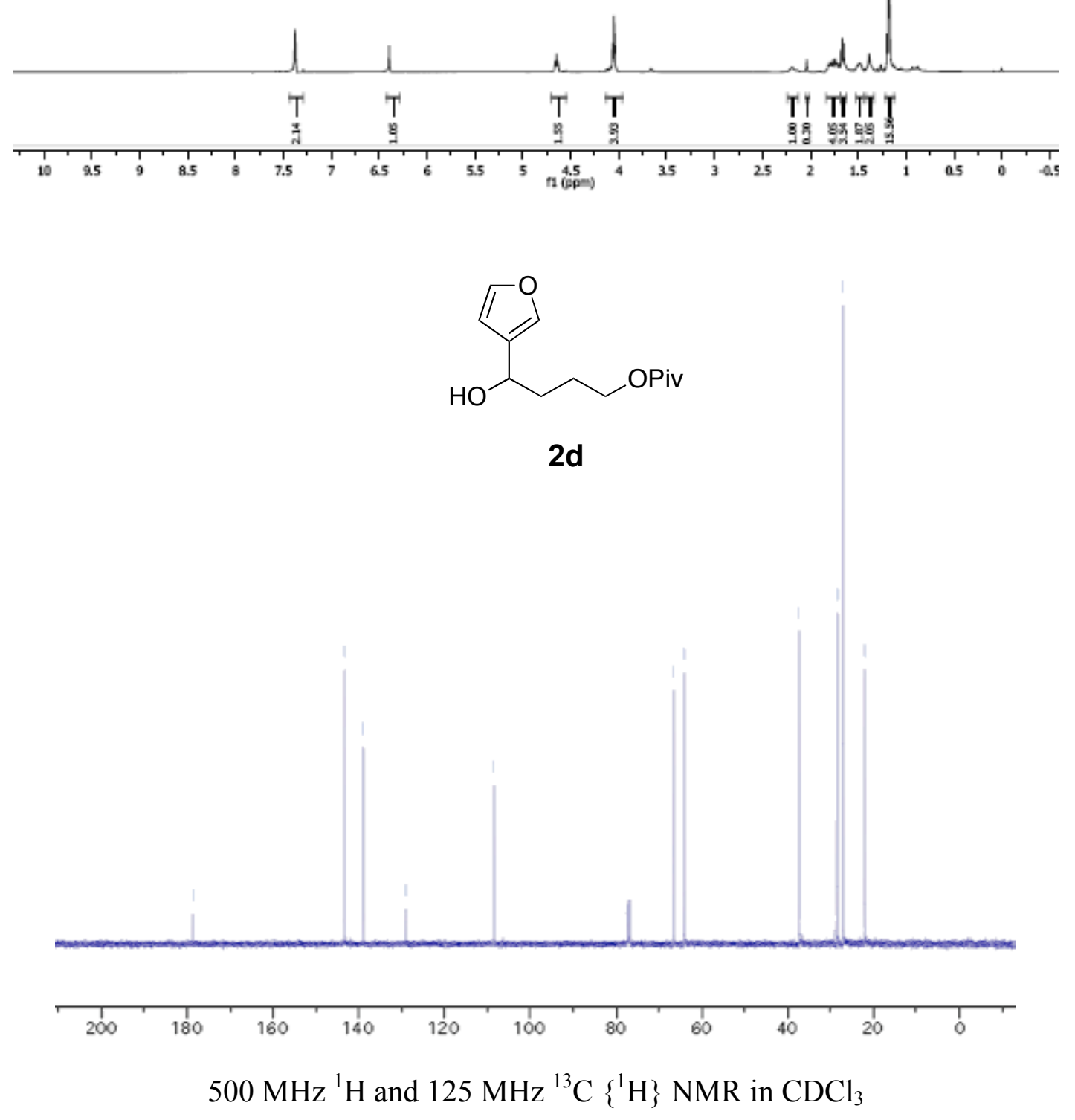

SI-44 


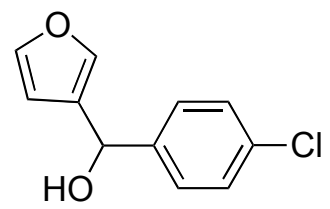

\section{$2 f$}
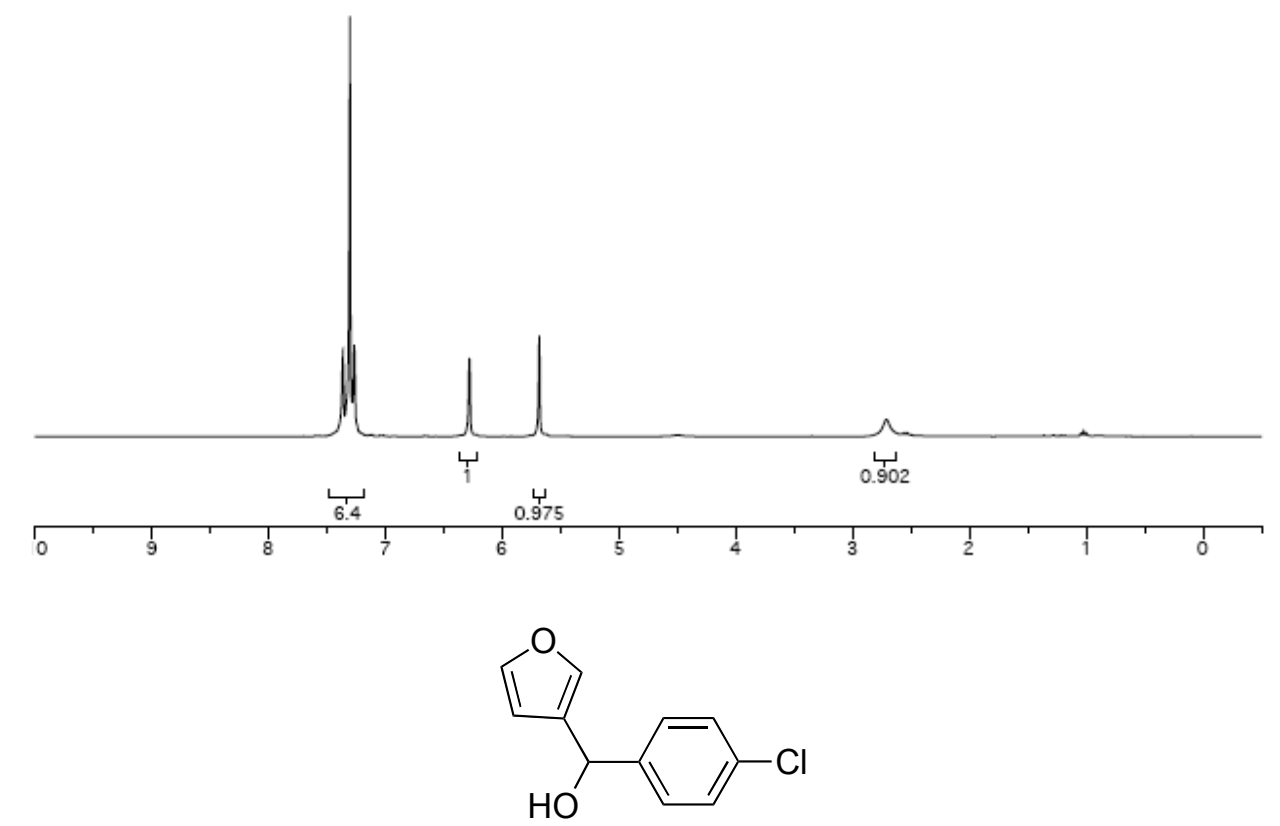

$2 f$
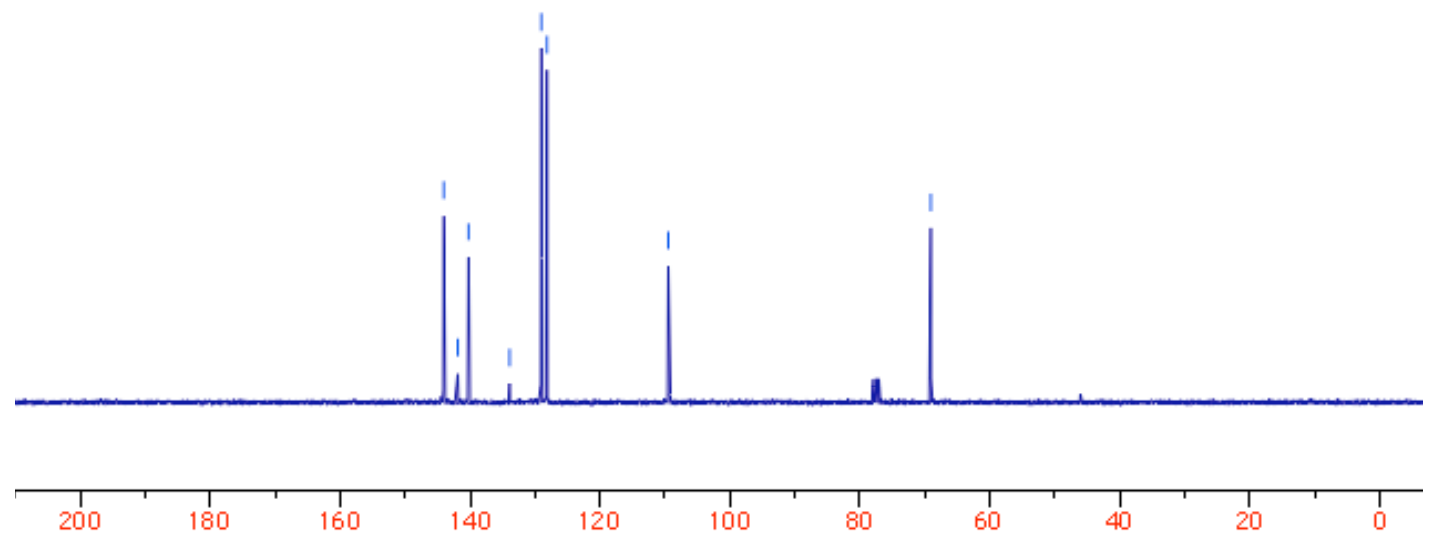

$300 \mathrm{MHz}{ }^{1} \mathrm{H}$ and $75 \mathrm{MHz}{ }^{13} \mathrm{C}\left\{{ }^{1} \mathrm{H}\right\} \mathrm{NMR}$ in $\mathrm{CDCl}_{3}$ 

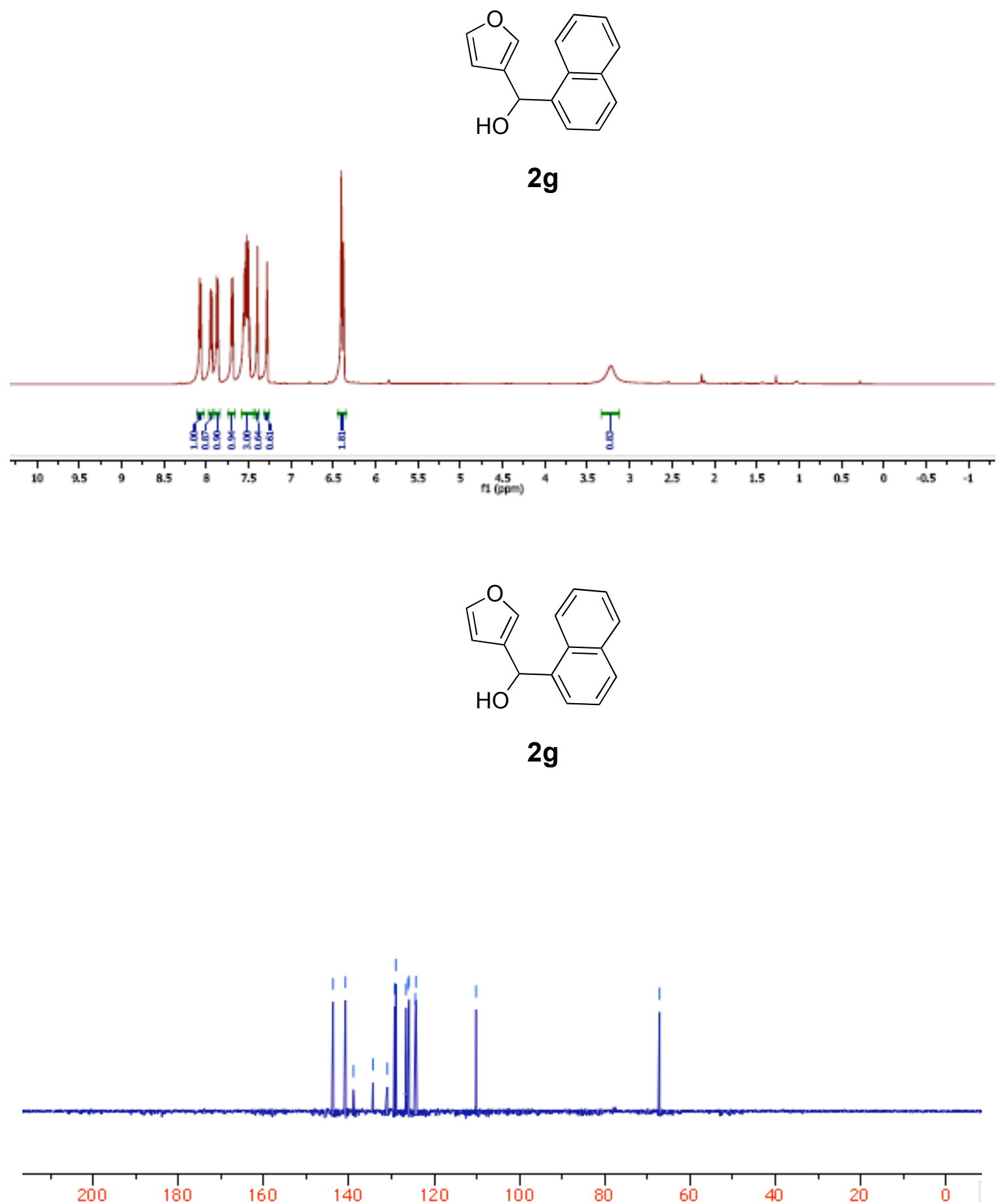

$500 \mathrm{MHz}{ }^{1} \mathrm{H}$ and $125 \mathrm{MHz}{ }^{13} \mathrm{C}\left\{{ }^{1} \mathrm{H}\right\}$ NMR in $\mathrm{CDCl}_{3}$ 


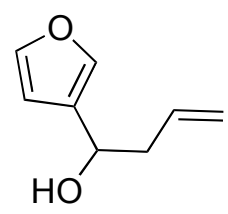

$2 \mathrm{~h}$
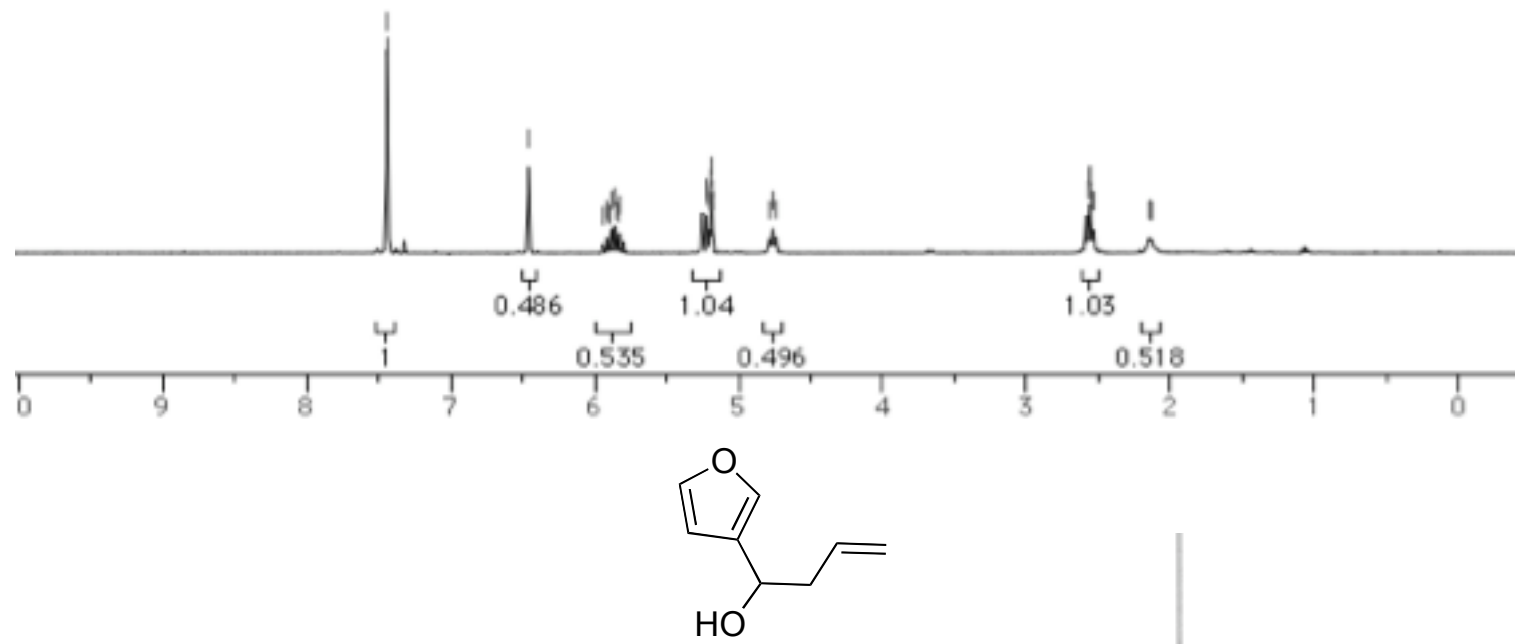

2h

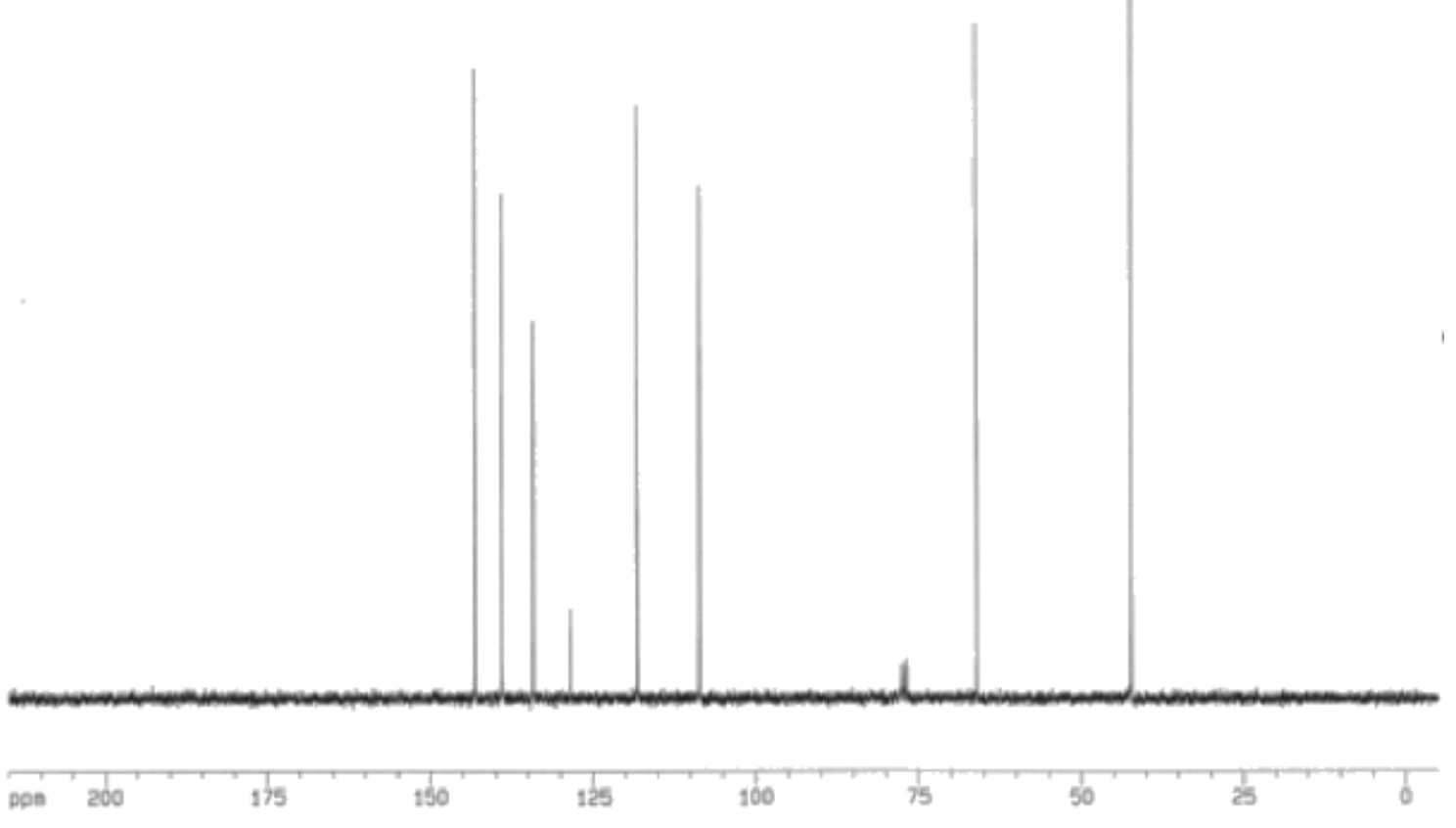

$300 \mathrm{MHz}{ }^{1} \mathrm{H}$ and $125 \mathrm{MHz}^{13} \mathrm{C}\left\{{ }^{1} \mathrm{H}\right\}$ NMR in $\mathrm{CDCl}_{3}$ 


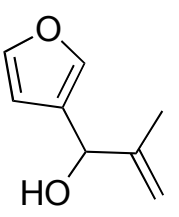

2i
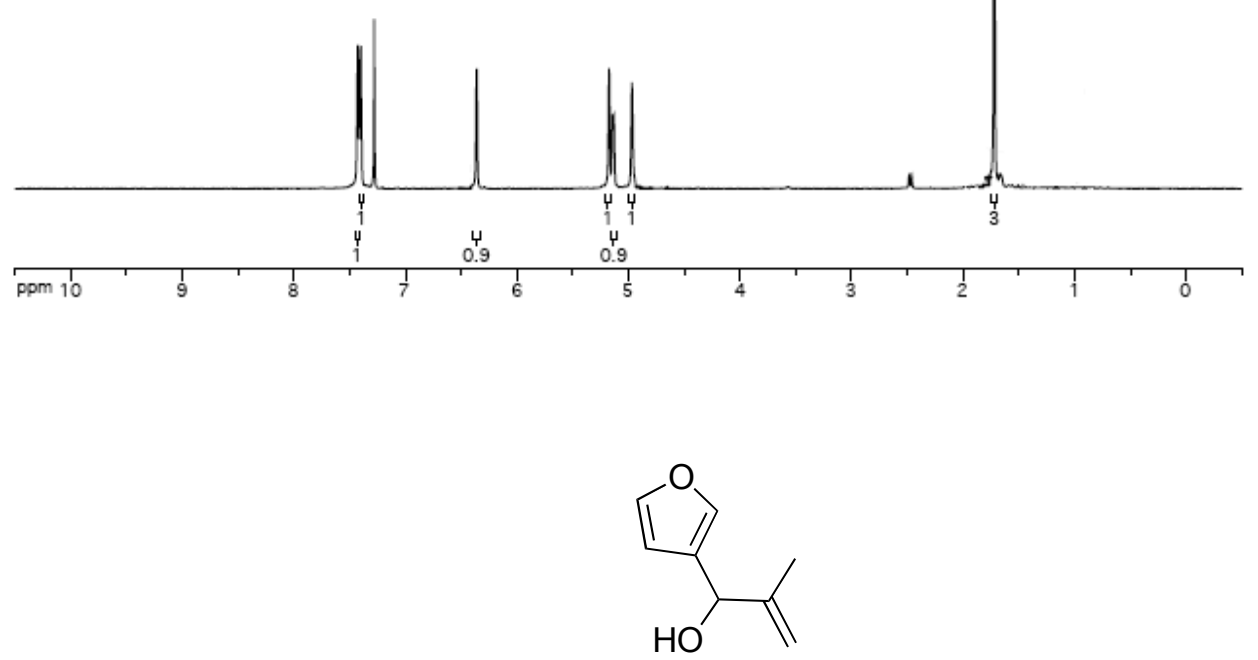

2i
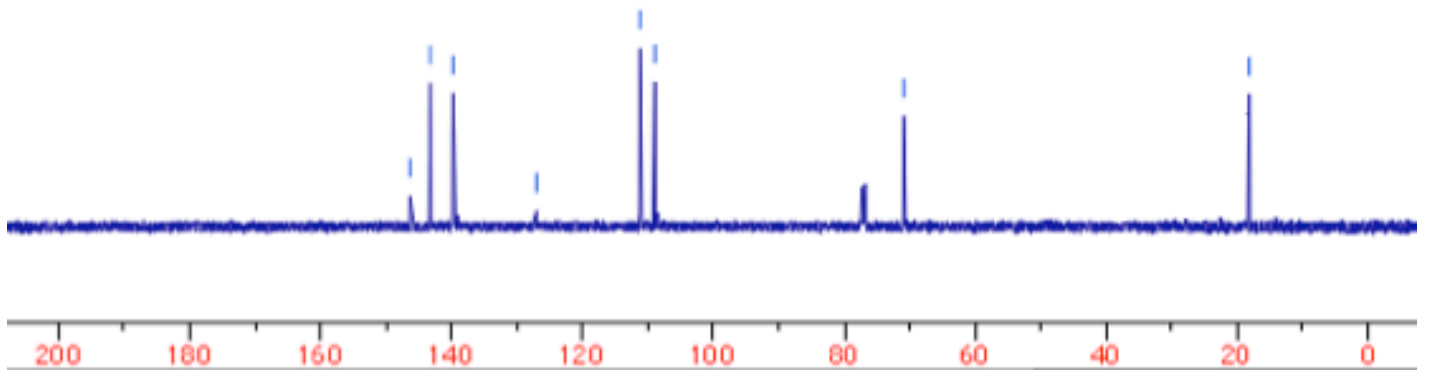

$300 \mathrm{MHz}{ }^{1} \mathrm{H}$ and $125 \mathrm{MHz}{ }^{13} \mathrm{C}\left\{{ }^{1} \mathrm{H}\right\} \mathrm{NMR}$ in $\mathrm{CDCl}_{3}$ 


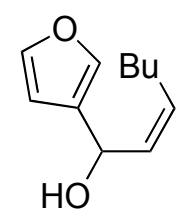

2j
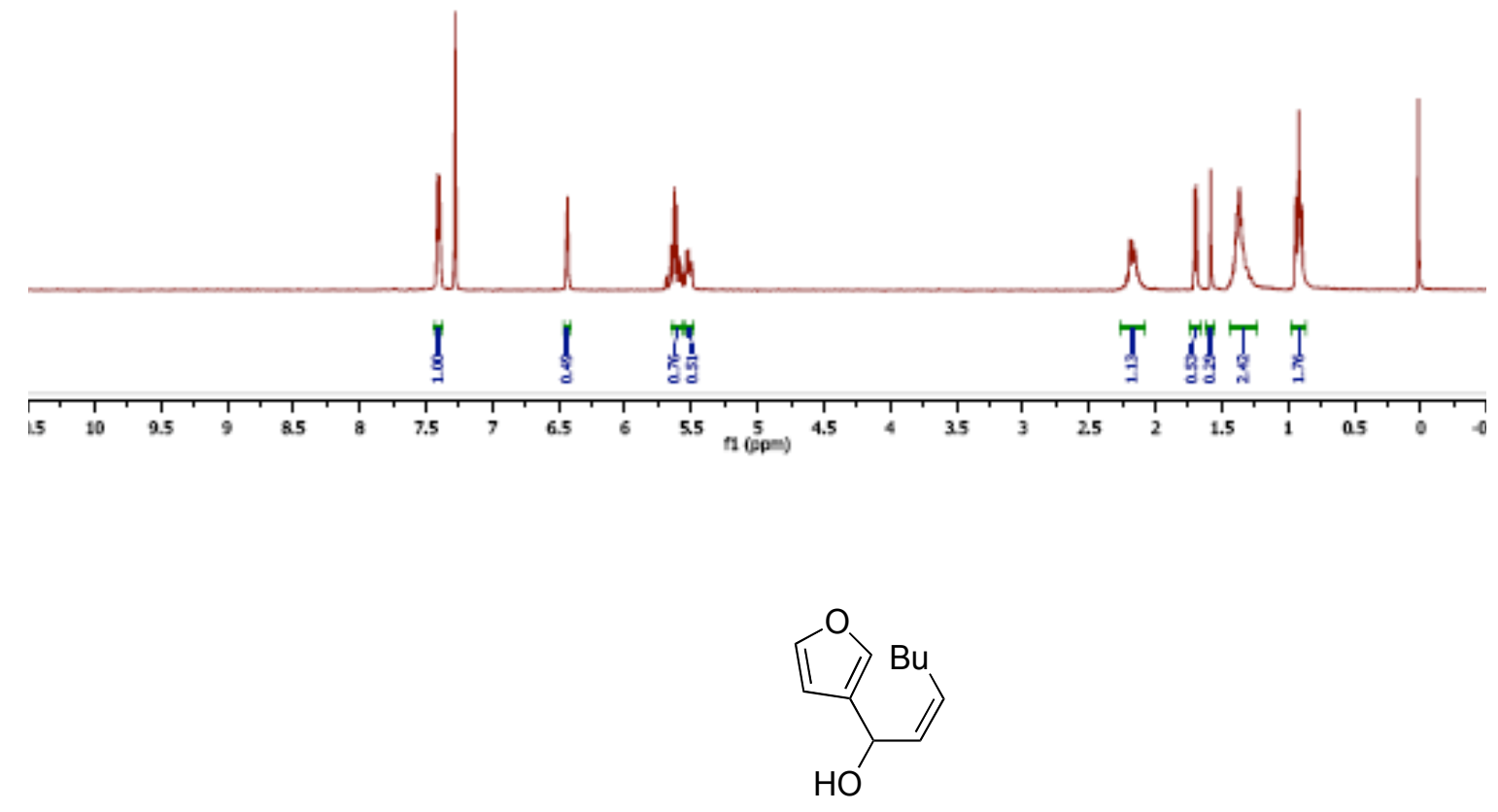

2j
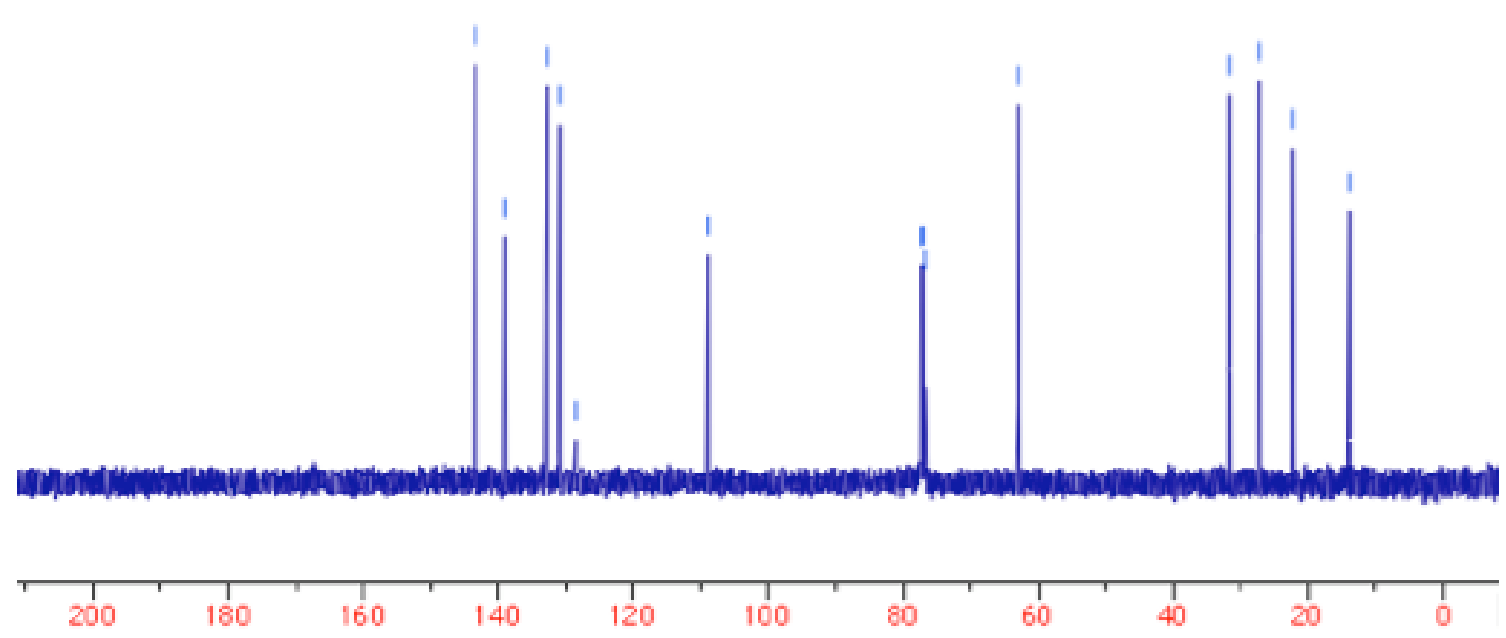

$500 \mathrm{MHz}{ }^{1} \mathrm{H}$ and $125 \mathrm{MHz}{ }^{13} \mathrm{C}\left\{{ }^{1} \mathrm{H}\right\} \mathrm{NMR}$ in $\mathrm{CDCl}_{3}$ 

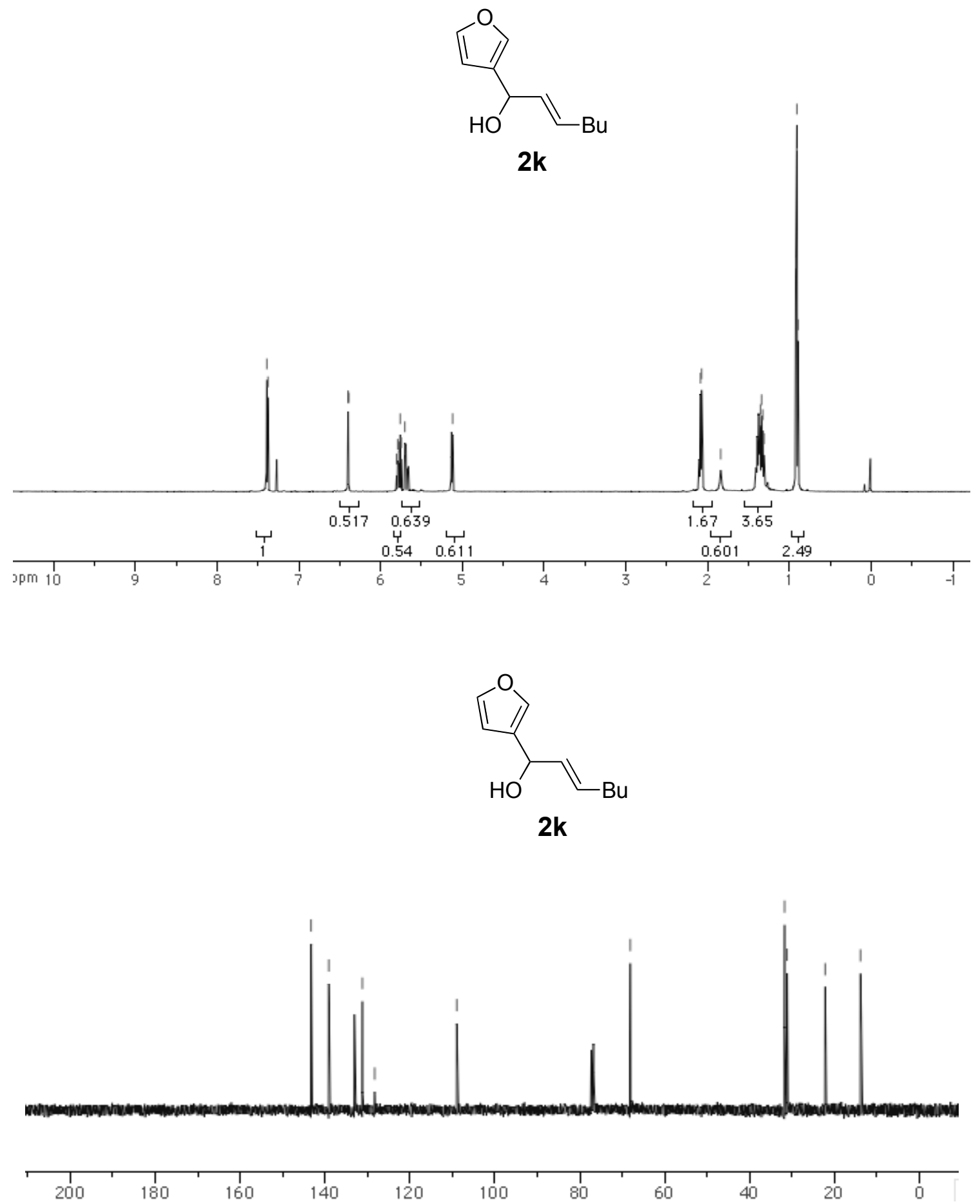

$500 \mathrm{MHz}{ }^{1} \mathrm{H}$ and $125 \mathrm{MHz}{ }^{13} \mathrm{C}\left\{{ }^{1} \mathrm{H}\right\} \mathrm{NMR}$ in $\mathrm{CDCl}_{3}$ 


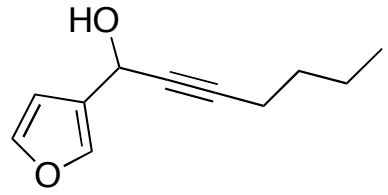

2I

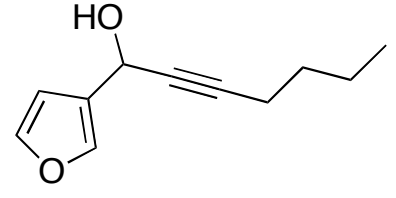

2I
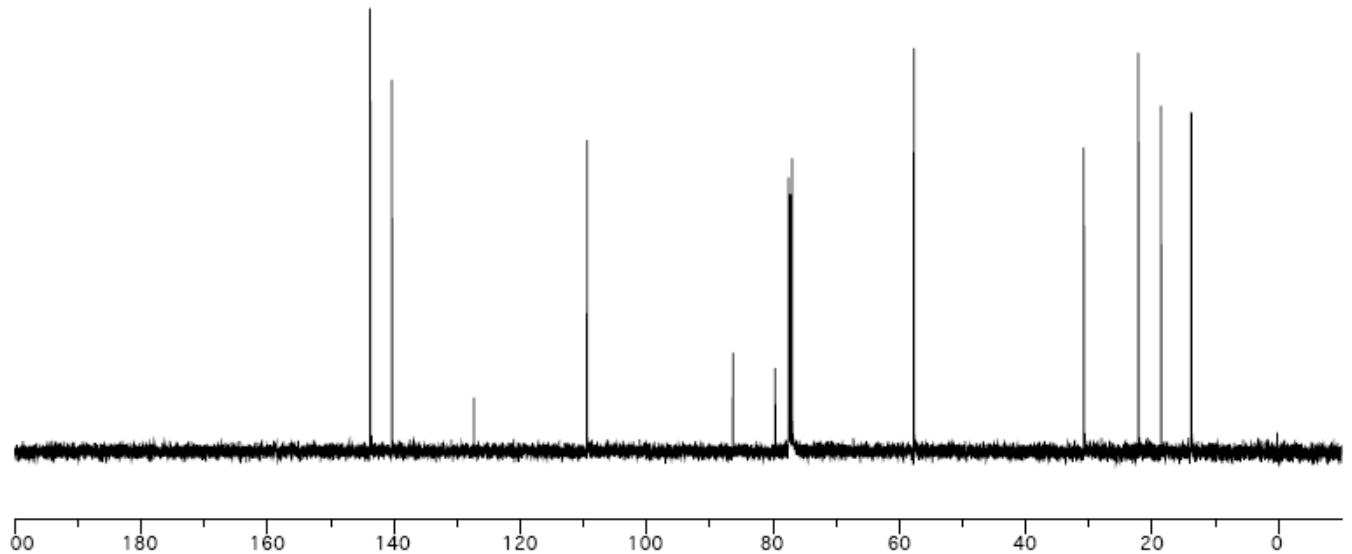

$500 \mathrm{MHz}{ }^{1} \mathrm{H}$ and $125 \mathrm{MHz}{ }^{13} \mathrm{C}\left\{{ }^{1} \mathrm{H}\right\}$ NMR in $\mathrm{CDCl}_{3}$. SI-51 


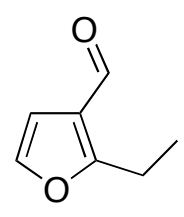

$3 a$
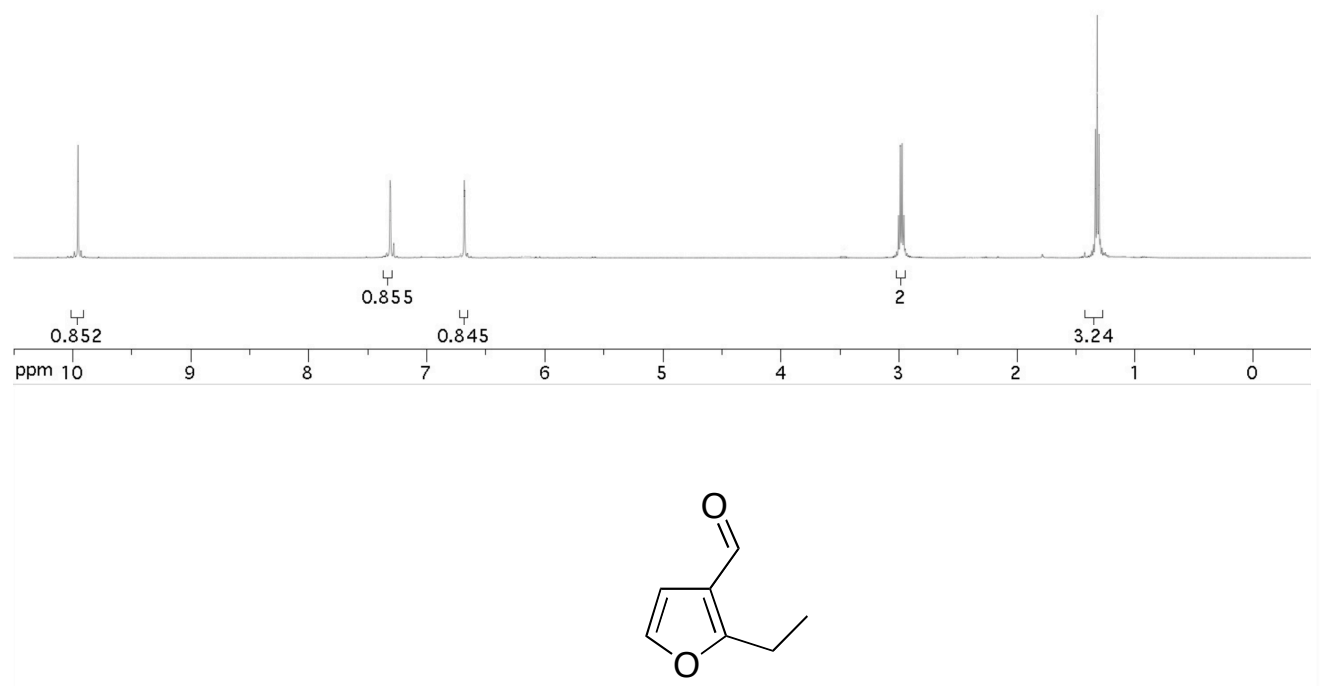

$3 a$

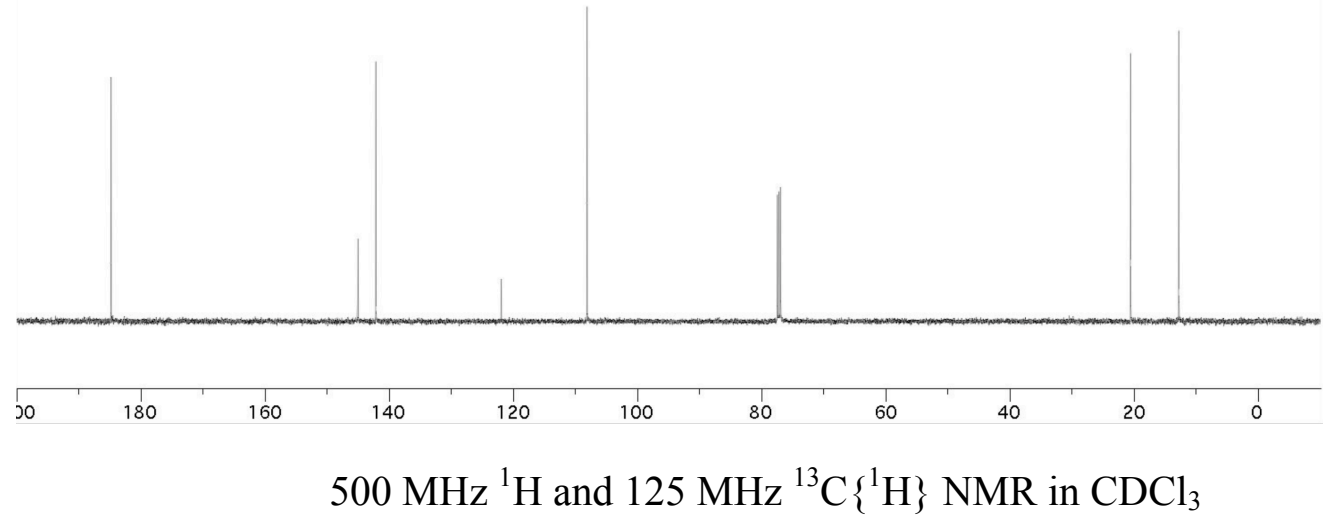

SI-52 


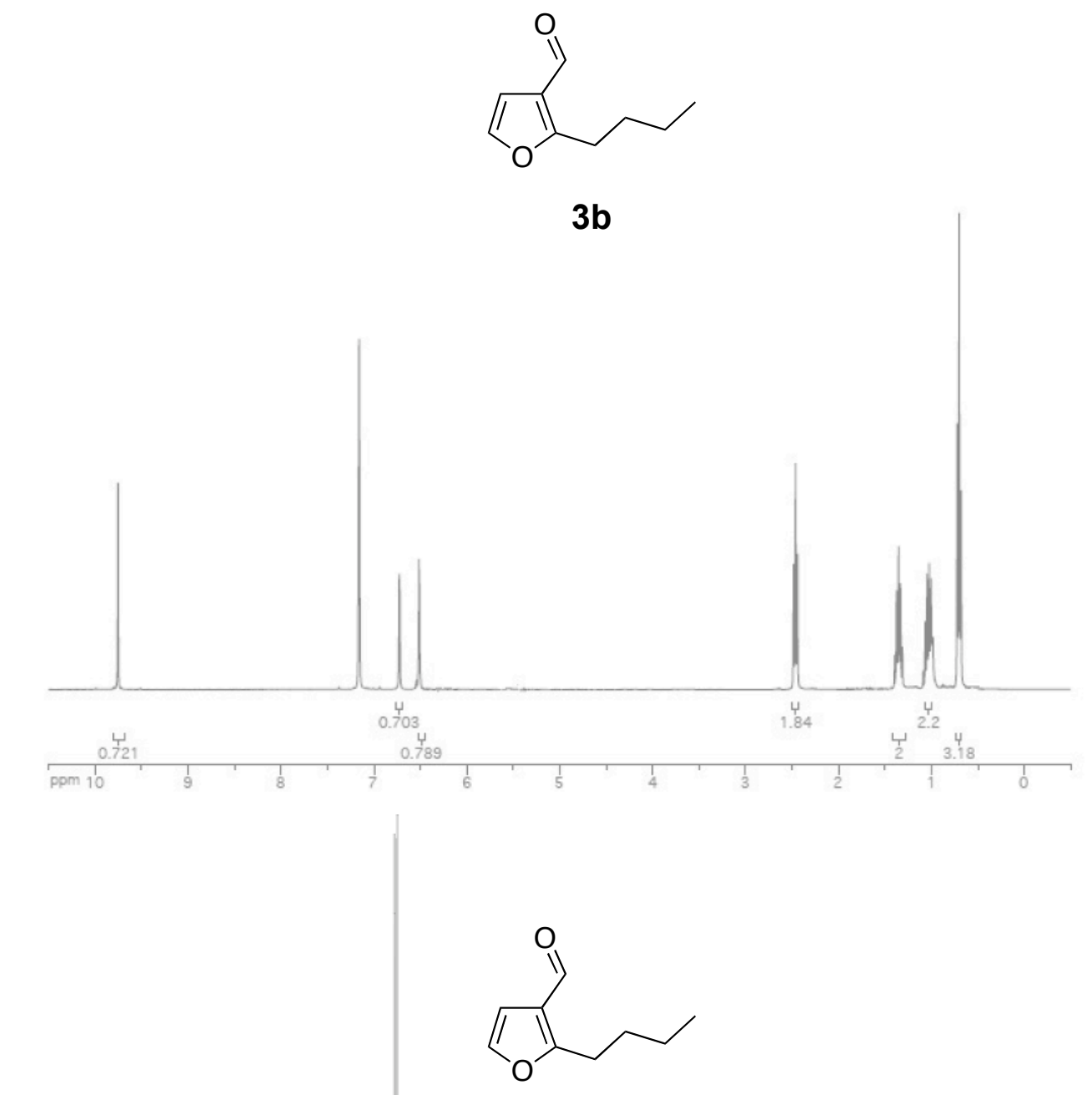

$3 b$

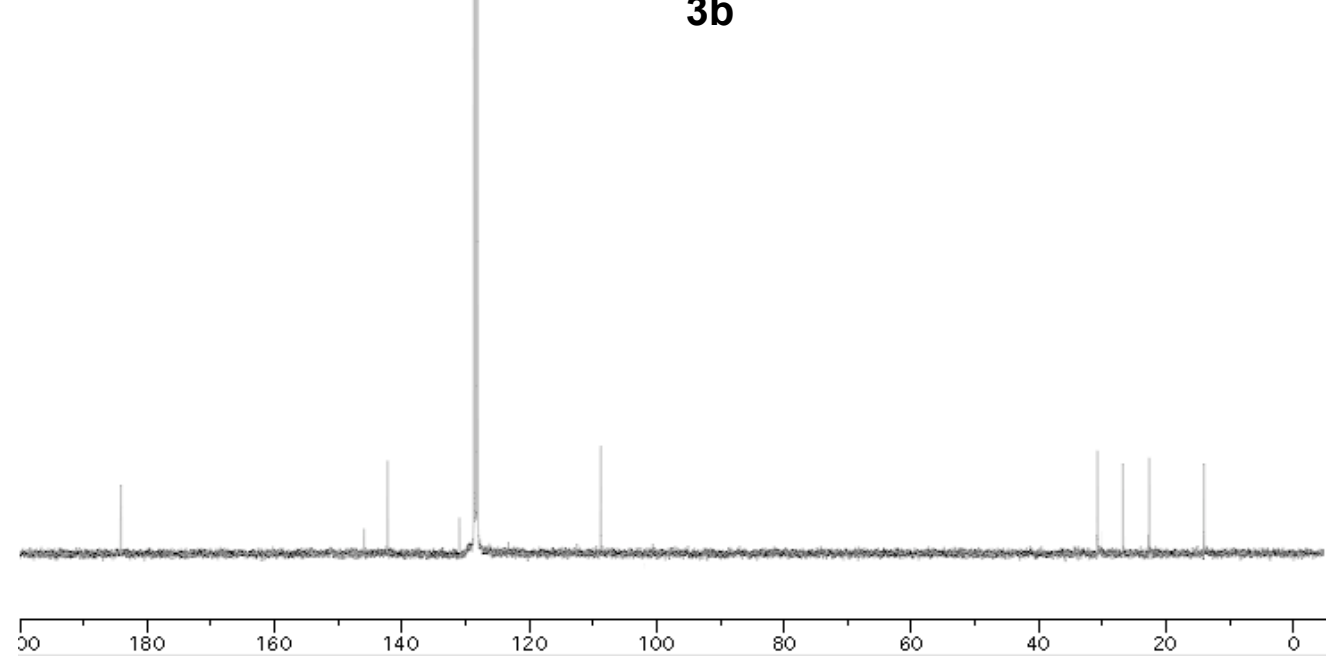

$360{ }^{1} \mathrm{H}$ and $90 \mathrm{MHz}{ }^{13} \mathrm{C}\left\{{ }^{1} \mathrm{H}\right\} \mathrm{NMR}$ in $\mathrm{C}_{6} \mathrm{D}_{6}$

SI-53 

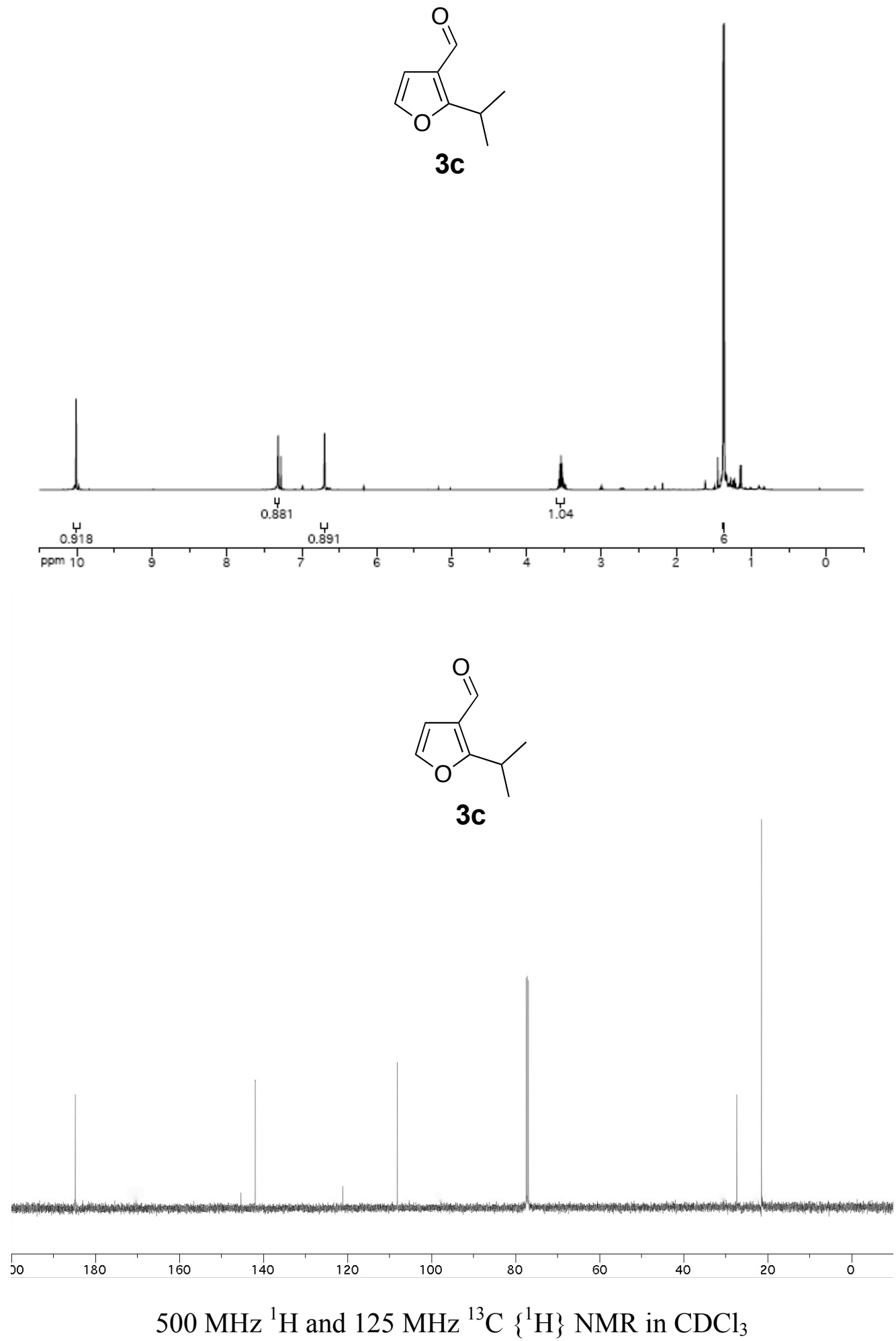

SI-54 

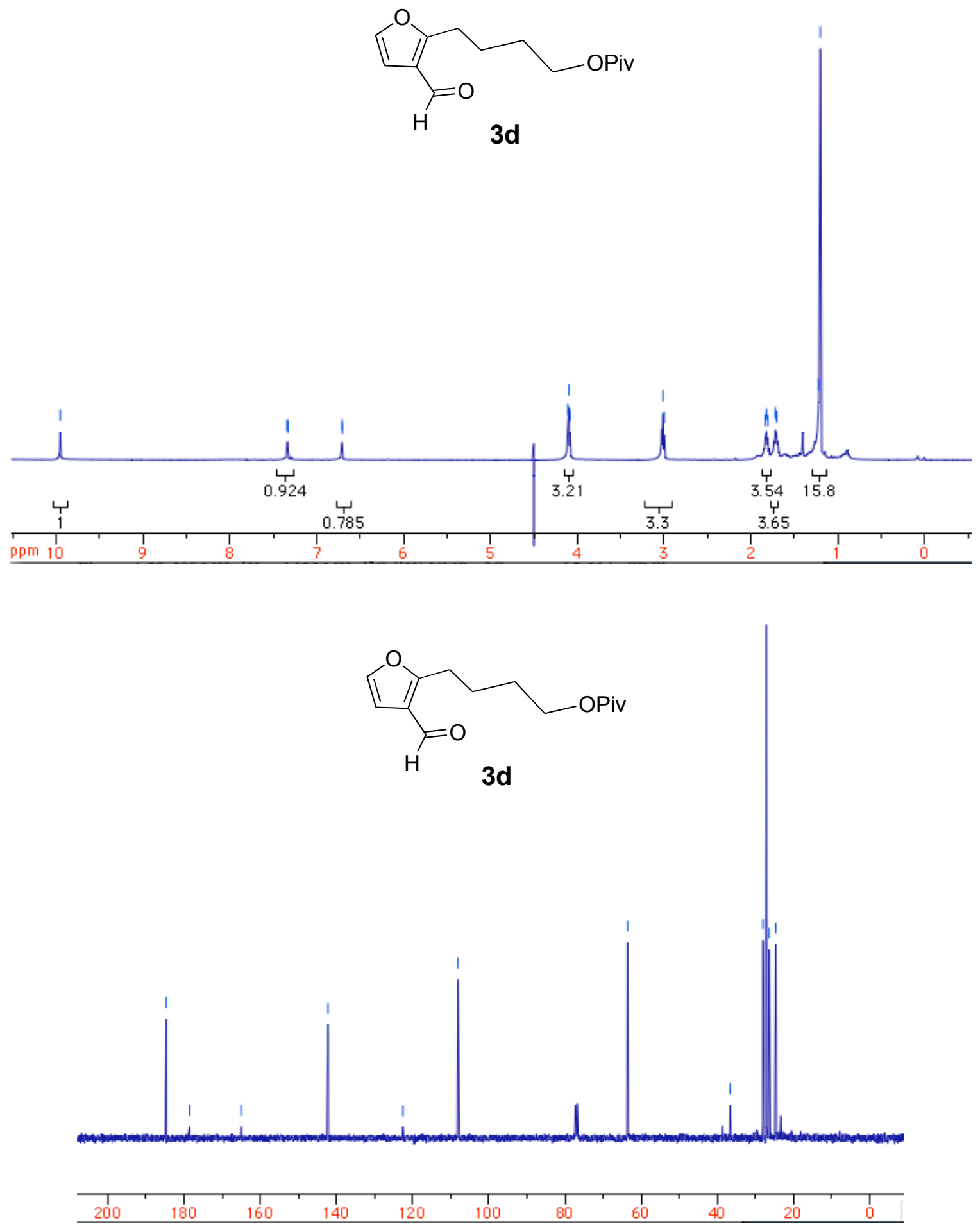

$500 \mathrm{MHz}{ }^{1} \mathrm{H}$ and $125 \mathrm{MHz}^{13} \mathrm{C}\left\{{ }^{1} \mathrm{H}\right\}$ NMR in $\mathrm{CDCl}_{3}$ SI-55 

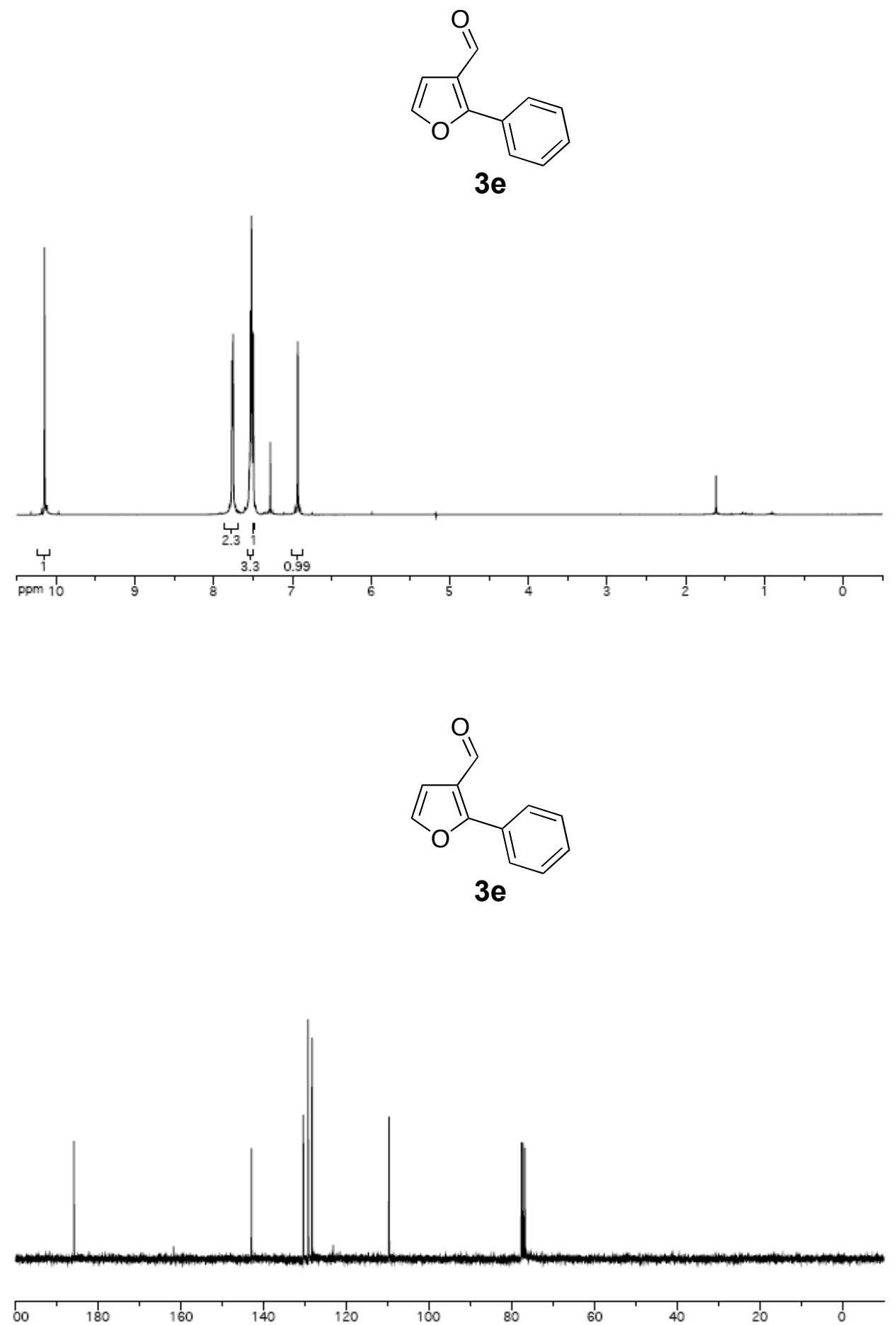

$500 \mathrm{MHz}{ }^{1} \mathrm{H}$ and $75 \mathrm{MHz}{ }^{13} \mathrm{C}\left\{{ }^{1} \mathrm{H}\right\}$ NMR in $\mathrm{CDCl}_{3}$

SI-56 

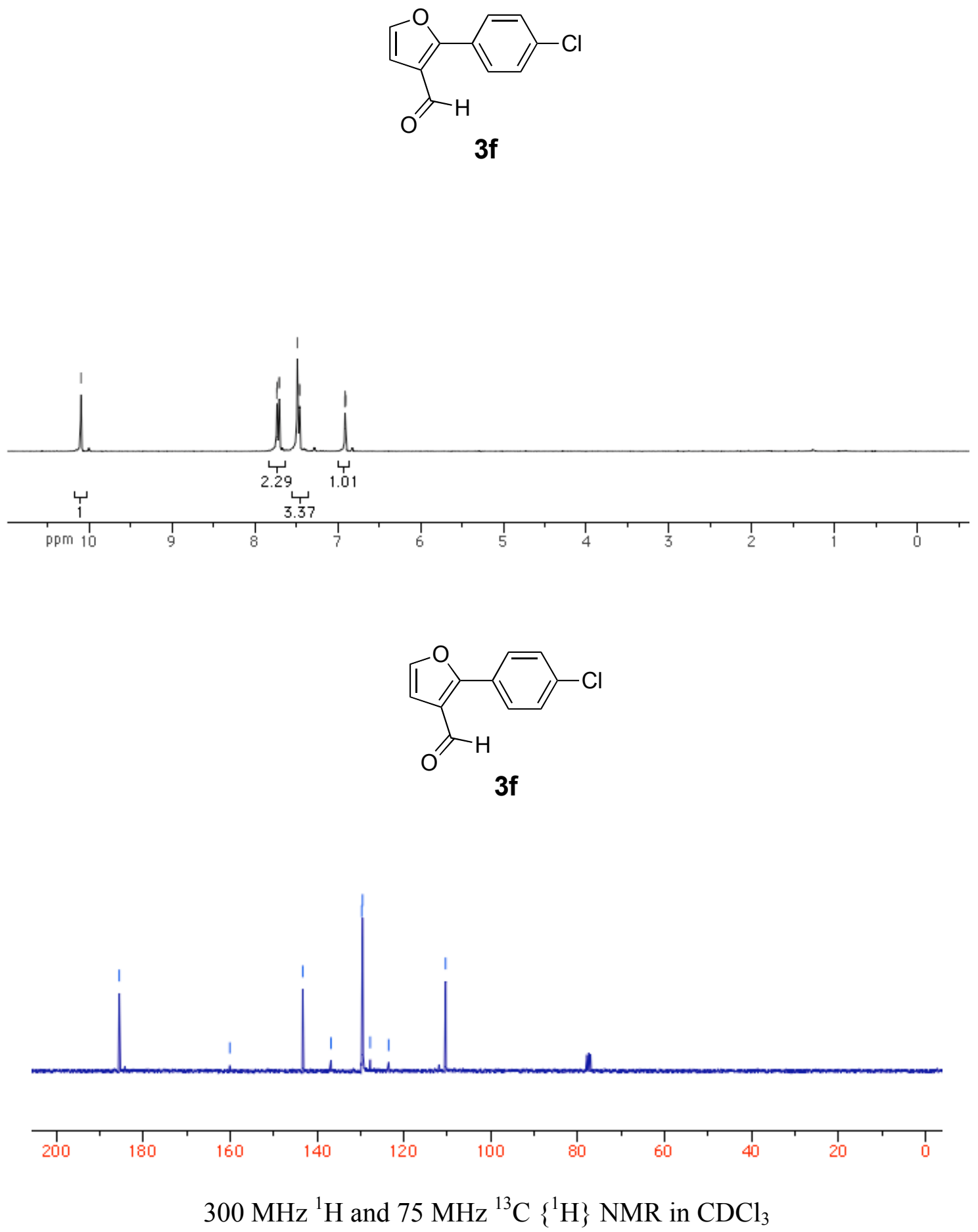


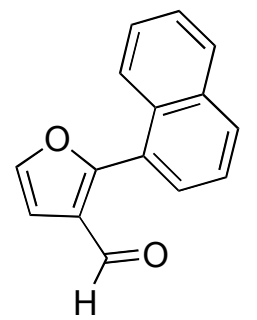

$3 \mathrm{~g}$
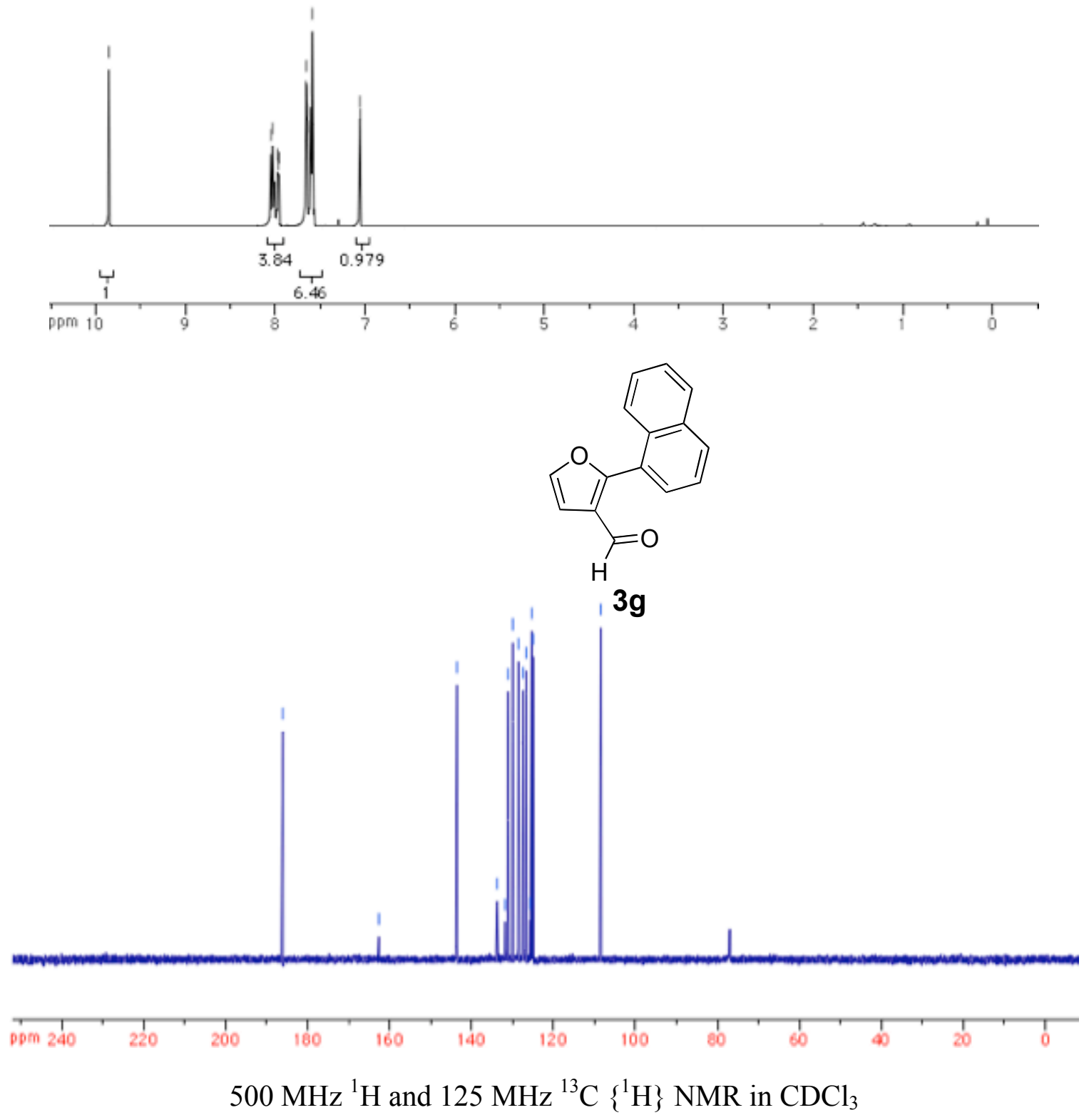

SI-58 


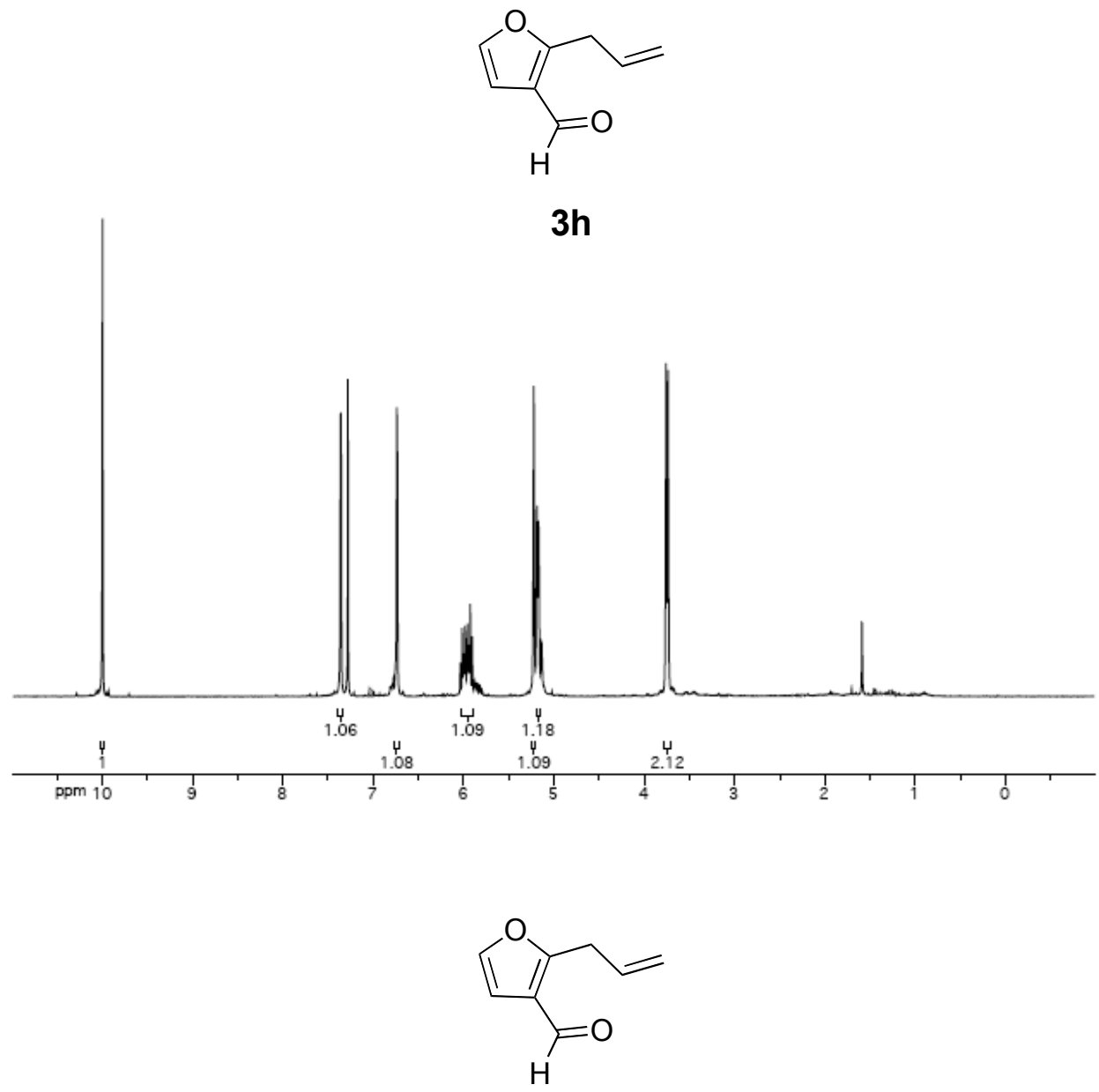

$3 h$
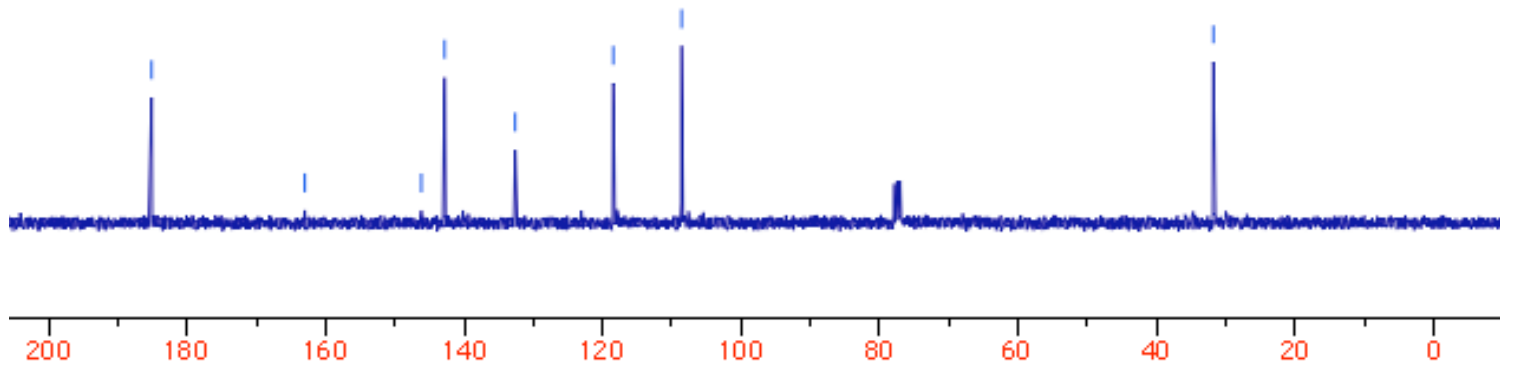

$300 \mathrm{MHz}{ }^{1} \mathrm{H}$ and $75 \mathrm{MHz}{ }^{13} \mathrm{C}\left\{{ }^{1} \mathrm{H}\right\}$ NMR in $\mathrm{CDCl}_{3}$ 

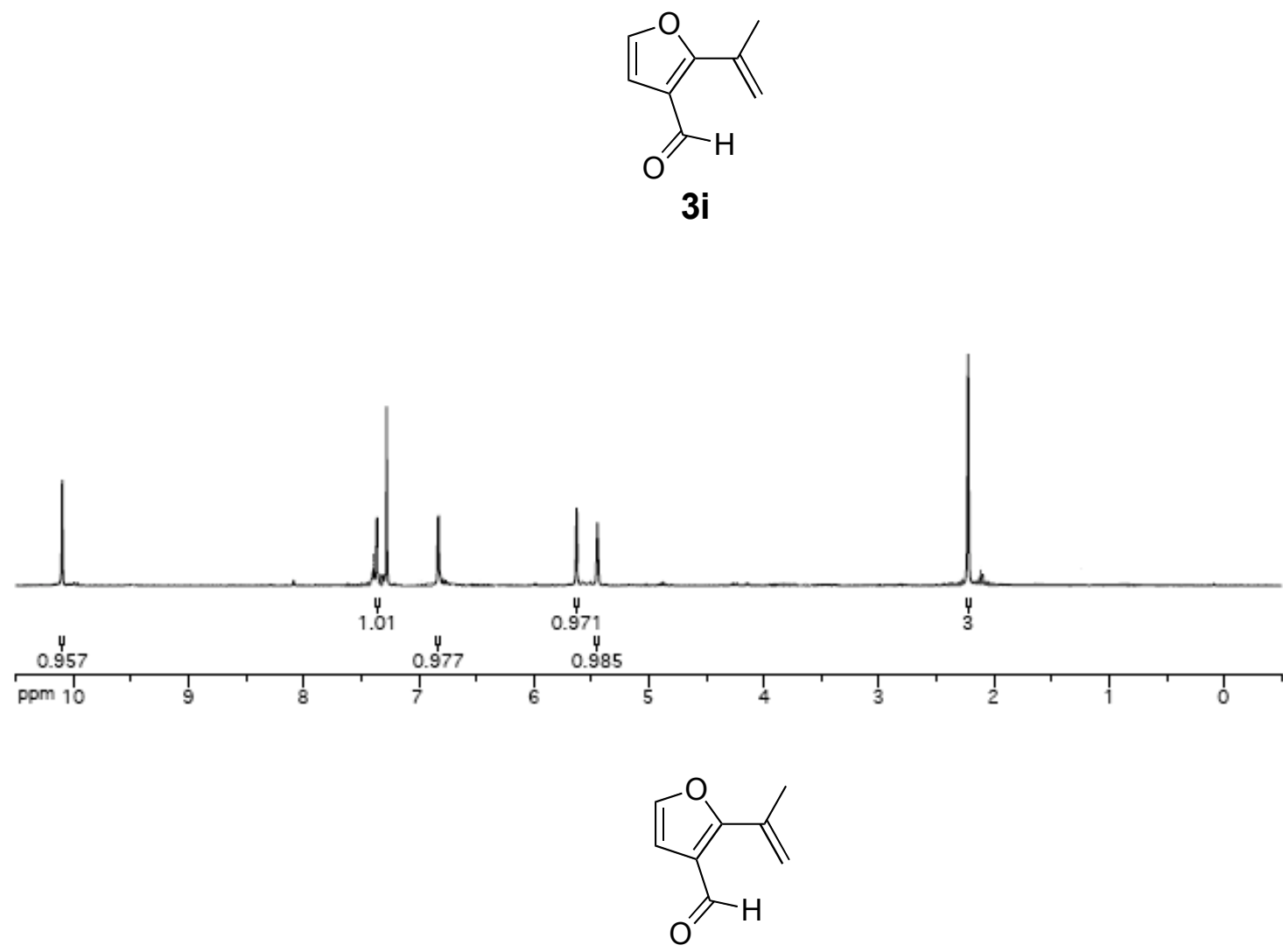

$3 \mathbf{i}$
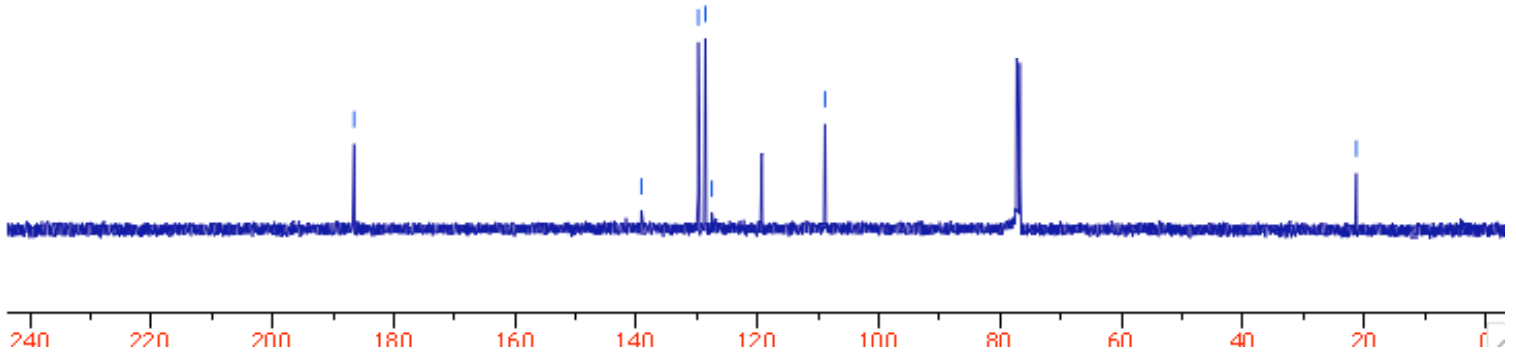

$300 \mathrm{MHz}{ }^{1} \mathrm{H}$ and $125 \mathrm{MHz}{ }^{13} \mathrm{C}\left\{{ }^{1} \mathrm{H}\right\}$ NMR in $\mathrm{CDCl}_{3}$ 

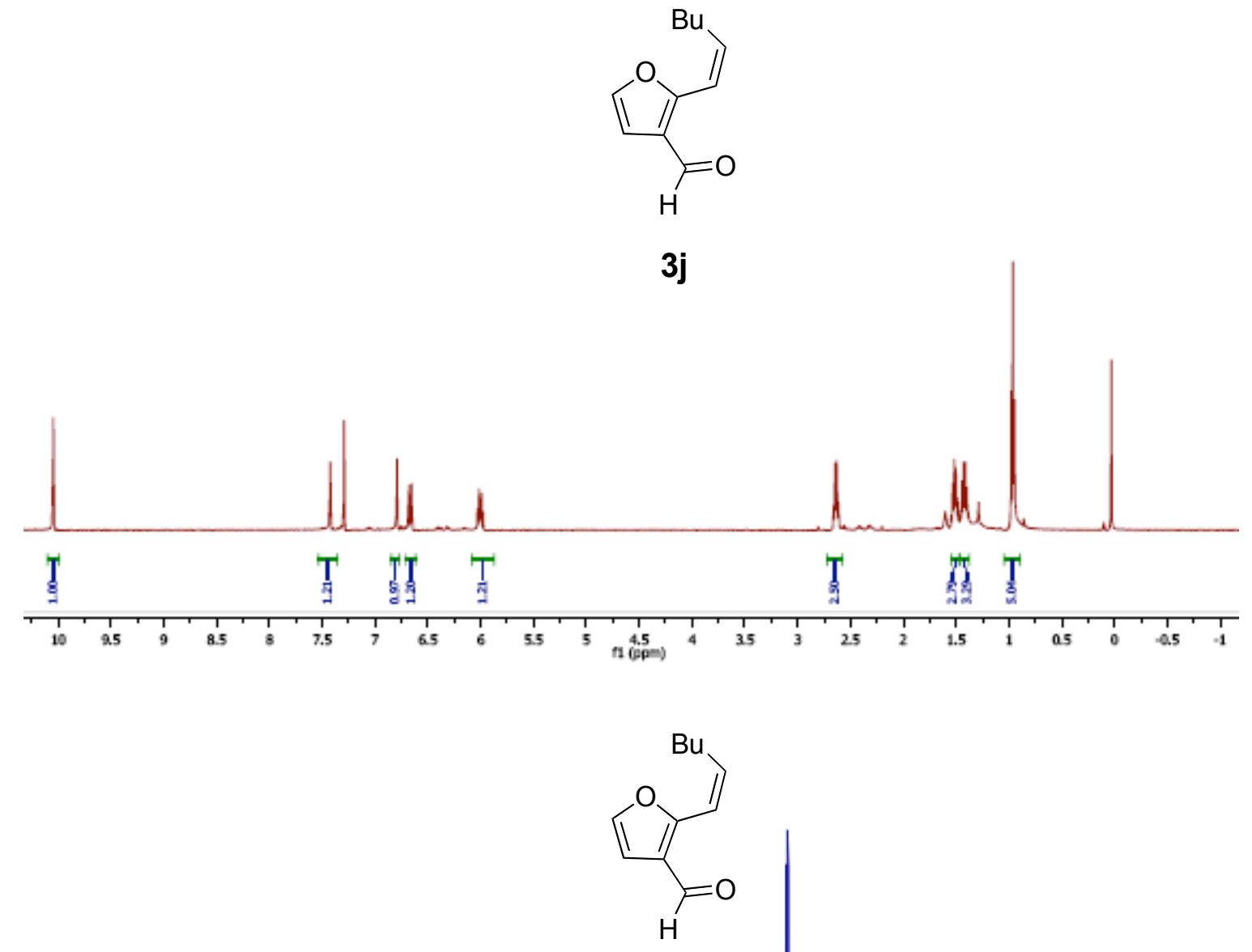

3j

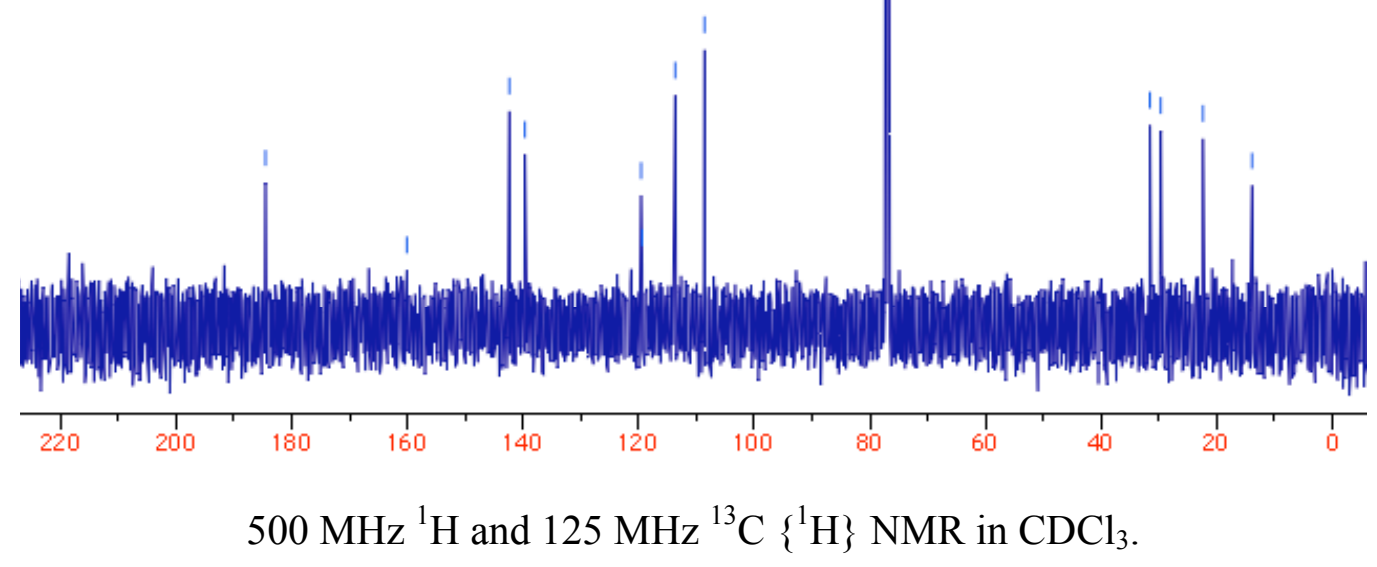

SI-61 

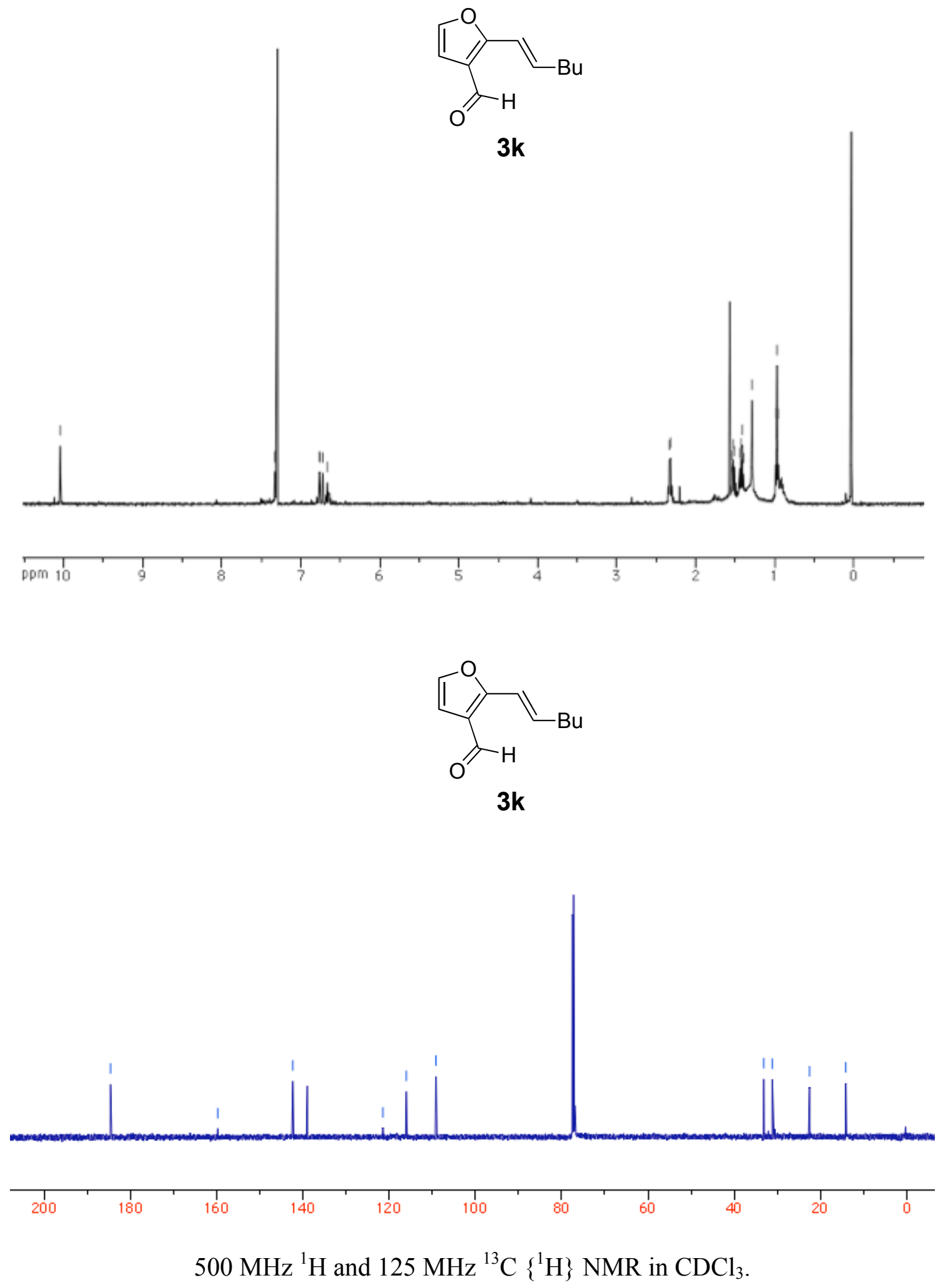

SI-62 


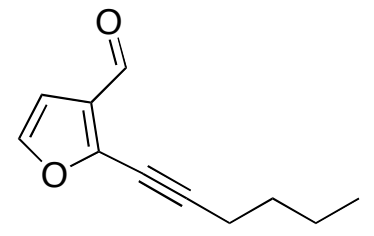

3I
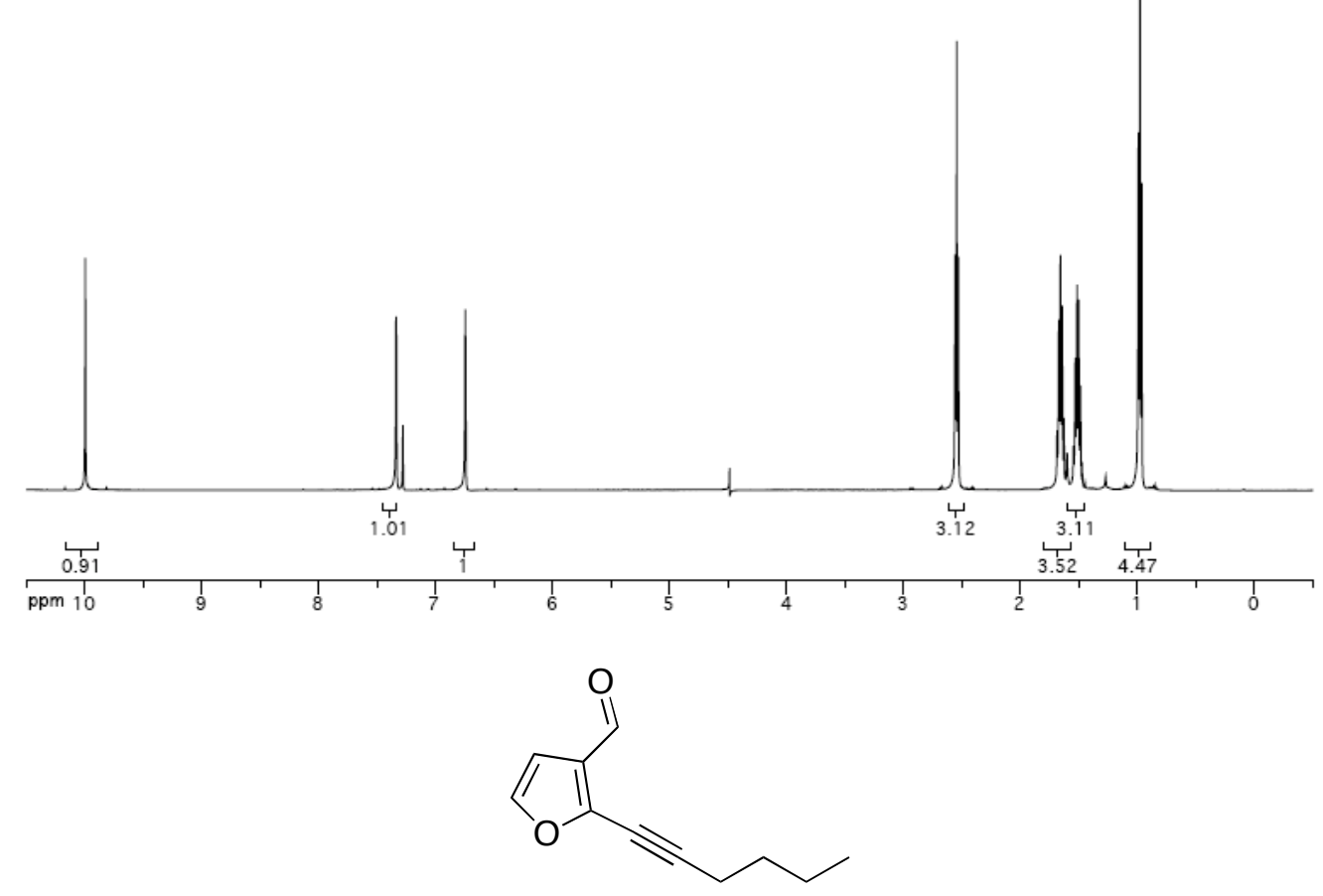

31

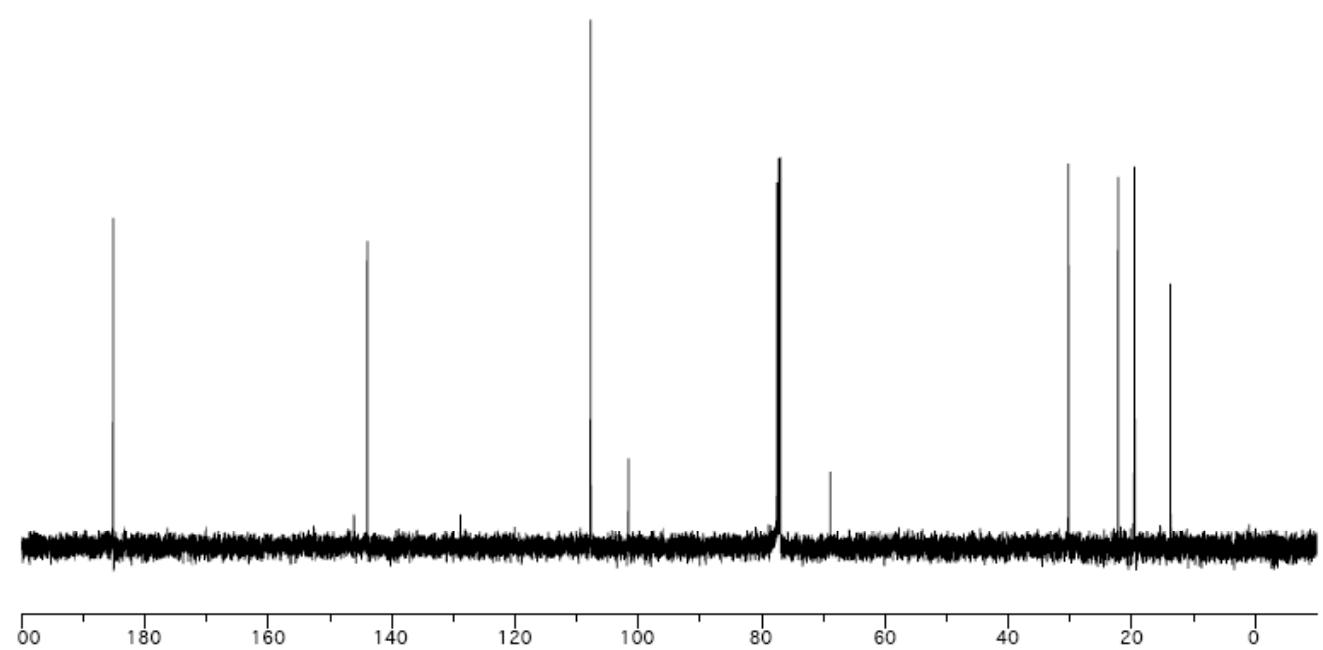

$500 \mathrm{MHz}{ }^{1} \mathrm{H}$ and $125 \mathrm{MHz}{ }^{13} \mathrm{C}\left\{{ }^{1} \mathrm{H}\right\}$ NMR in $\mathrm{CDCl}_{3}$. 

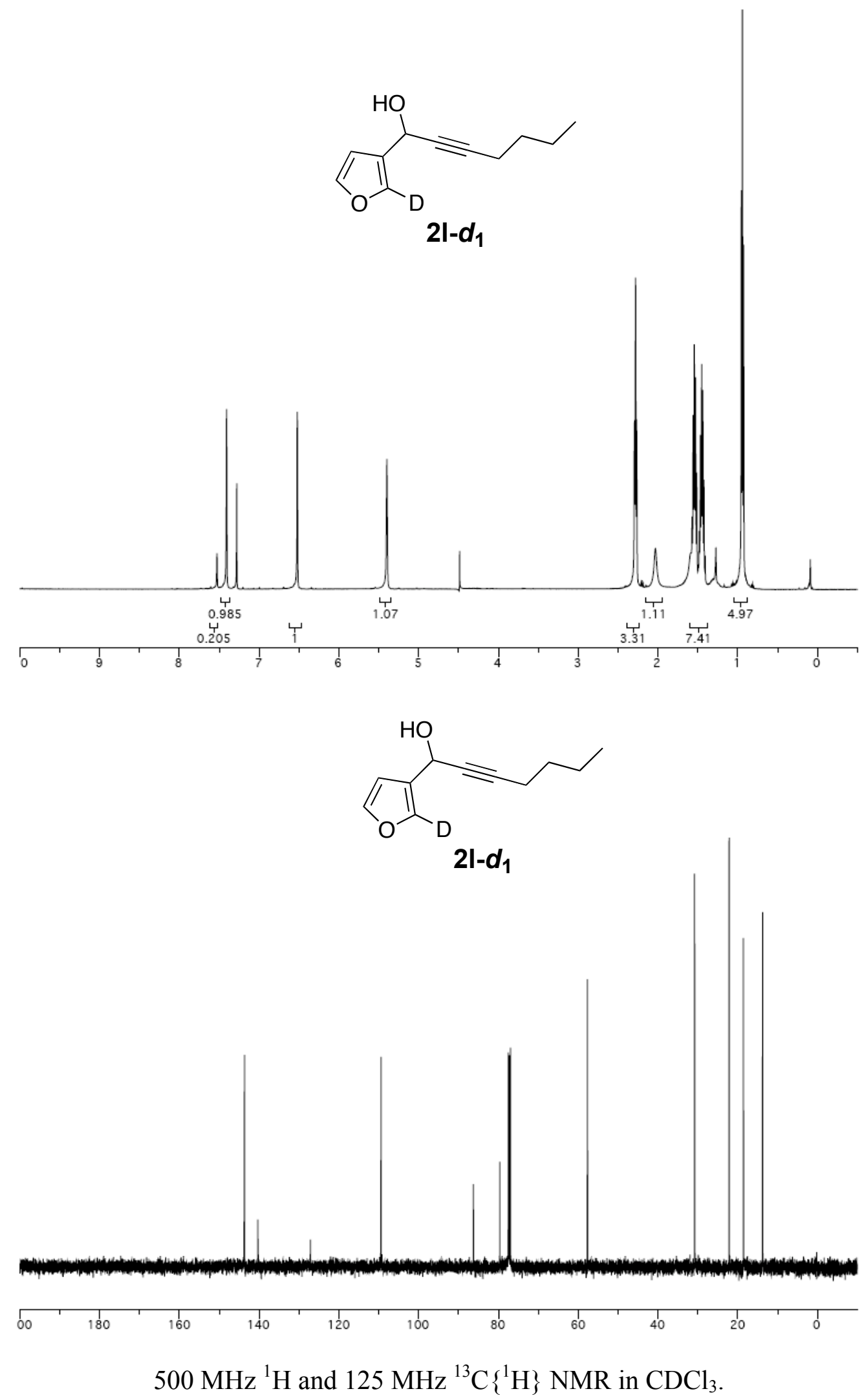

SI-64 

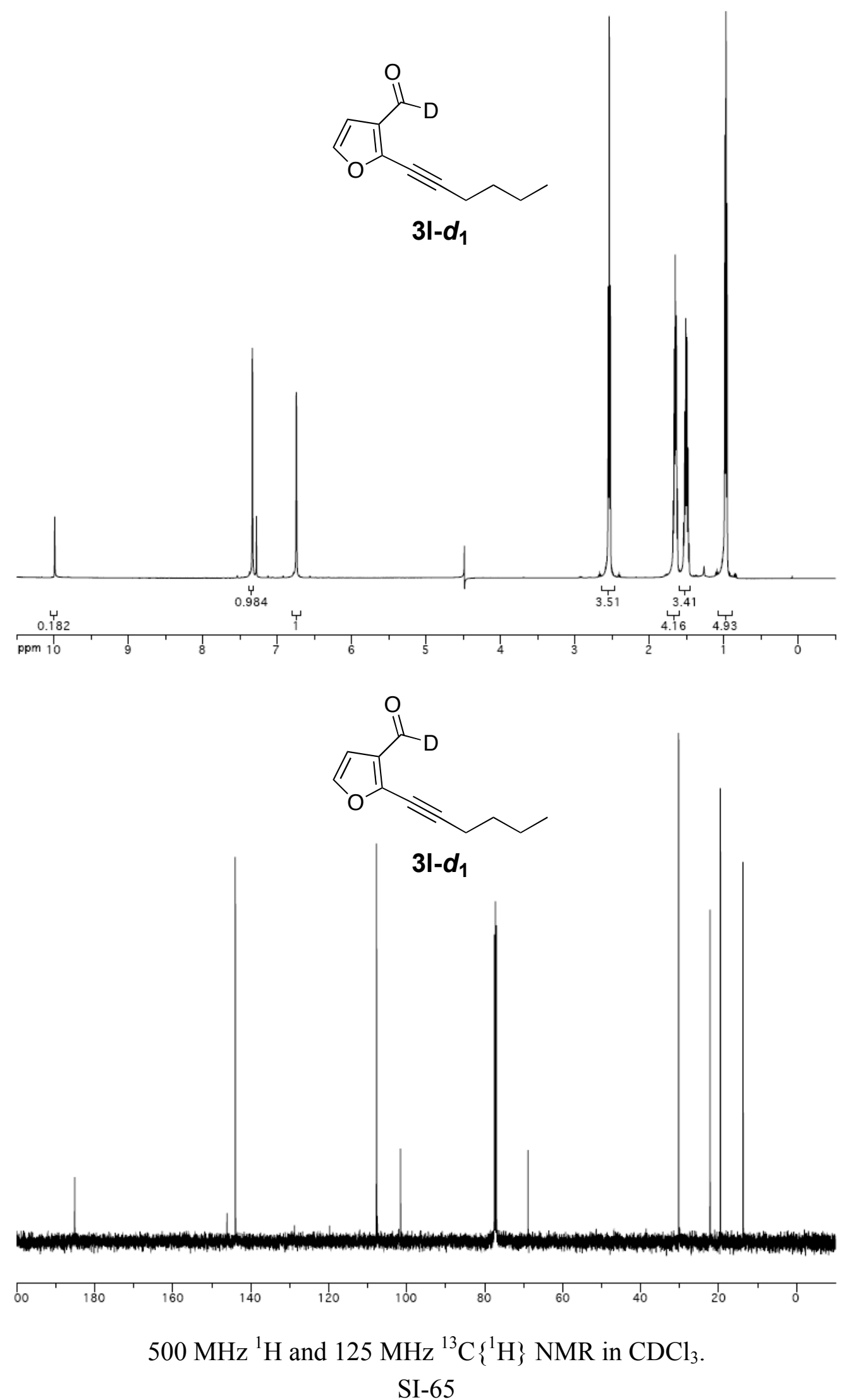

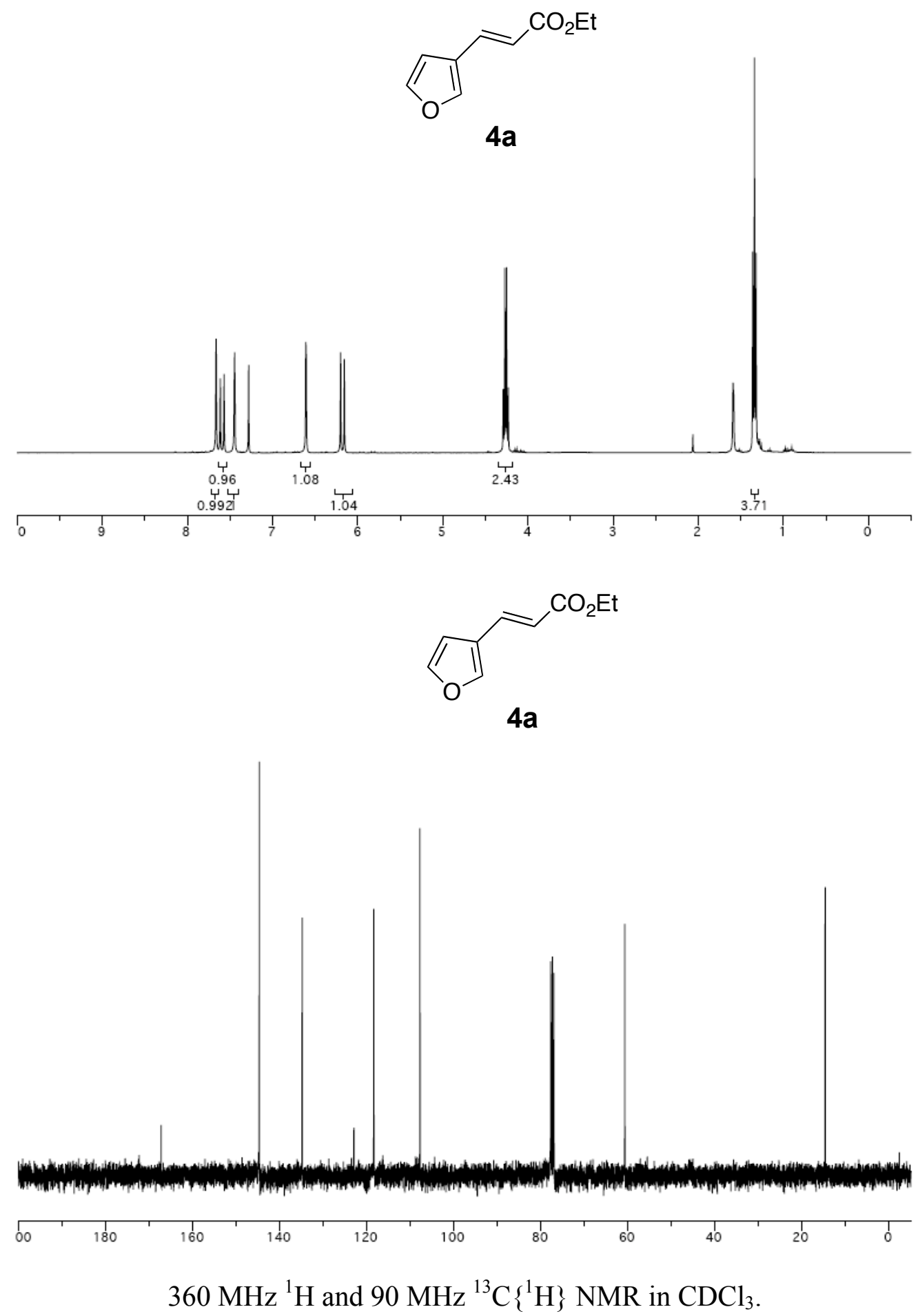

SI-66 


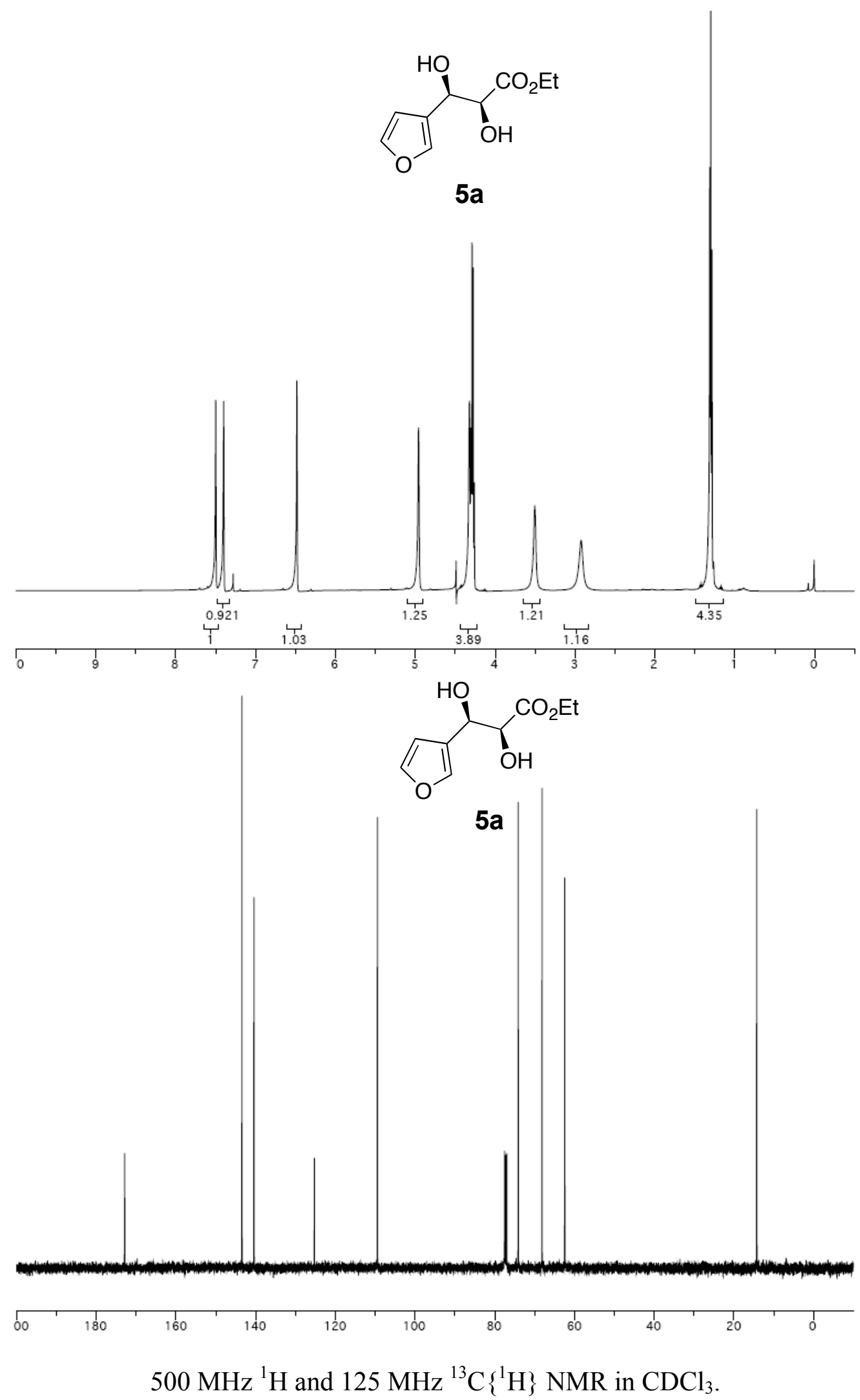

SI-67 

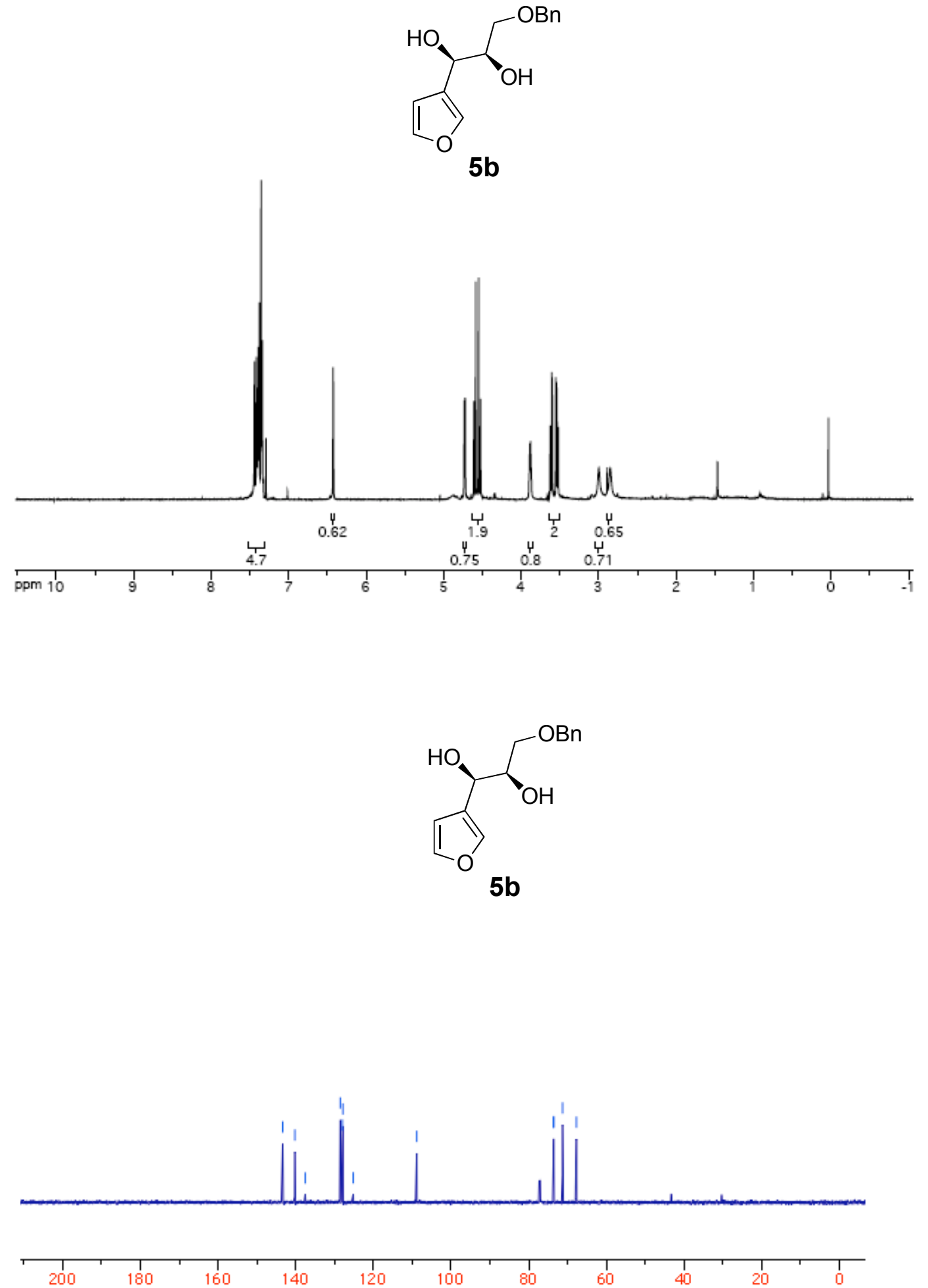

$500 \mathrm{MHz}{ }^{1} \mathrm{H}$ and $125 \mathrm{MHz}^{13} \mathrm{C}\left\{{ }^{1} \mathrm{H}\right\} \mathrm{NMR}$ in $\mathrm{CDCl}_{3}$ 

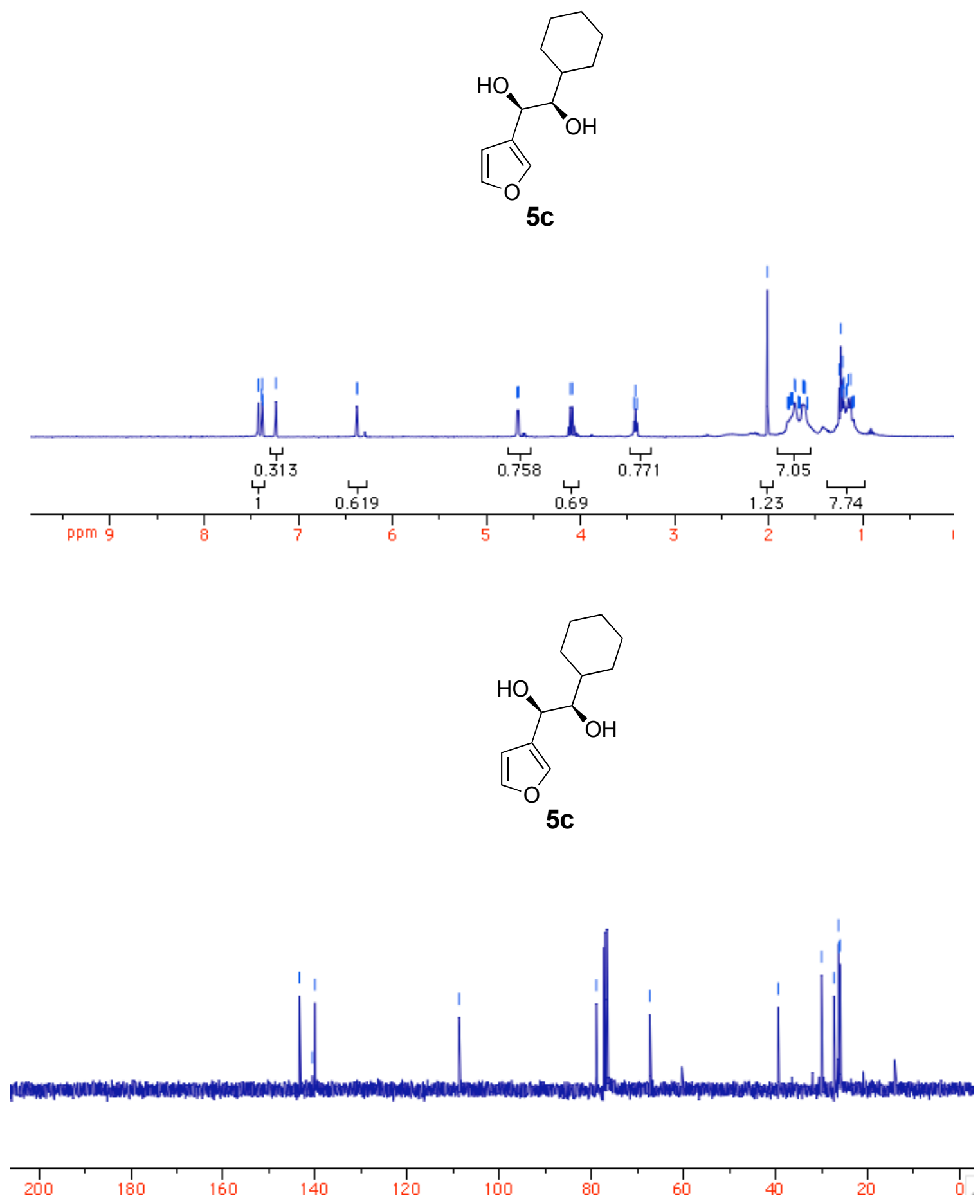

$360 \mathrm{MHz}{ }^{1} \mathrm{H}$ and $90 \mathrm{MHz}{ }^{13} \mathrm{C}\left\{{ }^{1} \mathrm{H}\right\} \mathrm{NMR}$ in $\mathrm{CDCl}_{3}$ 

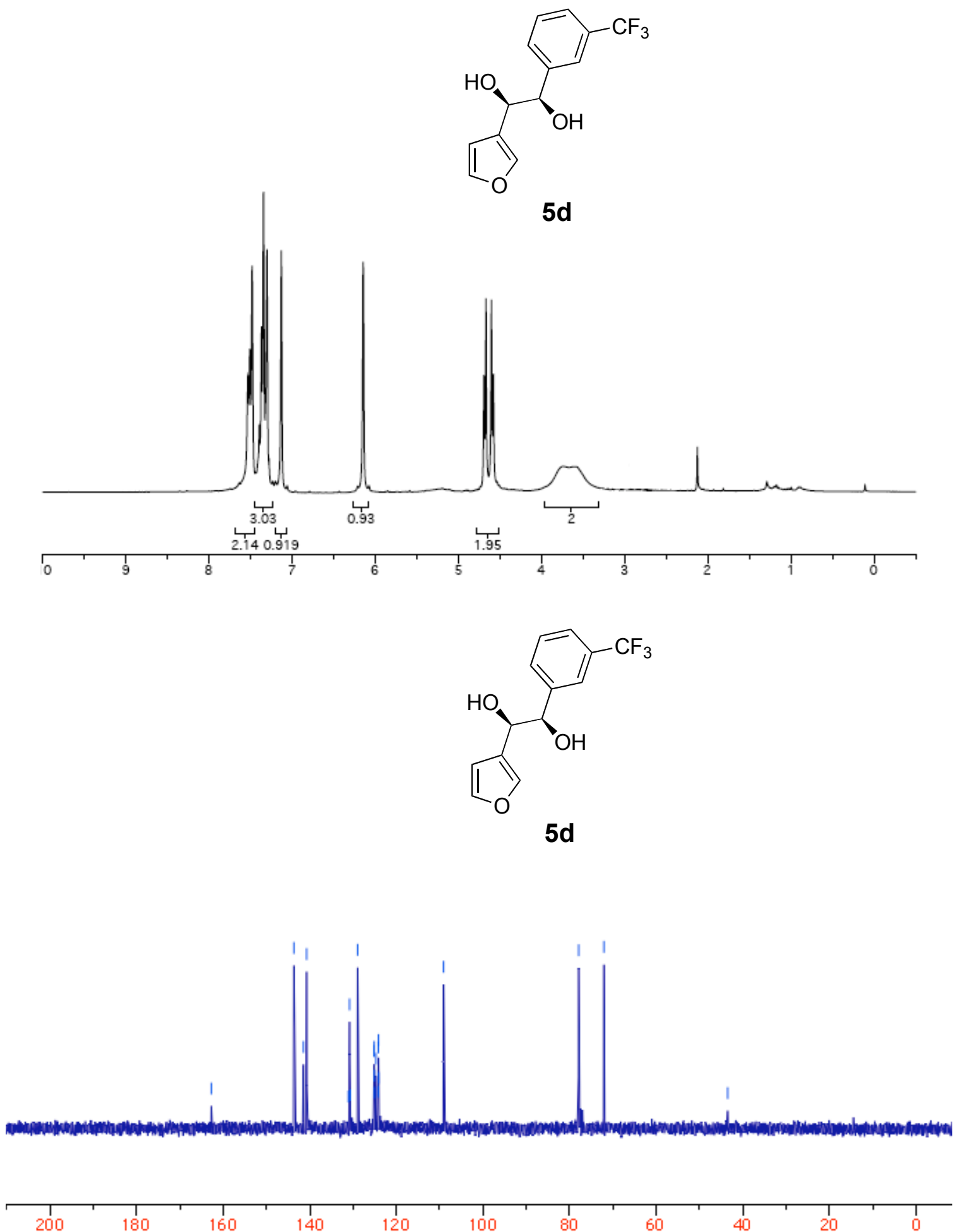

$300 \mathrm{MHz}{ }^{1} \mathrm{H}$ and $75 \mathrm{MHz}{ }^{13} \mathrm{C}\left\{{ }^{1} \mathrm{H}\right\}$ NMR in $\mathrm{CDCl}_{3}$ 

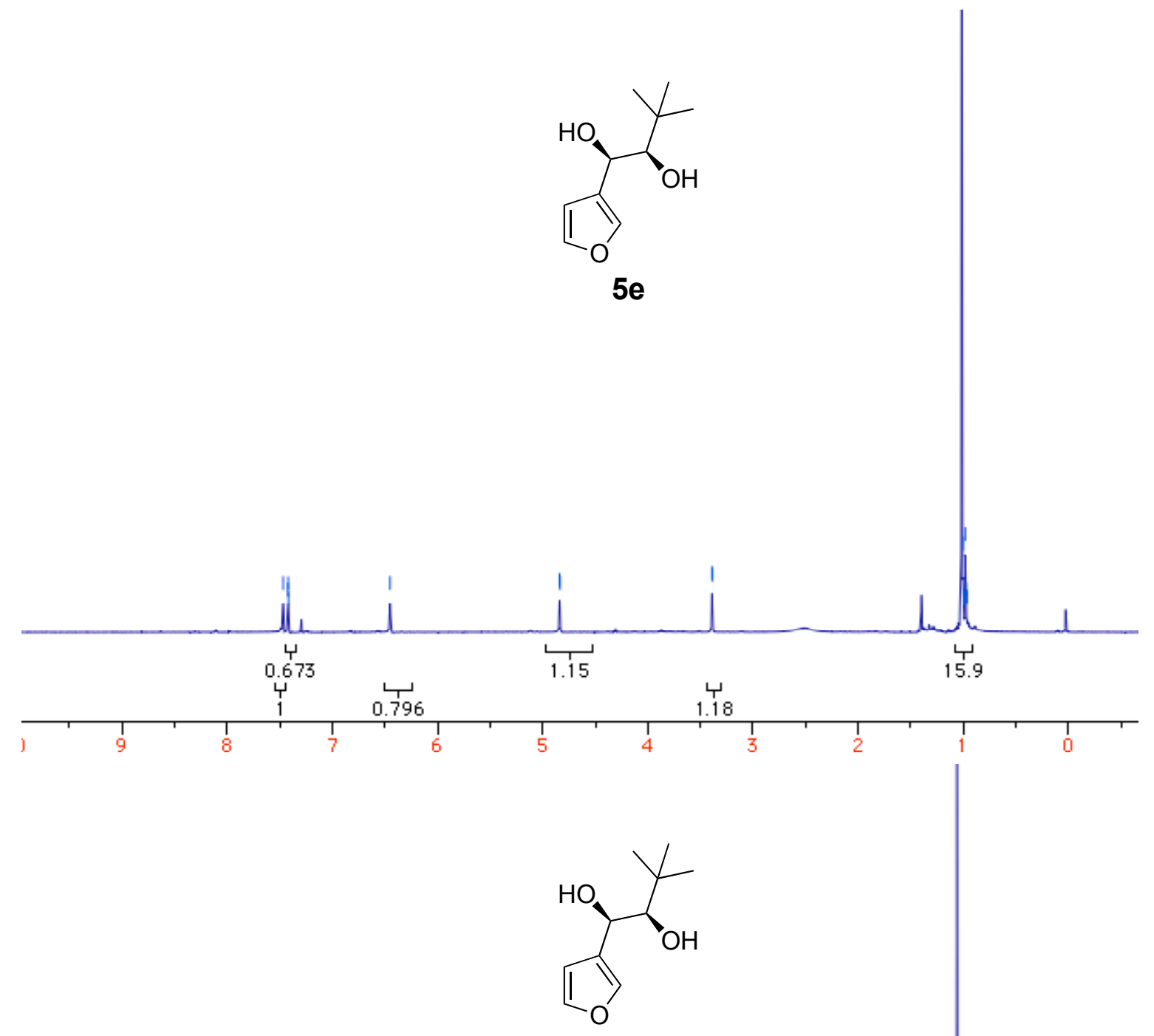

$5 e$
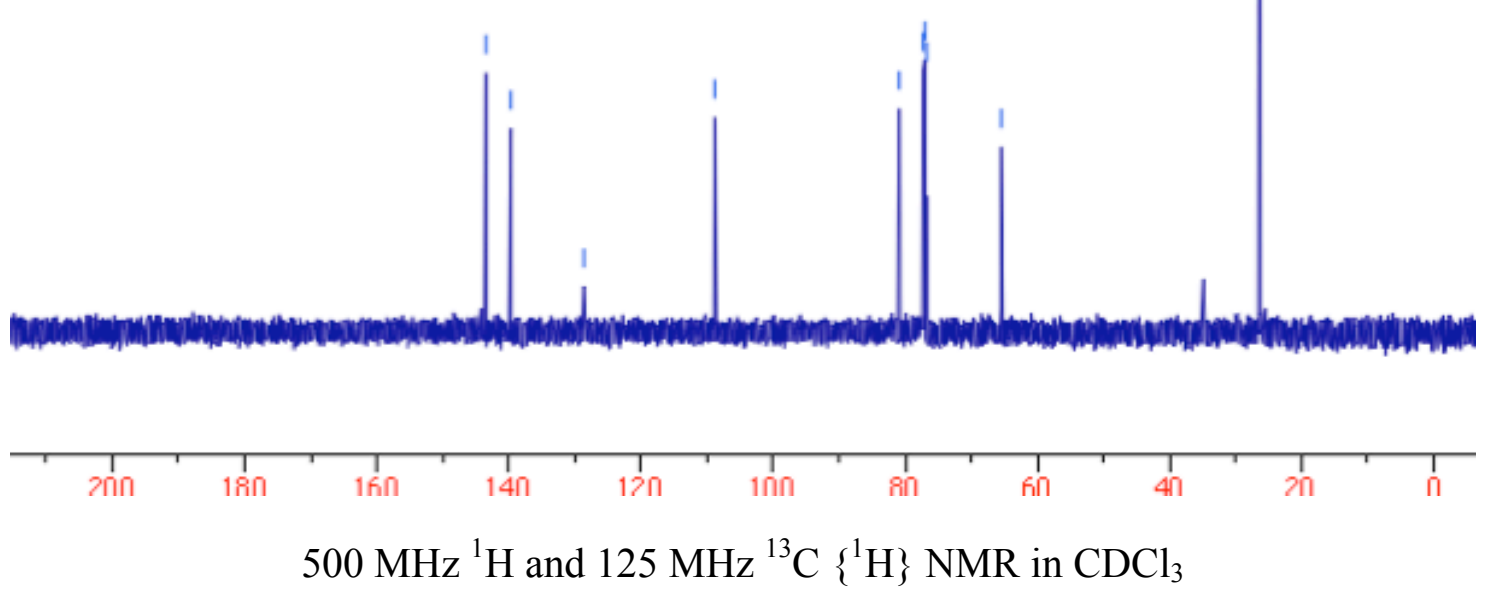

SI-71 


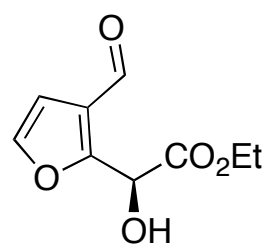

$6 a$
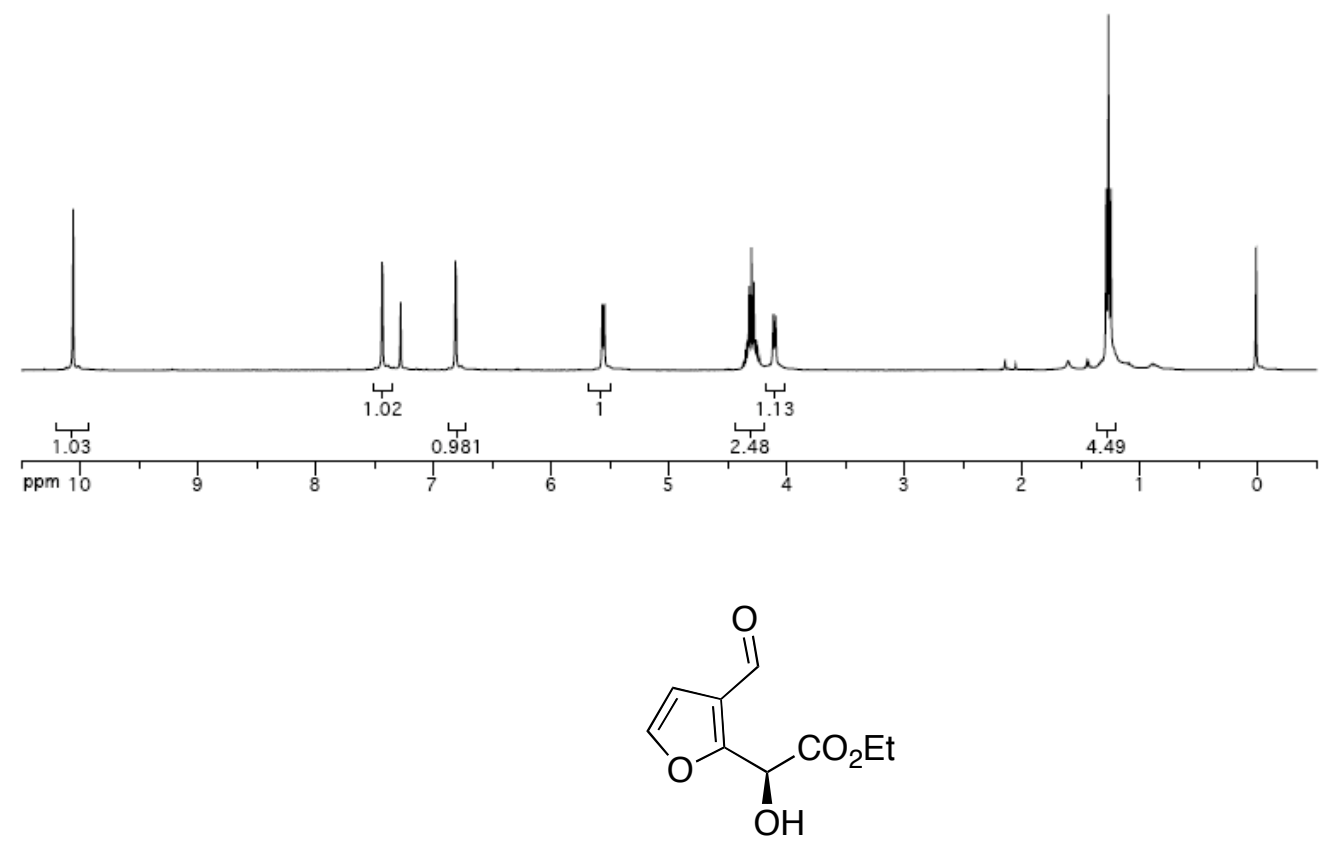

$6 a$

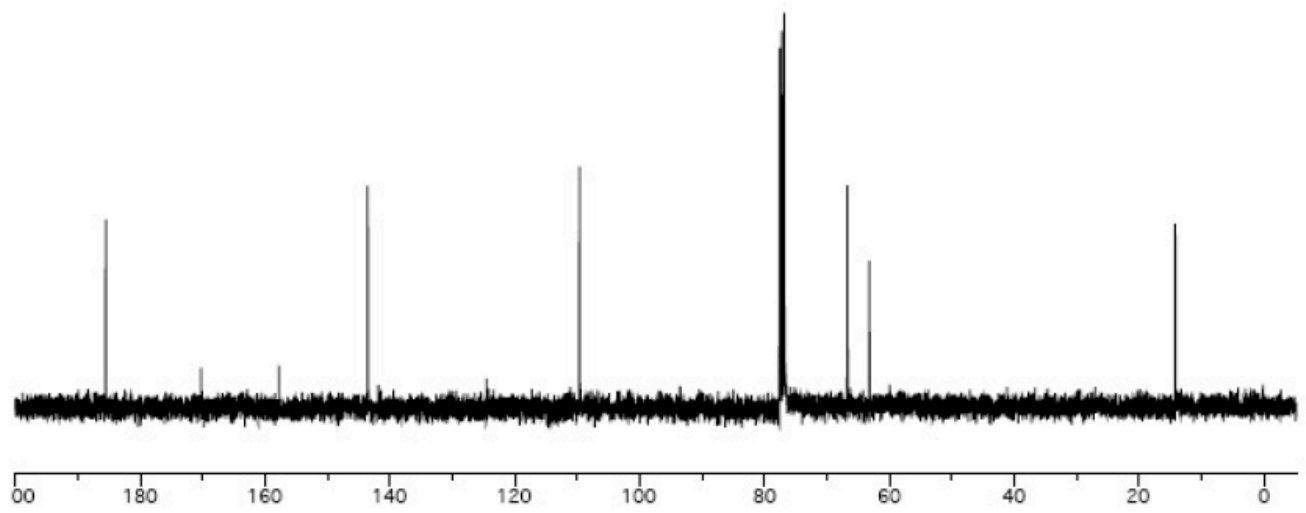

$360 \mathrm{MHz}{ }^{1} \mathrm{H}$ and $90 \mathrm{MHz}{ }^{13} \mathrm{C}\left\{{ }^{1} \mathrm{H}\right\} \mathrm{NMR}$ in $\mathrm{CDCl}_{3}$.

SI-72 


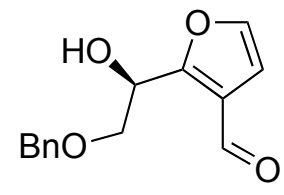

$6 b$
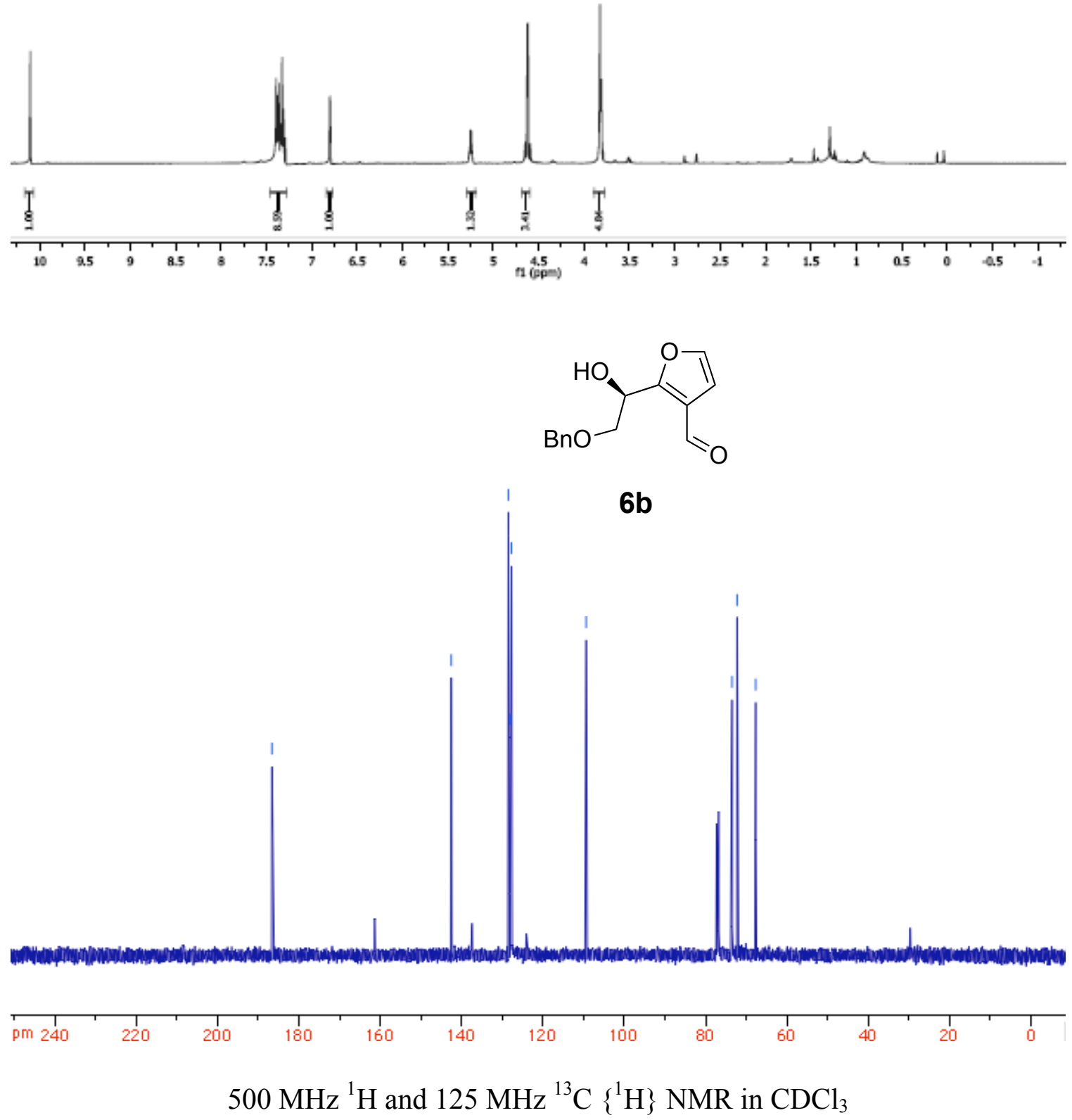

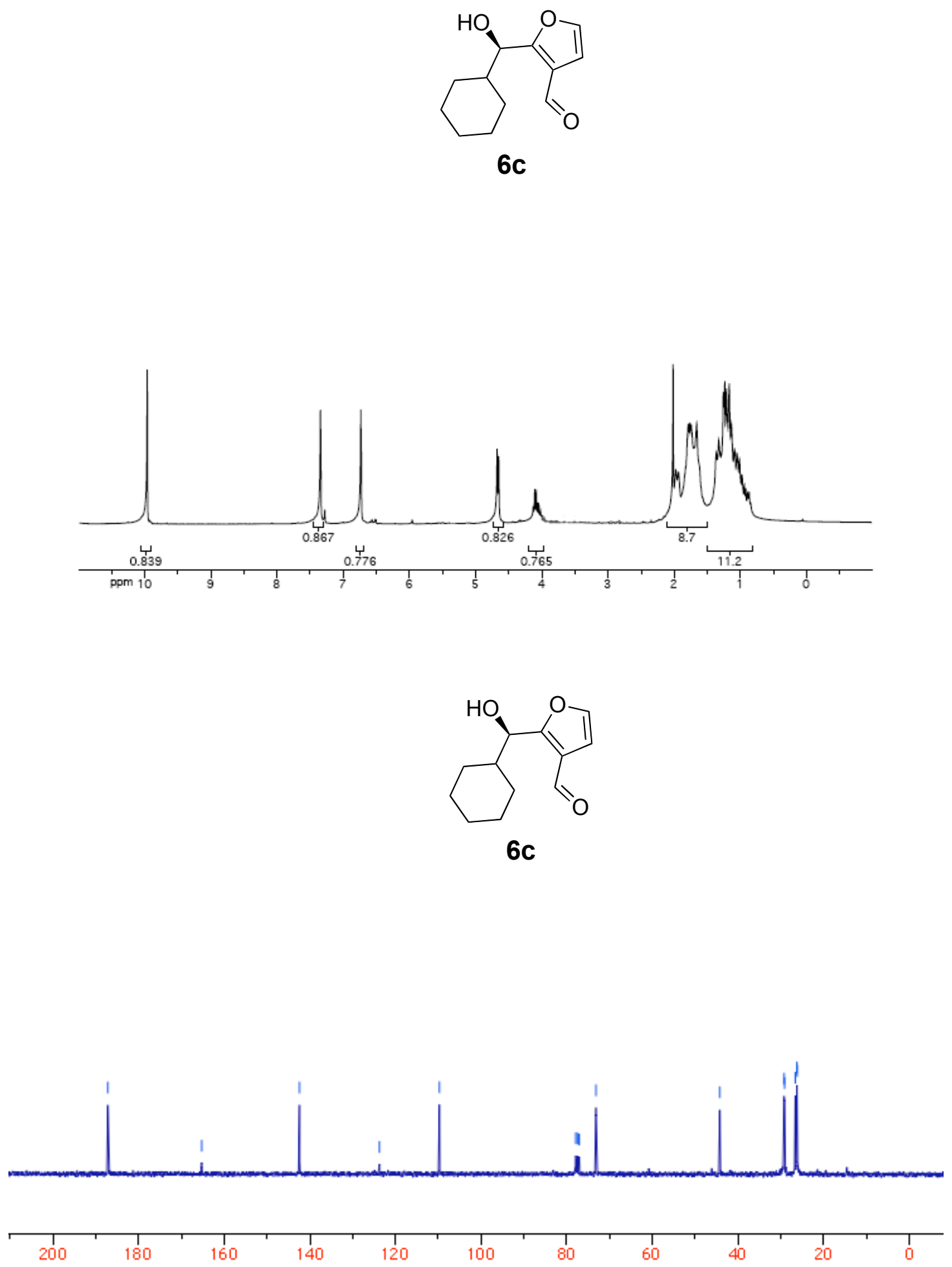

$300 \mathrm{MHz}{ }^{1} \mathrm{H}$ and $75 \mathrm{MHz}{ }^{13} \mathrm{C}\left\{{ }^{1} \mathrm{H}\right\} \mathrm{NMR}$ in $\mathrm{CDCl}_{3}$ SI-74 


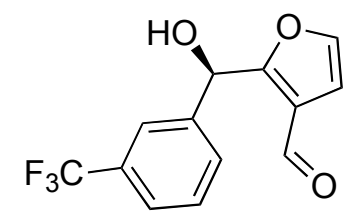

$6 d$
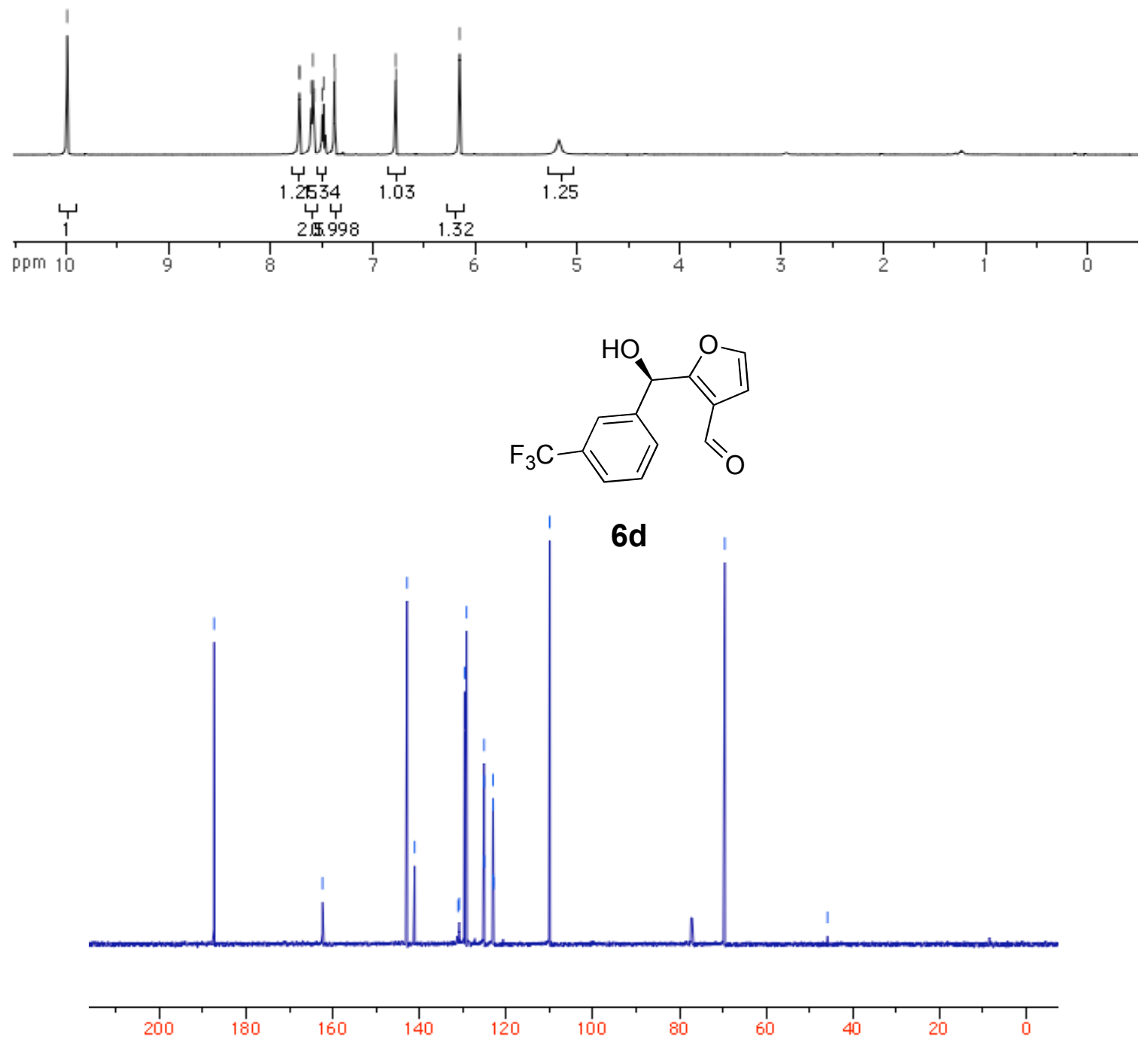

$500 \mathrm{MHz}{ }^{1} \mathrm{H}$ and $125 \mathrm{MHz}{ }^{13} \mathrm{C}\left\{{ }^{1} \mathrm{H}\right\}$ NMR in $\mathrm{CDCl}_{3}$ 


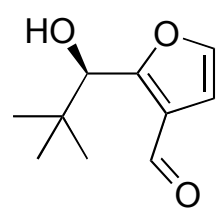

$6 e$
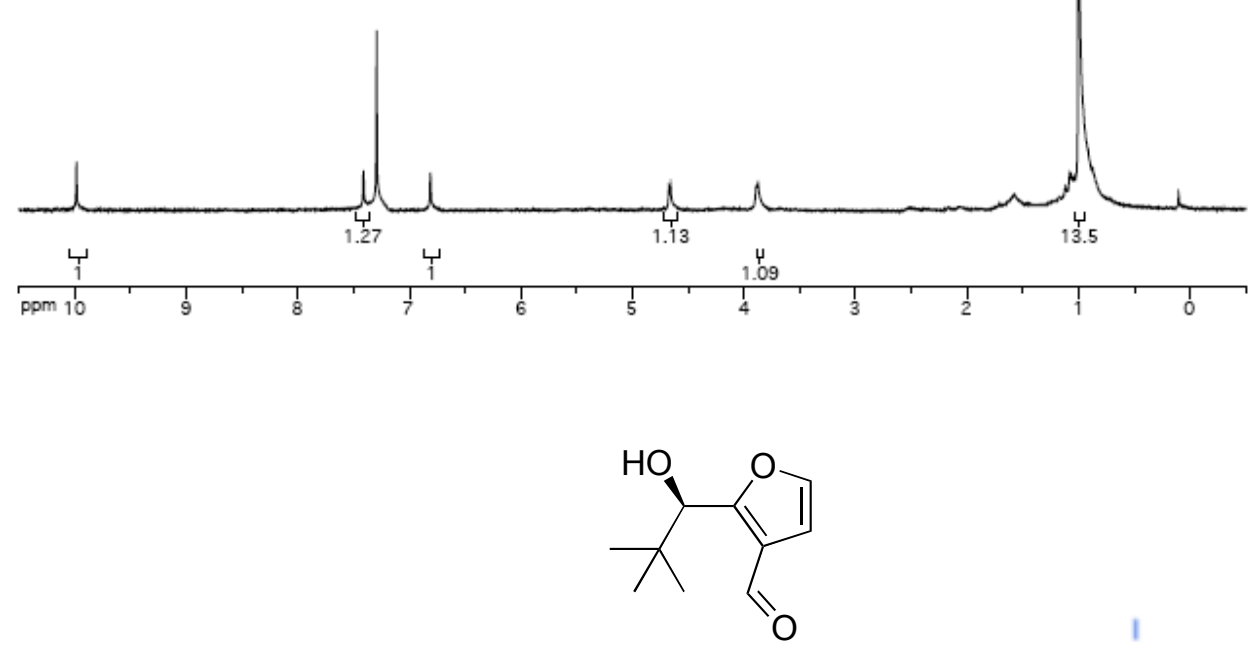

$6 e$

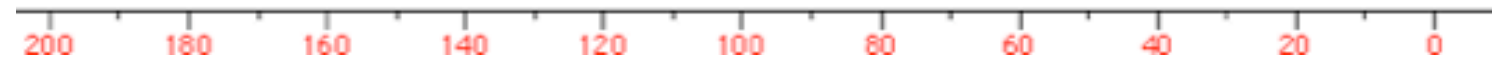

$500 \mathrm{MHz}{ }^{1} \mathrm{H}$ and $125 \mathrm{MHz}{ }^{13} \mathrm{C}\left\{{ }^{1} \mathrm{H}\right\} \mathrm{NMR}$ in $\mathrm{CDCl}_{3}$ 

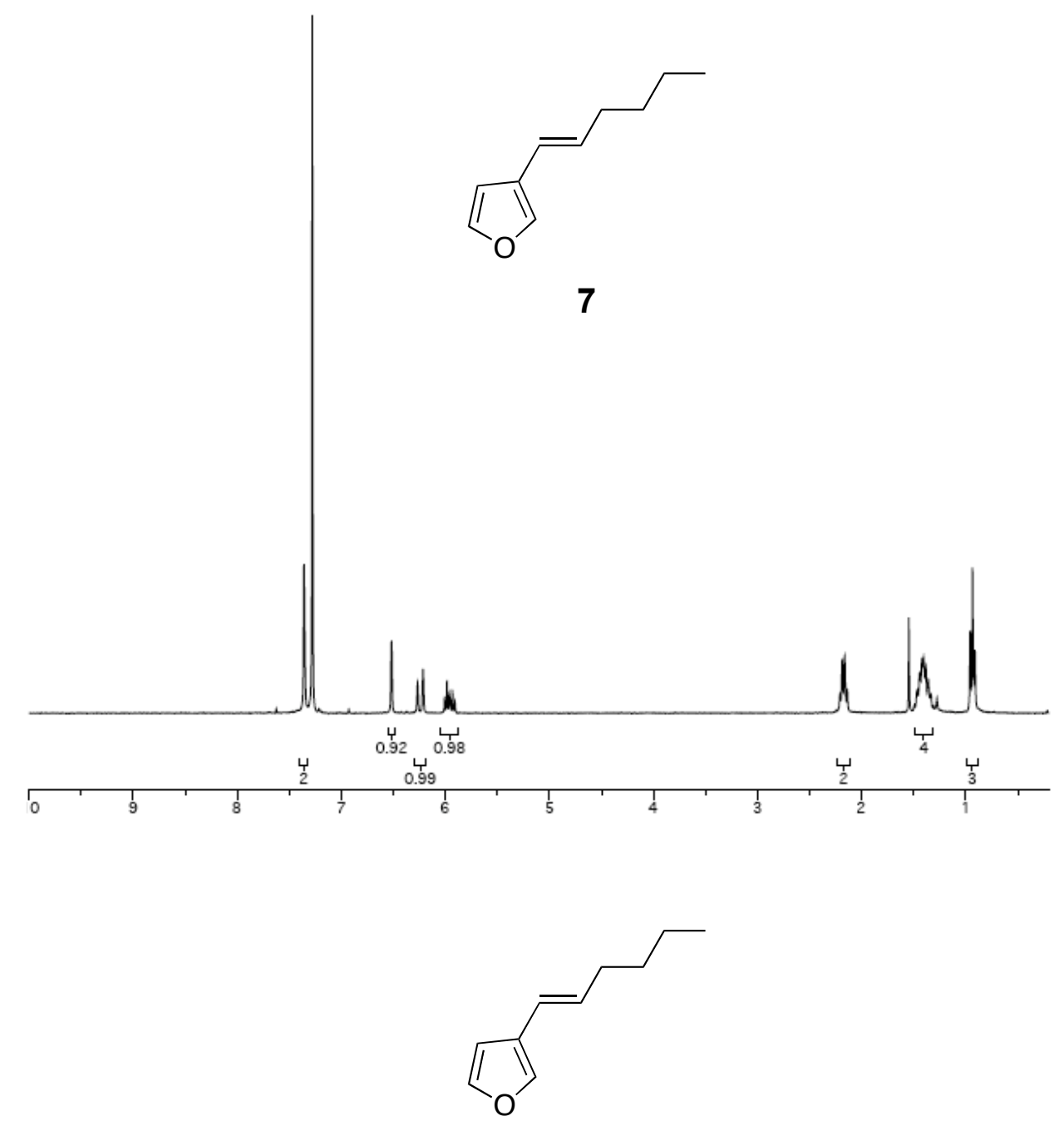

7

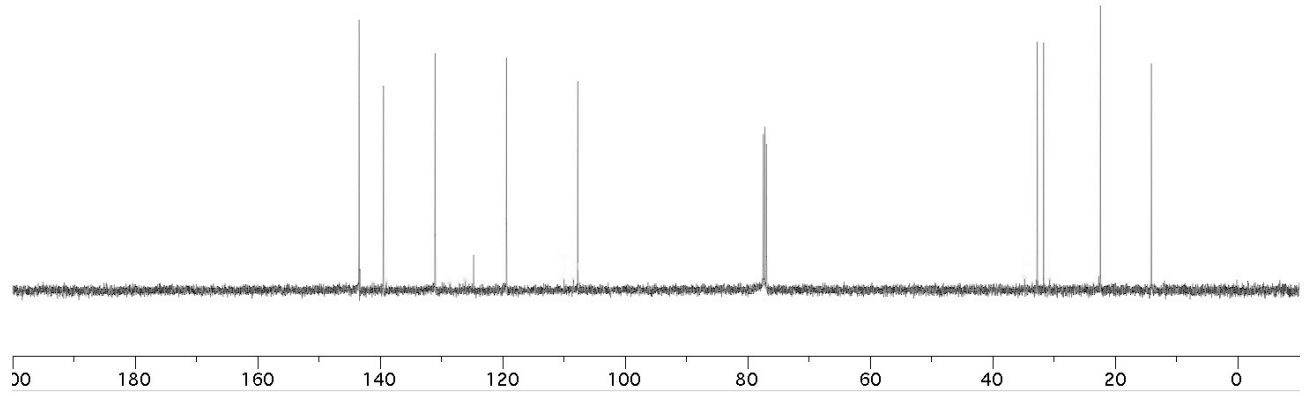

$360 \mathrm{MHz}{ }^{1} \mathrm{H}$ and $125 \mathrm{MHz}{ }^{13} \mathrm{C}\left\{{ }^{1} \mathrm{H}\right\}$ NMR in $\mathrm{CDCl}_{3}$

SI-77 

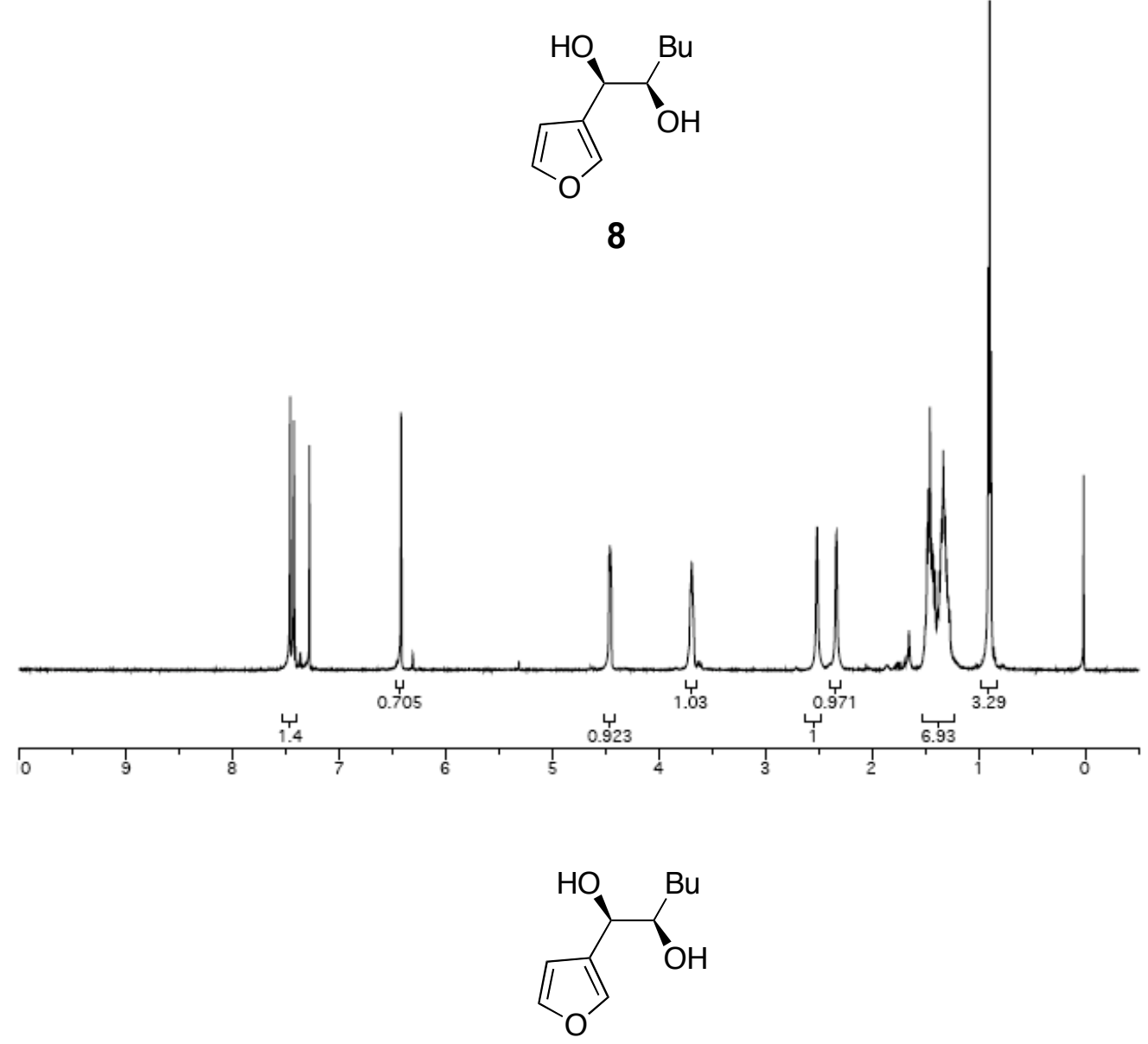

8

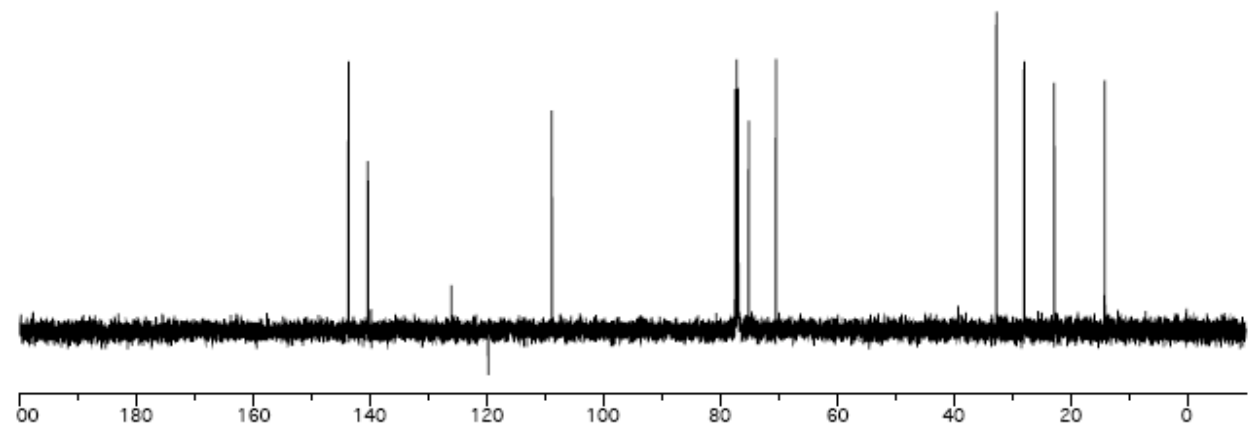

$500 \mathrm{MHz}{ }^{1} \mathrm{H}$ and $125 \mathrm{MHz}{ }^{13} \mathrm{C}\left\{{ }^{1} \mathrm{H}\right\} \mathrm{NMR}$ in $\mathrm{CDCl}_{3}$ 


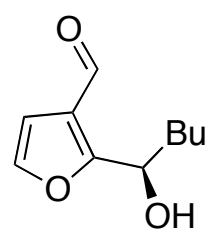

9
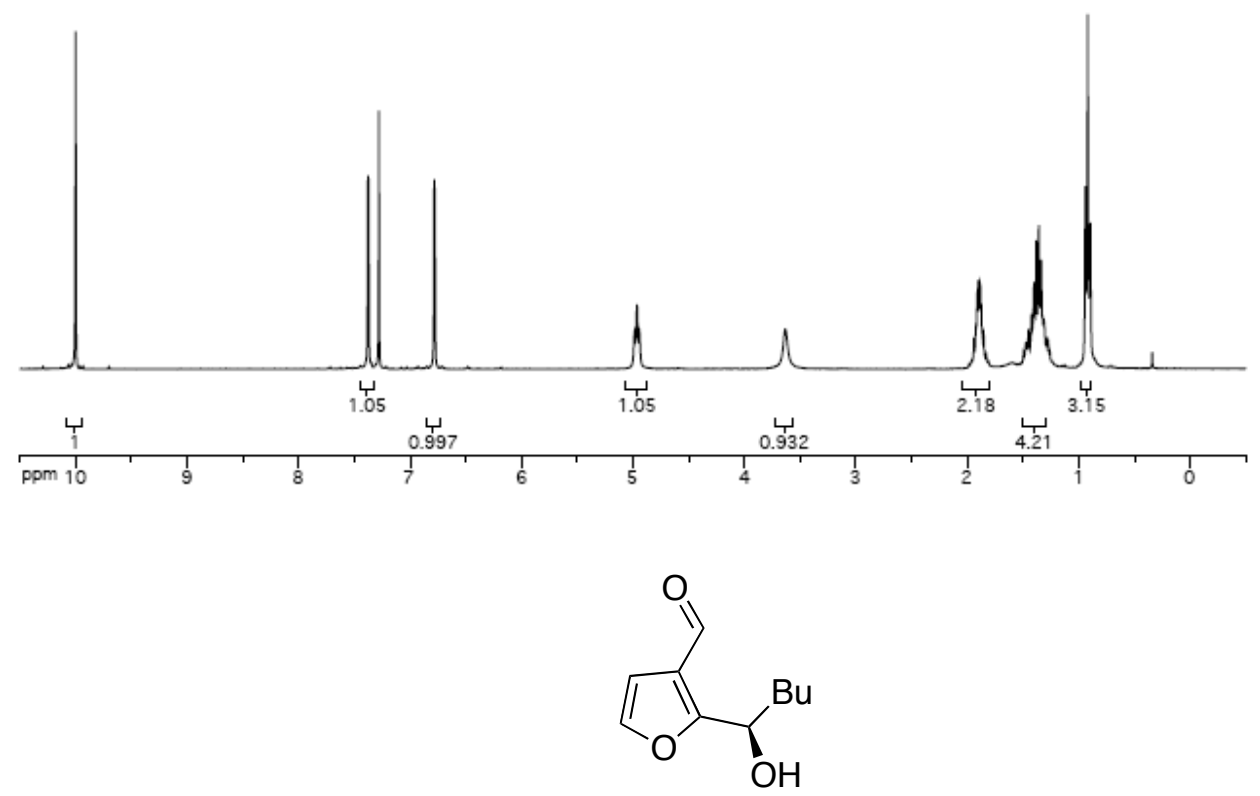

9

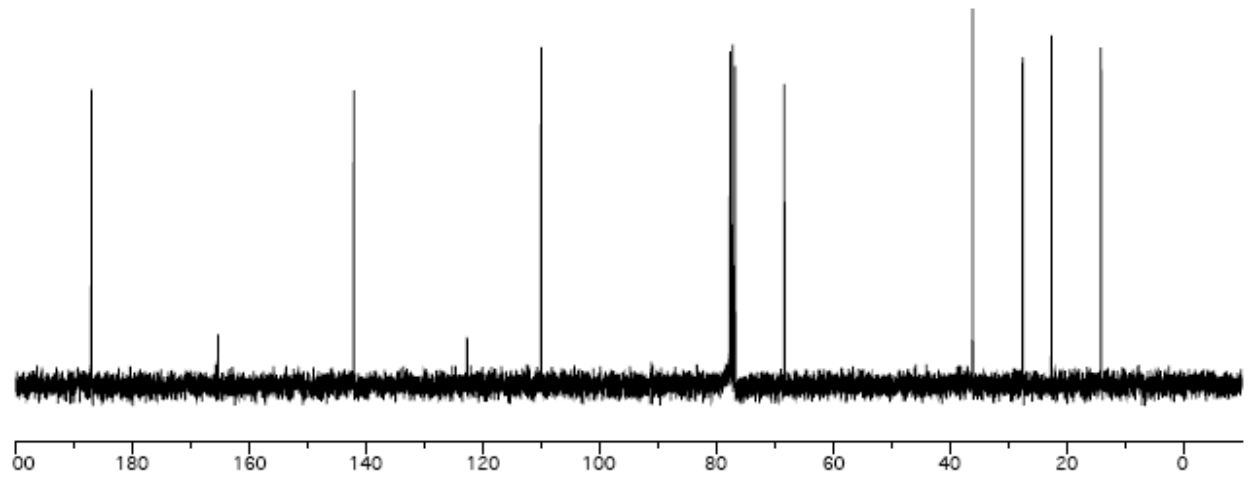

$300 \mathrm{MHz}{ }^{1} \mathrm{H}$ and $90 \mathrm{MHz}{ }^{13} \mathrm{C}\left\{{ }^{1} \mathrm{H}\right\} \mathrm{NMR}$ in $\mathrm{CDCl}_{3}$ 

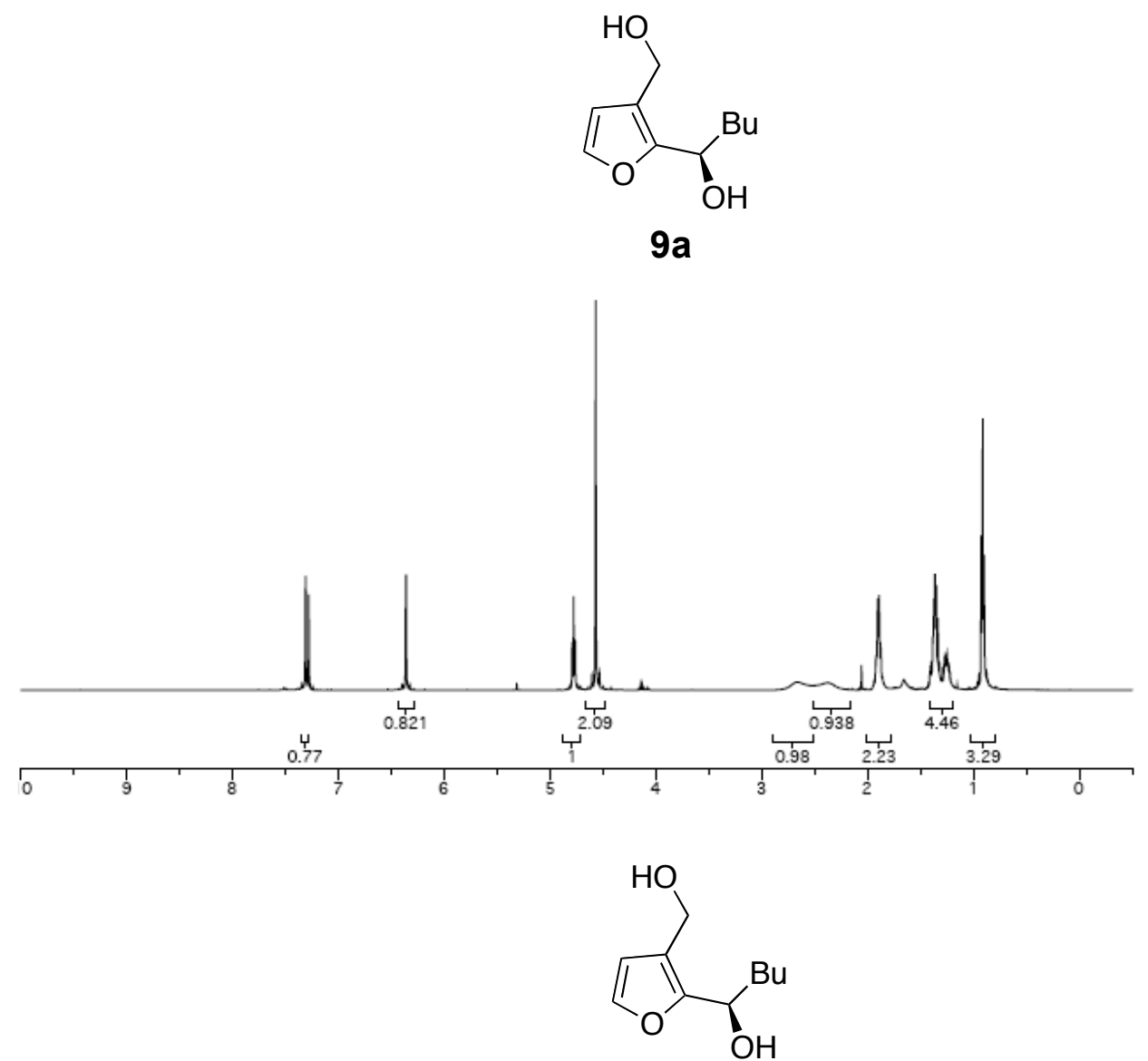

9a

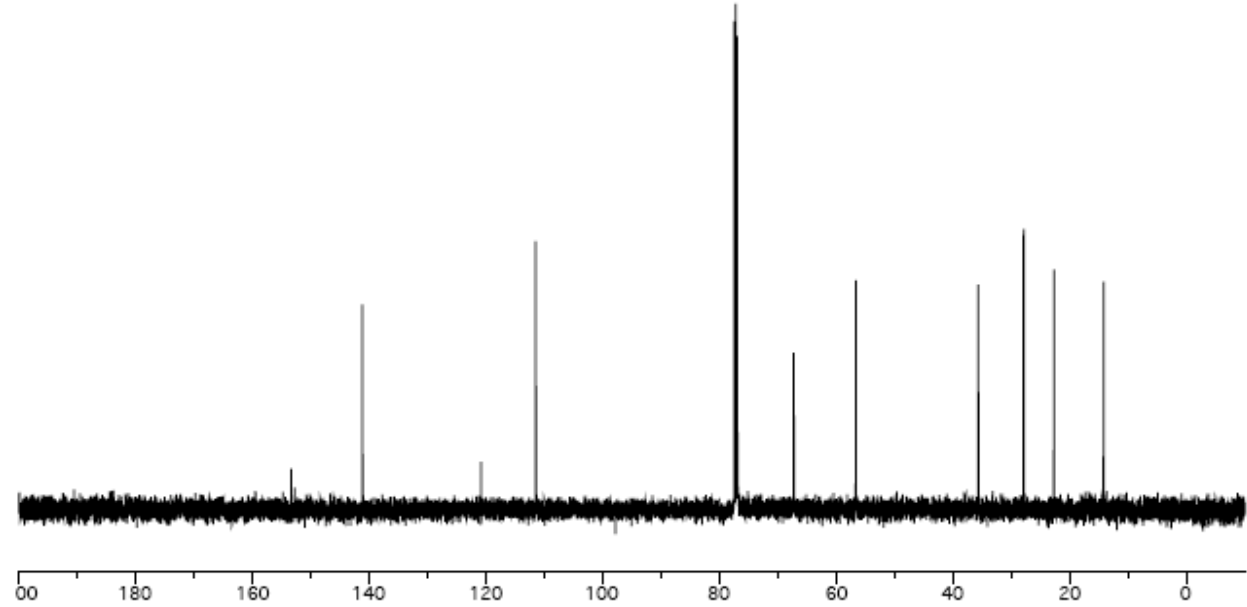

$500 \mathrm{MHz}{ }^{1} \mathrm{H}$ and $125 \mathrm{MHz}{ }^{13} \mathrm{C}\left\{{ }^{1} \mathrm{H}\right\}$ NMR in $\mathrm{CDCl}_{3}$ 


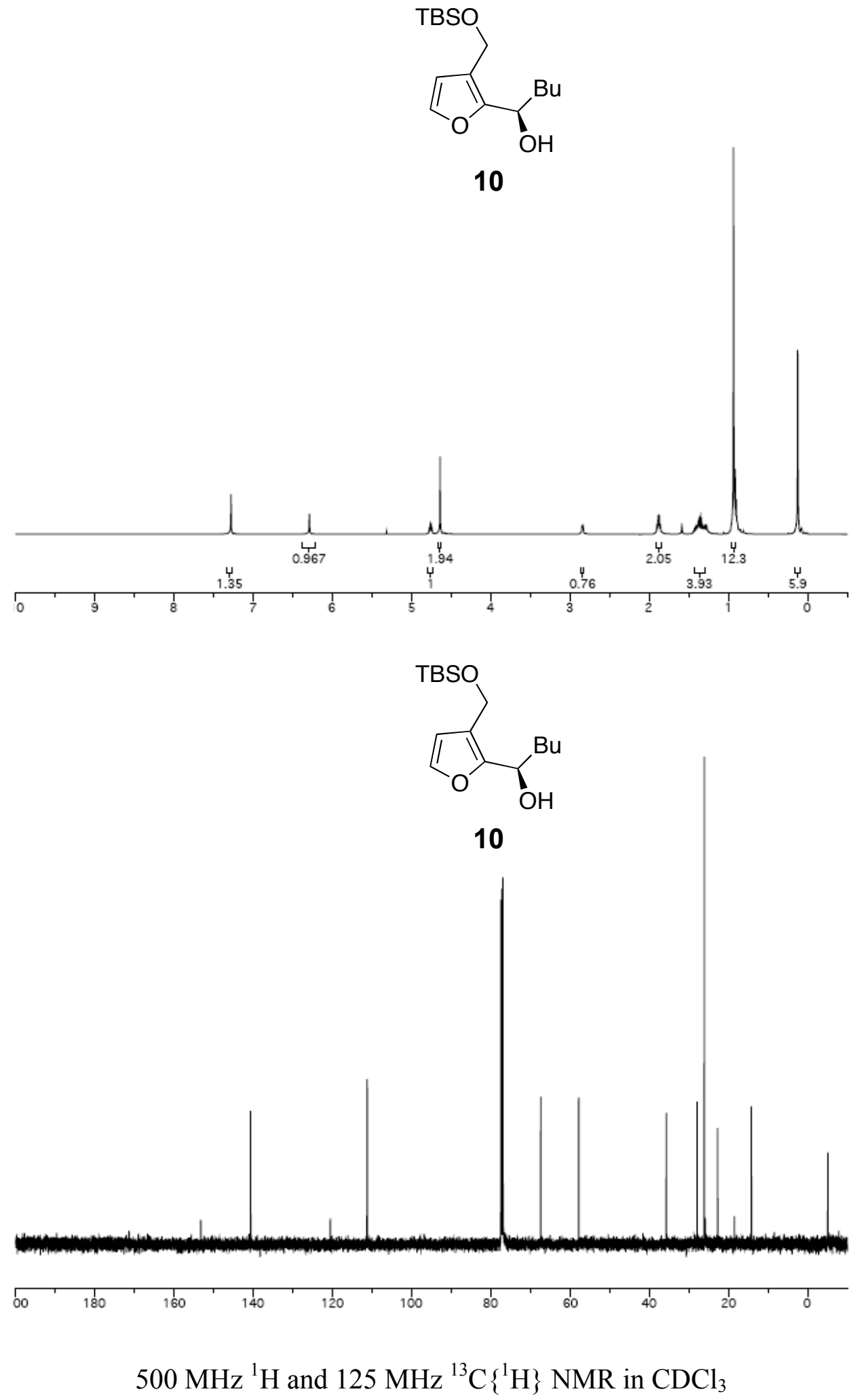

SI-81 

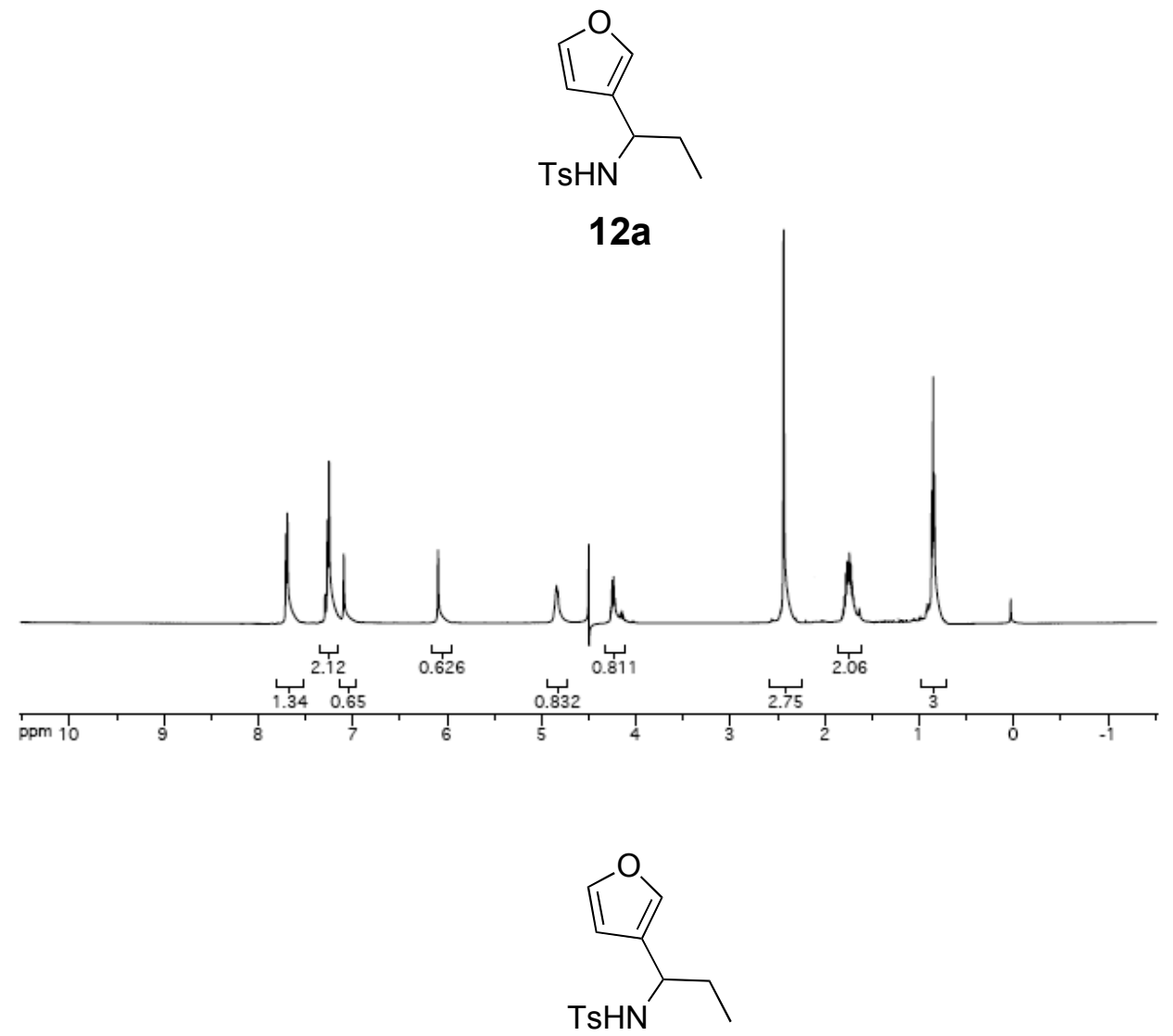

12a
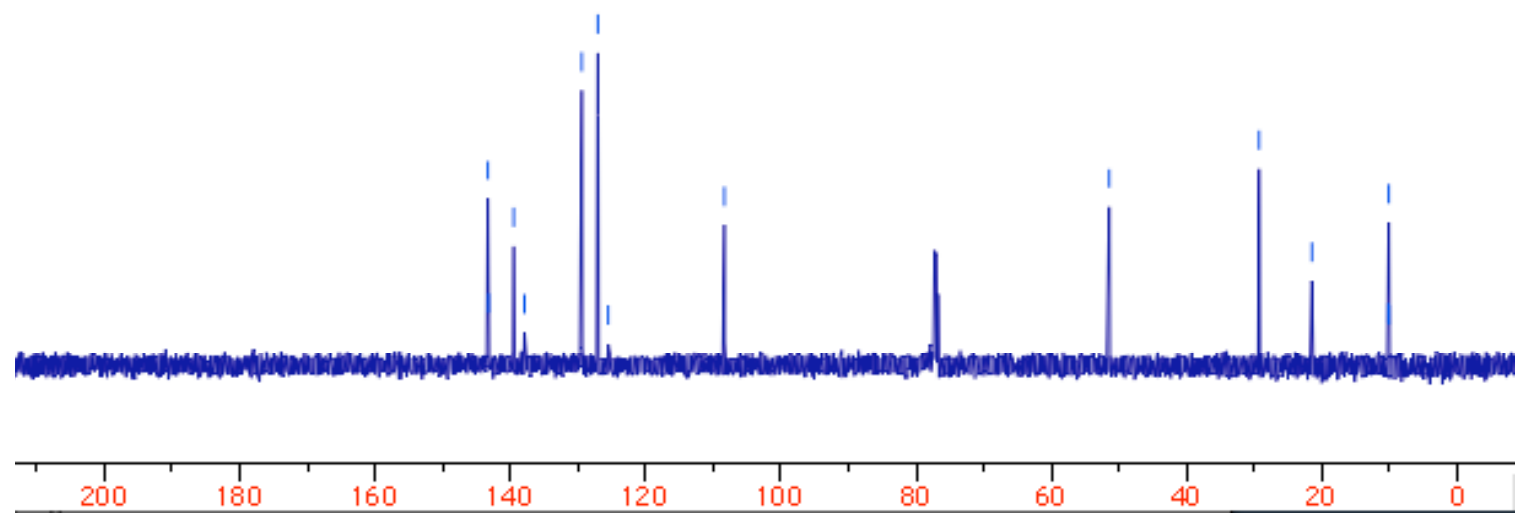

$500 \mathrm{MHz}{ }^{1} \mathrm{H}$ and $125 \mathrm{MHz}{ }^{13} \mathrm{C}\left\{{ }^{1} \mathrm{H}\right\} \mathrm{NMR}$ in $\mathrm{CDCl}_{3}$ 

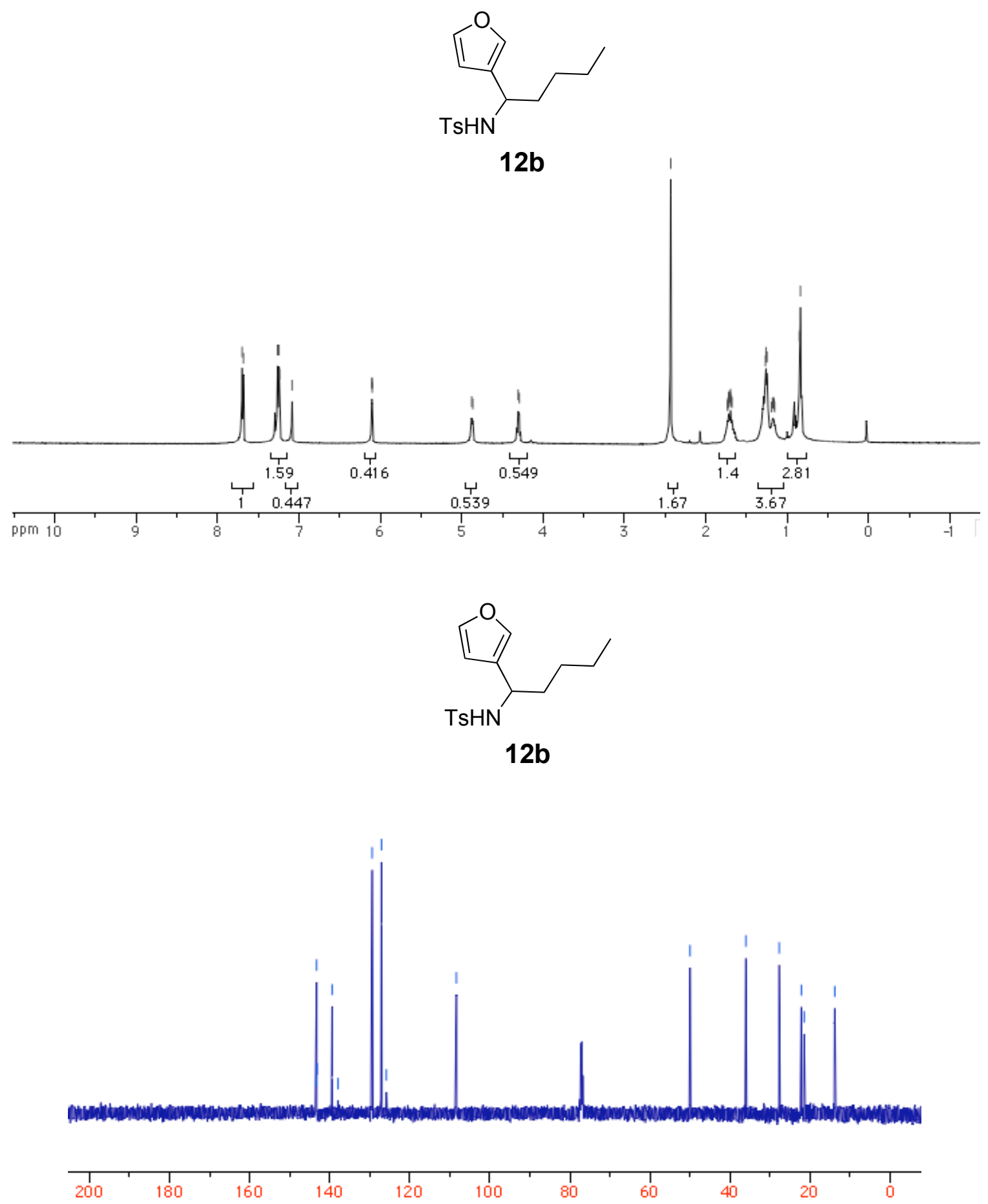

$500 \mathrm{MHz}{ }^{1} \mathrm{H}$ and $125 \mathrm{MHz}{ }^{13} \mathrm{C}\left\{{ }^{1} \mathrm{H}\right\}$ NMR in $\mathrm{CDCl}_{3}$ 

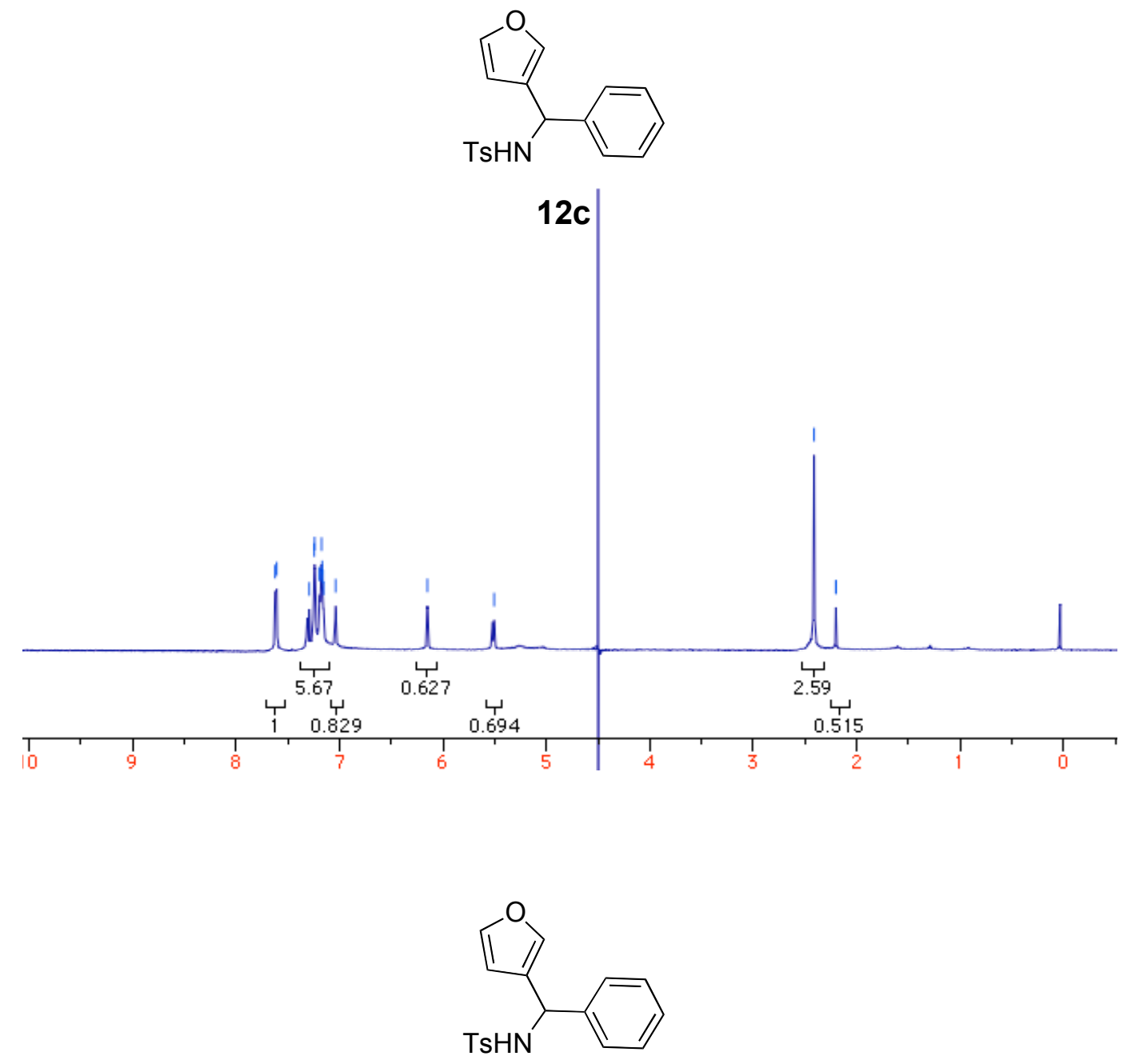

12c

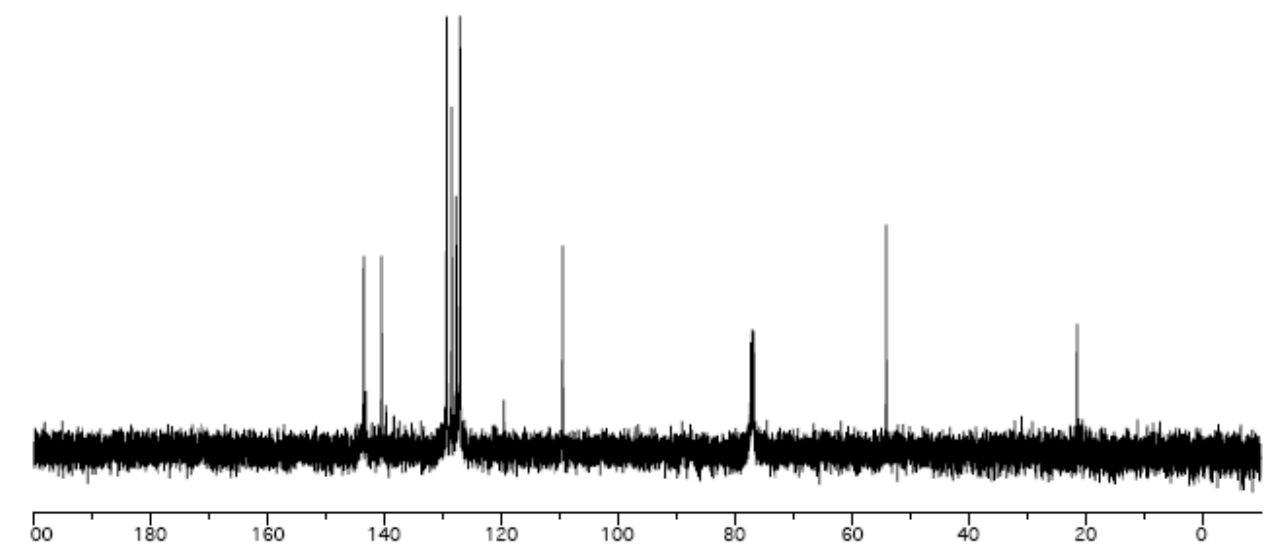

$500 \mathrm{MHz}{ }^{1} \mathrm{H}$ and $125 \mathrm{MHz}{ }^{13} \mathrm{C}\left\{{ }^{1} \mathrm{H}\right\} \mathrm{NMR}$ in $\mathrm{CDCl}_{3}$ 


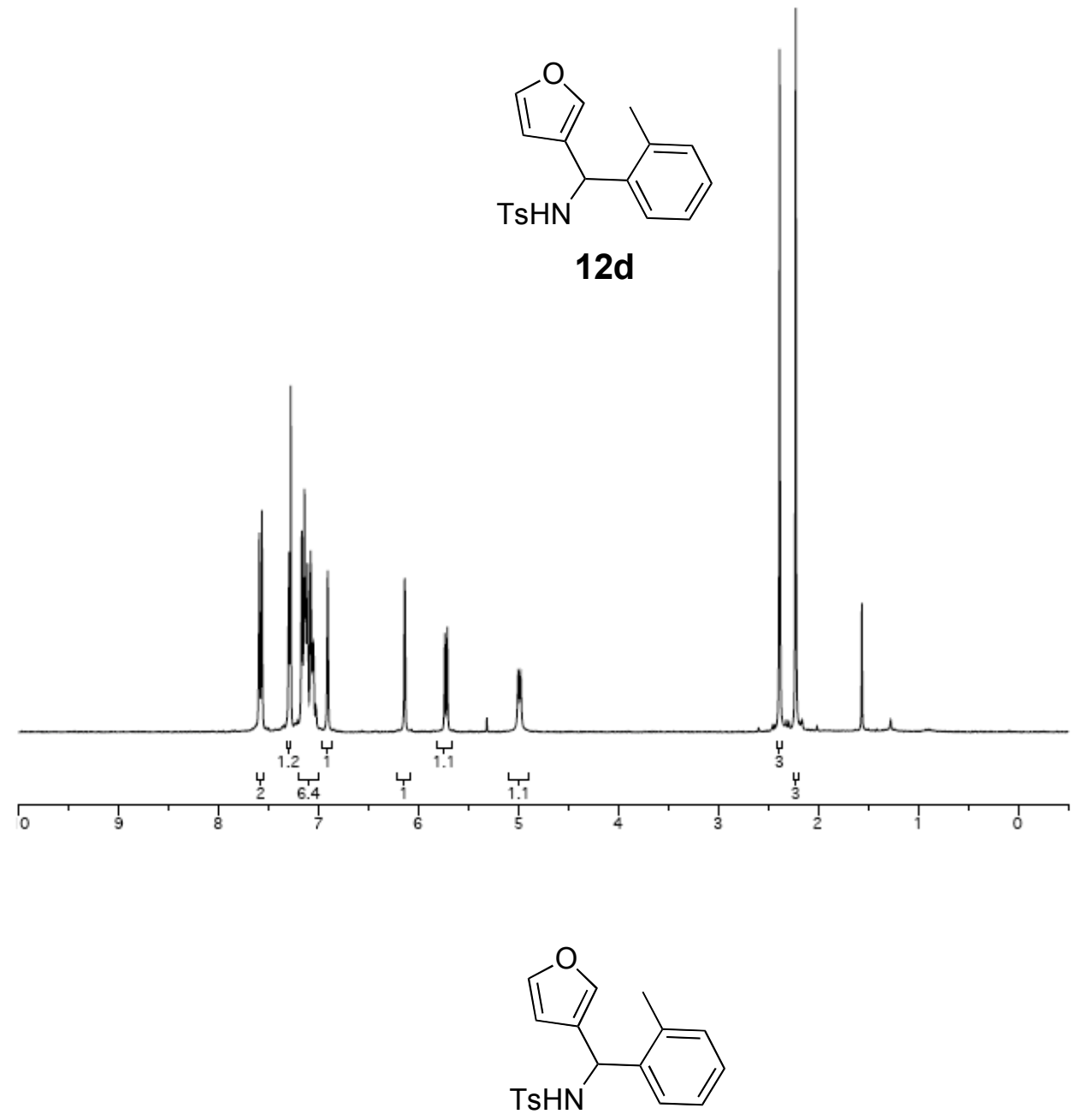

12d
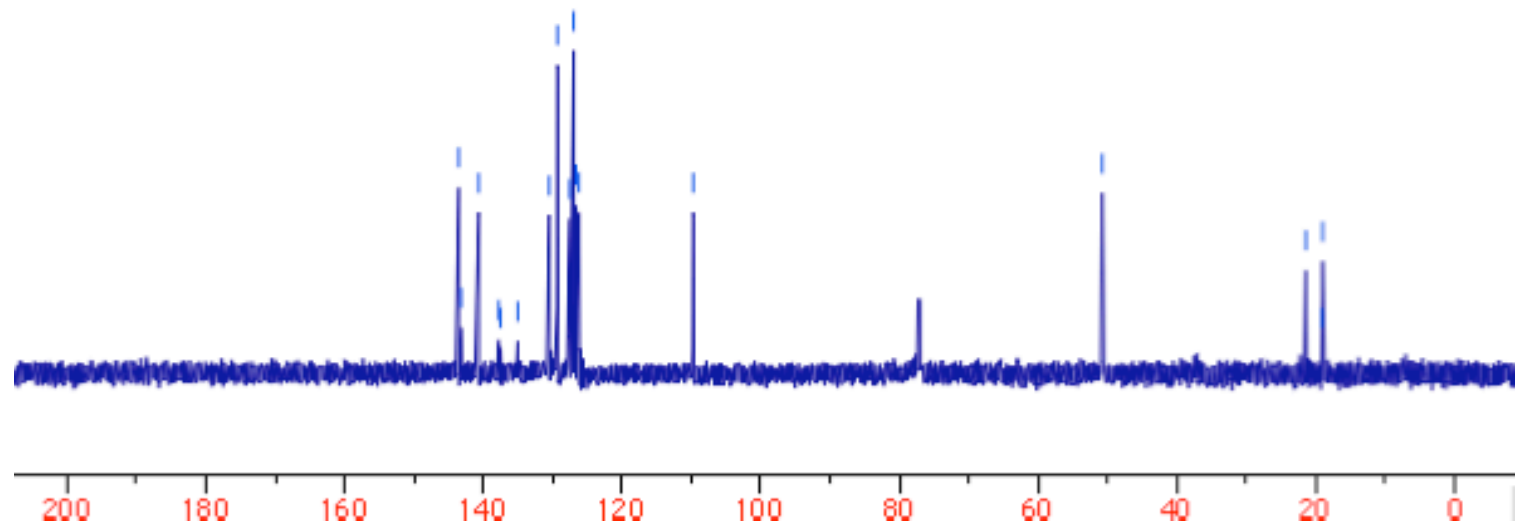

$500 \mathrm{MHz}{ }^{1} \mathrm{H}$ and $125 \mathrm{MHz}{ }^{13} \mathrm{C}\left\{{ }^{1} \mathrm{H}\right\}$ NMR in $\mathrm{CDCl}_{3}$ 


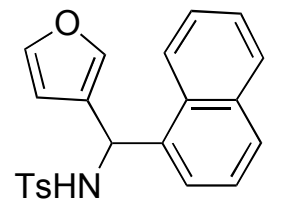

$12 e$
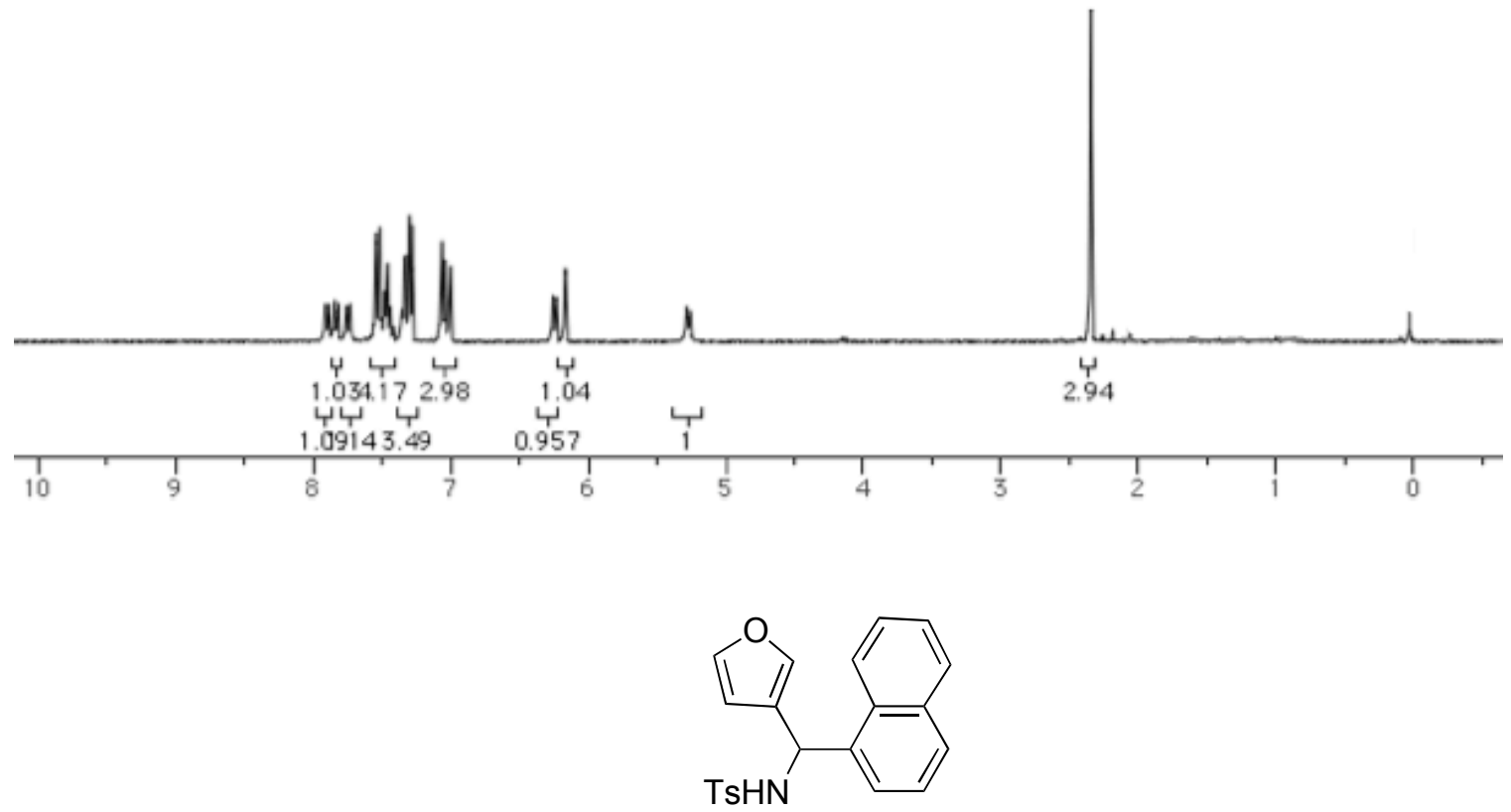

$12 \mathrm{e}$
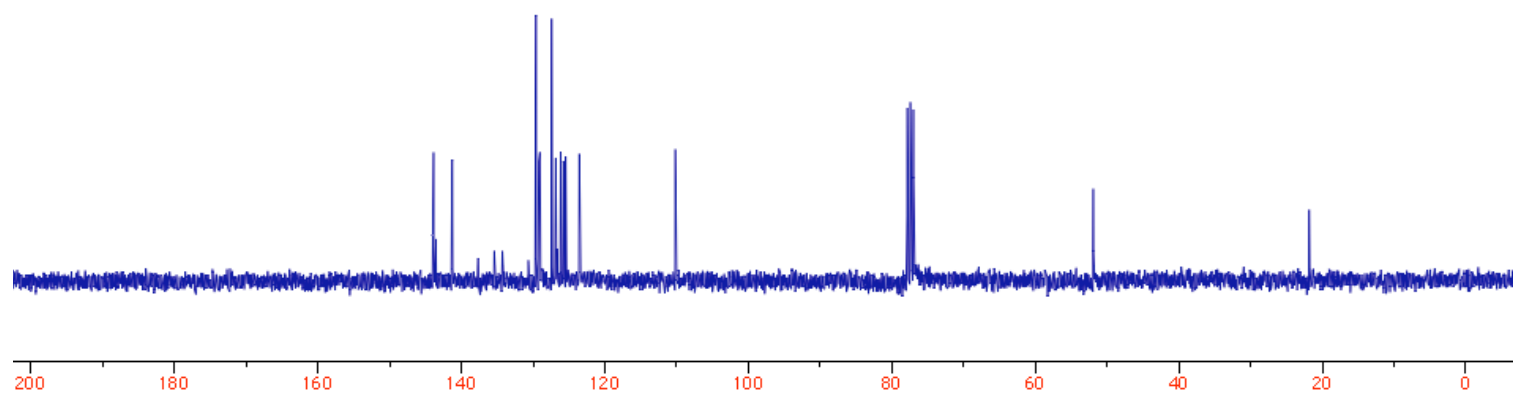

$500 \mathrm{MHz}{ }^{1} \mathrm{H}$ and $125 \mathrm{MHz}{ }^{13} \mathrm{C}\left\{{ }^{1} \mathrm{H}\right\} \mathrm{NMR}$ in $\mathrm{CDCl}_{3}$ 


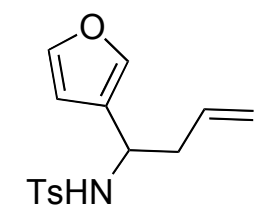

$12 f$
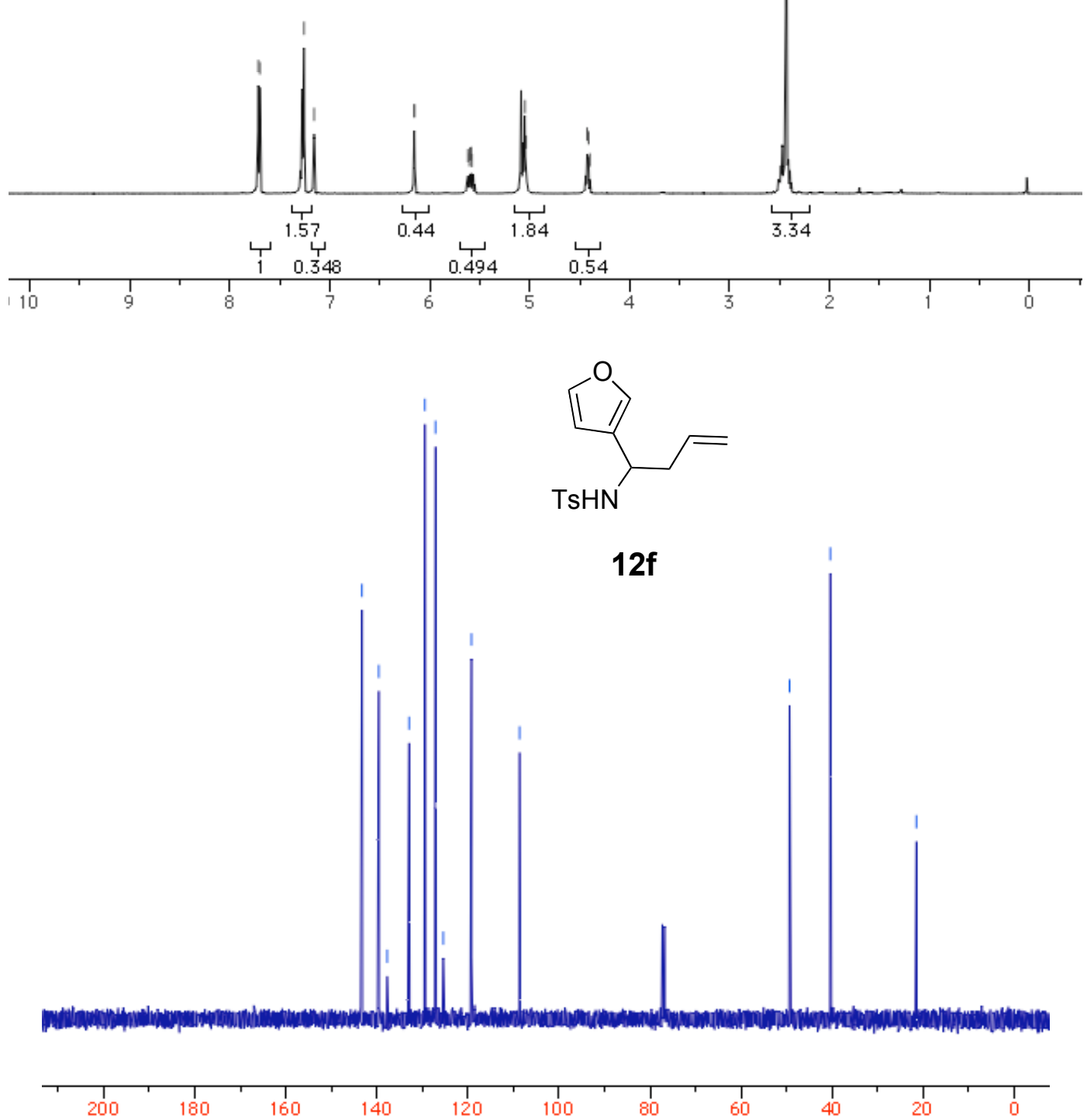

$500 \mathrm{MHz}{ }^{1} \mathrm{H}$ and $125 \mathrm{MHz}{ }^{13} \mathrm{C}\left\{{ }^{1} \mathrm{H}\right\}$ NMR in $\mathrm{CDCl}_{3}$ 


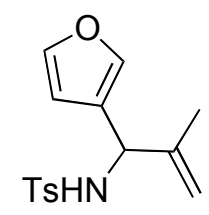

$12 \mathrm{~g}$
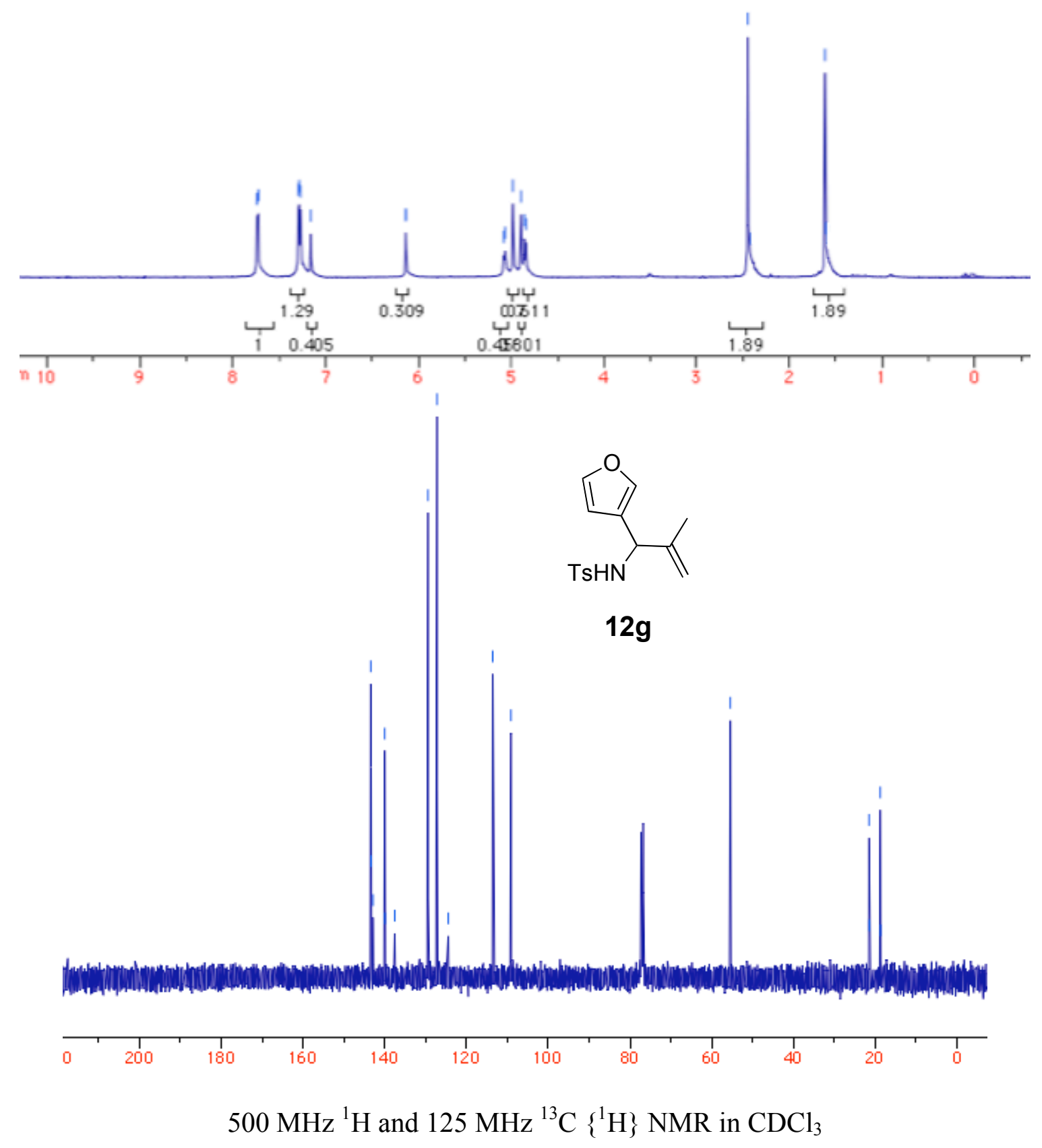

SI-88 


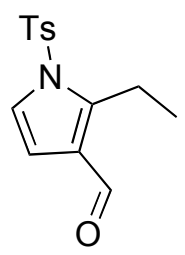

$13 a$

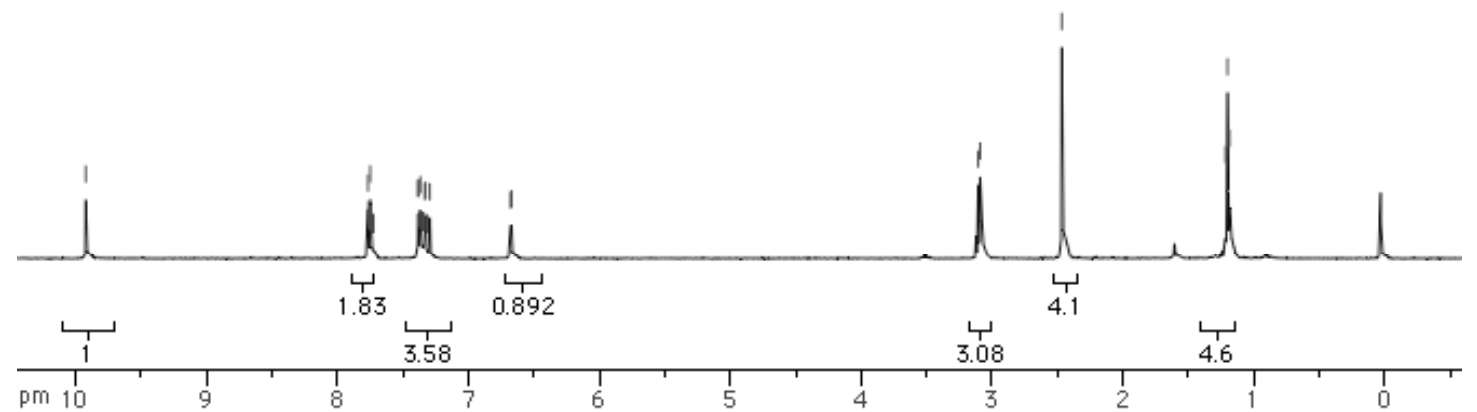

Ts

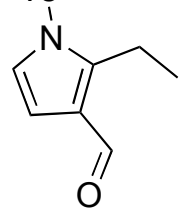

$13 a$
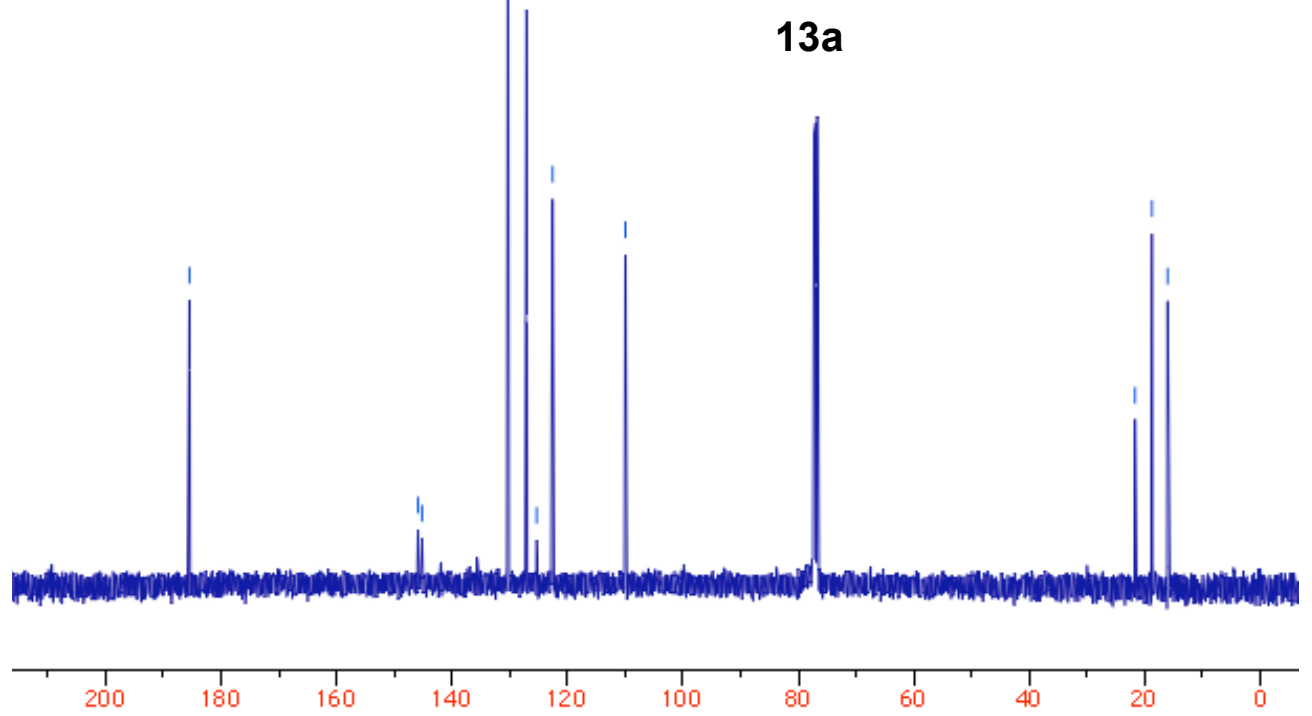

$500 \mathrm{MHz}{ }^{1} \mathrm{H}$ and $125 \mathrm{MHz}^{13} \mathrm{C}\left\{{ }^{1} \mathrm{H}\right\} \mathrm{NMR}$ in $\mathrm{CDCl}_{3}$ 


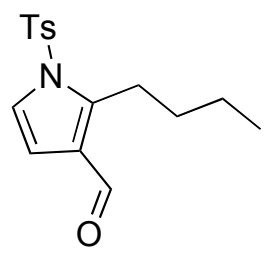

13b
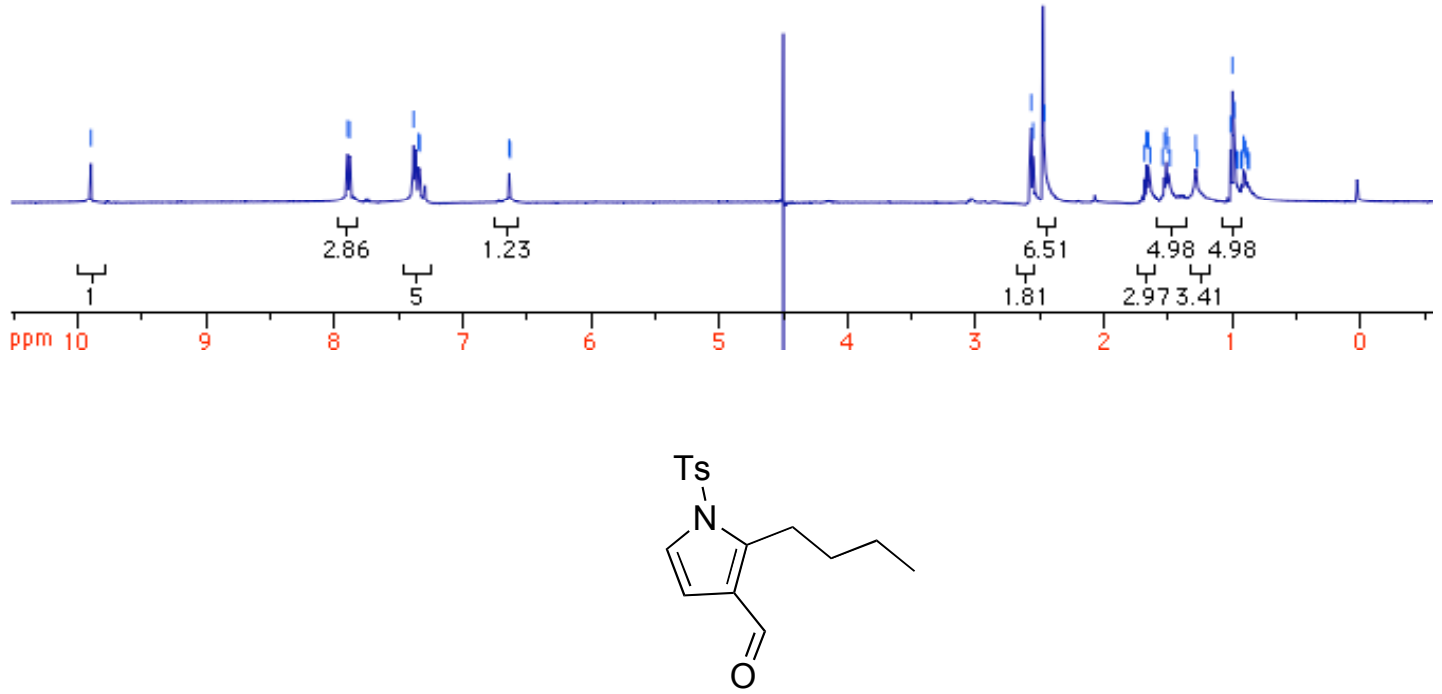

13b

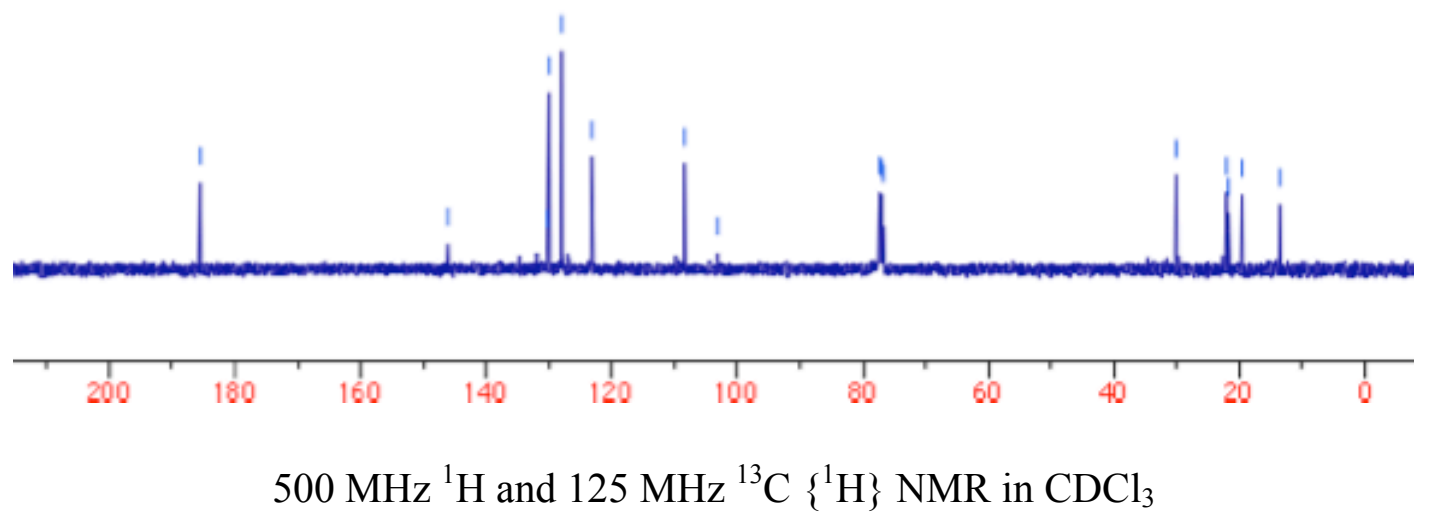




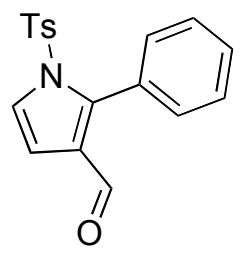

$13 c$
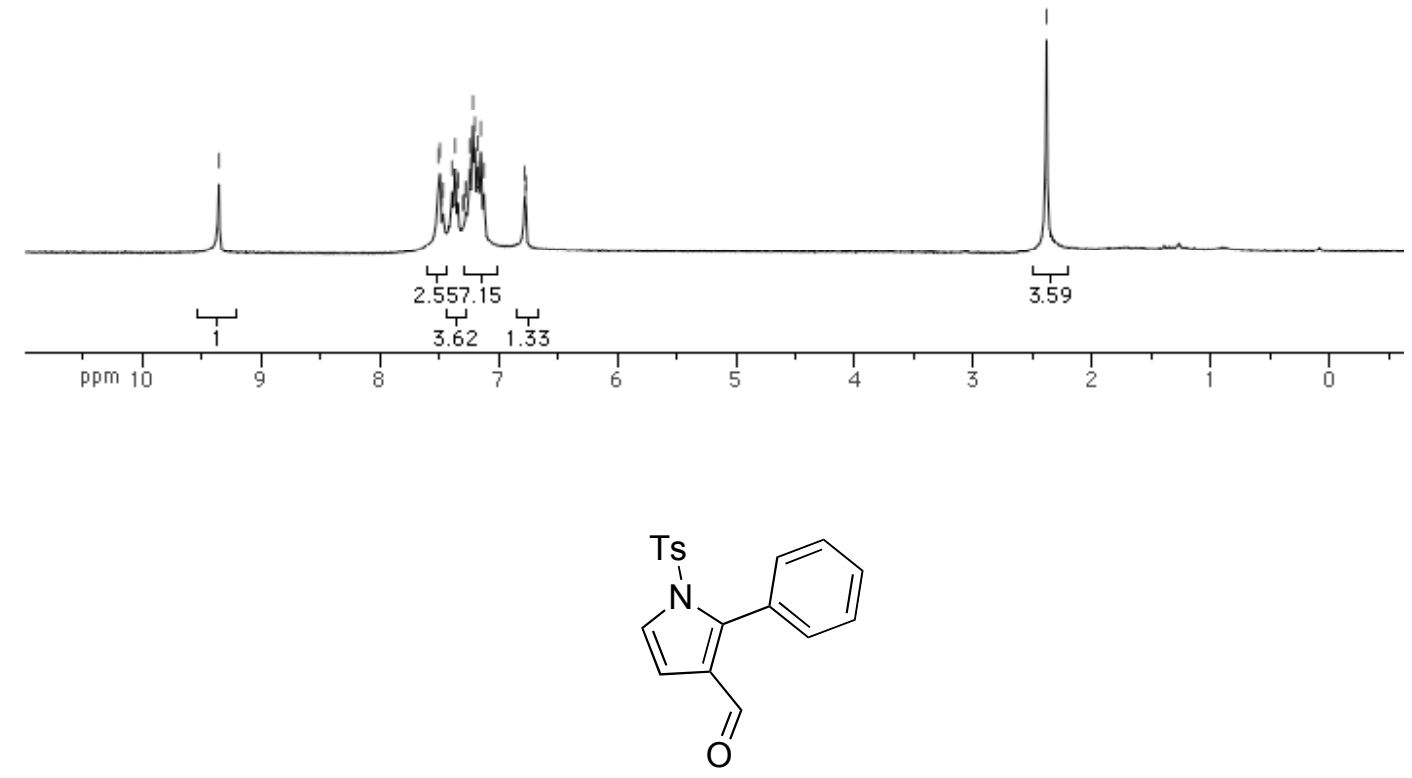

$13 c$
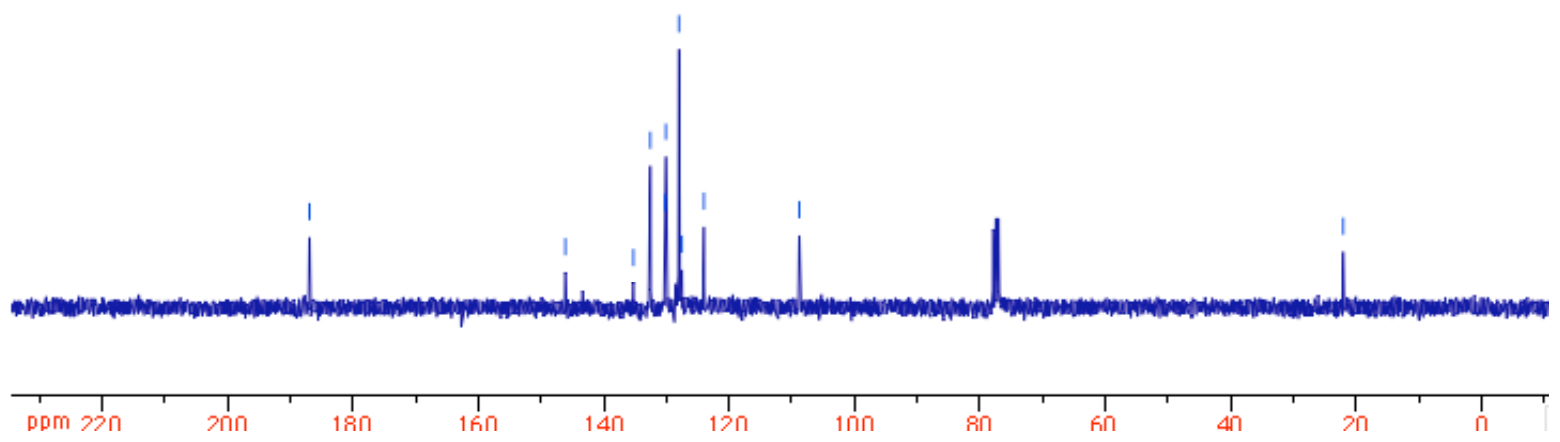

$300 \mathrm{MHz}{ }^{1} \mathrm{H}$ and $75 \mathrm{MHz}{ }^{13} \mathrm{C}\left\{{ }^{1} \mathrm{H}\right\} \mathrm{NMR}$ in $\mathrm{CDCl}_{3}$ 

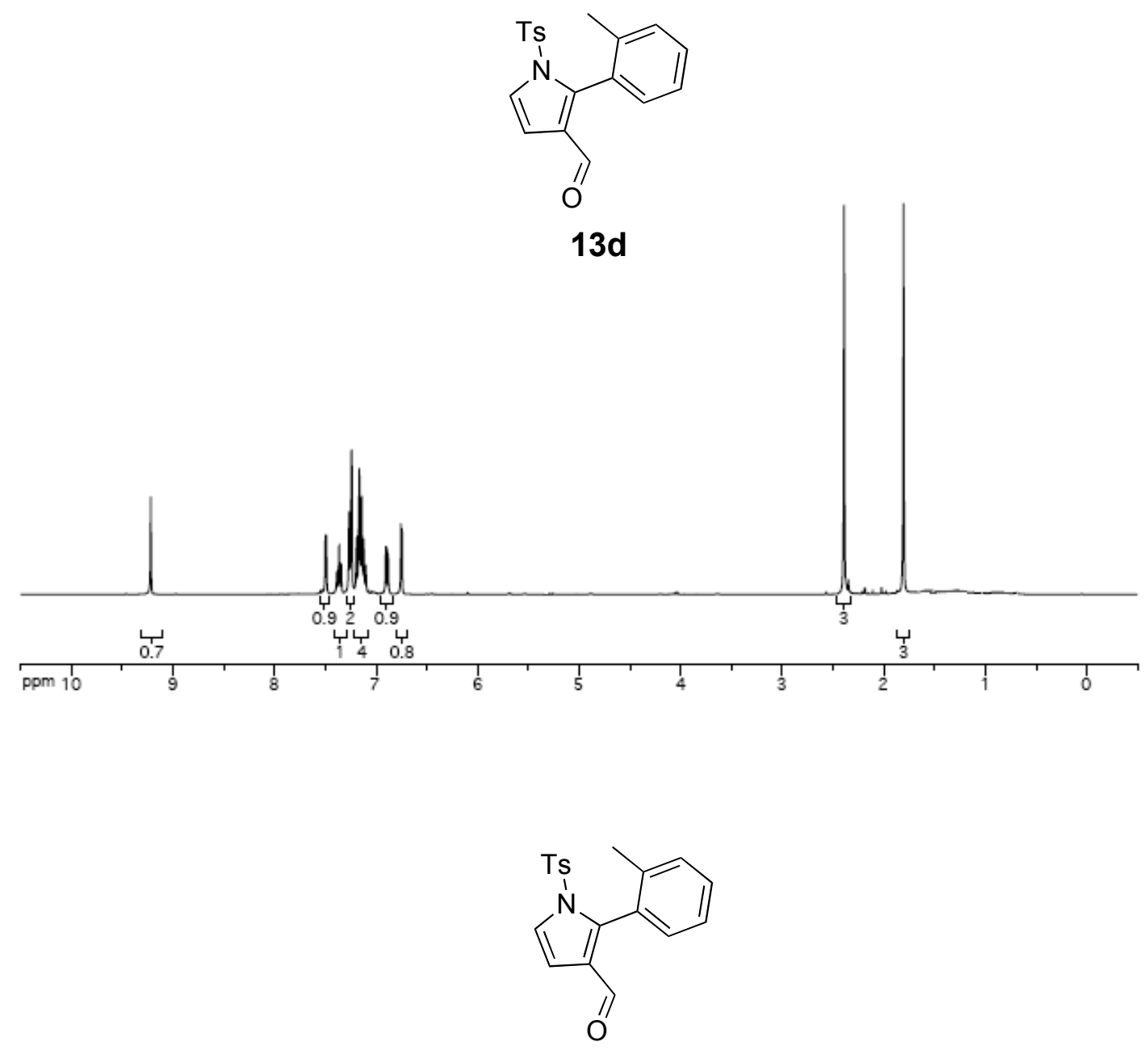

13d
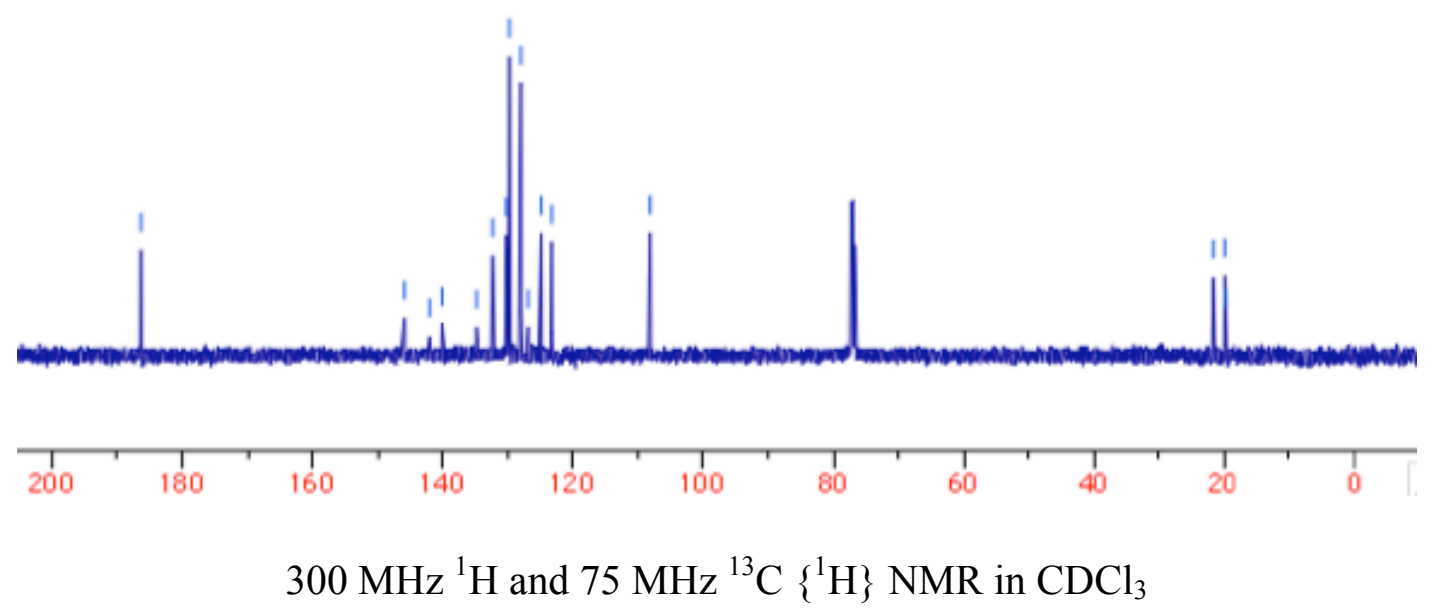

SI-92 


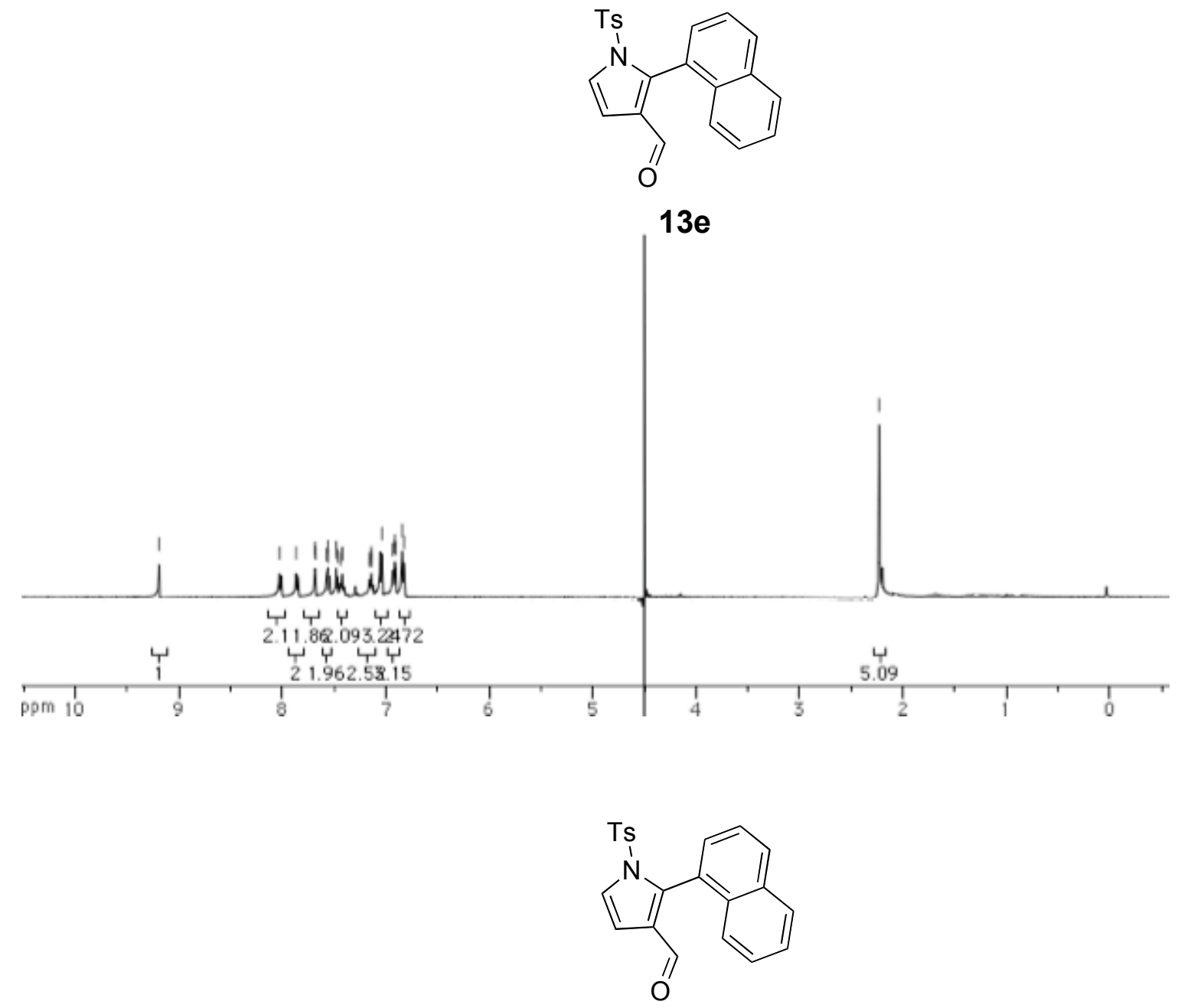

$13 e$
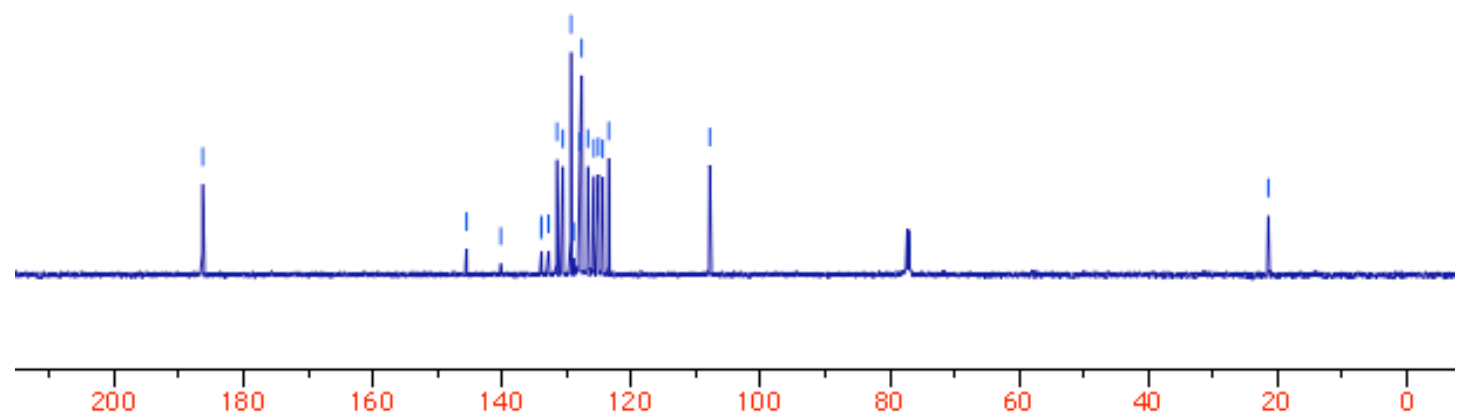

$500 \mathrm{MHz}{ }^{1} \mathrm{H}$ and $125 \mathrm{MHz}{ }^{13} \mathrm{C}\left\{{ }^{1} \mathrm{H}\right\}$ NMR in $\mathrm{CDCl}_{3}$ 

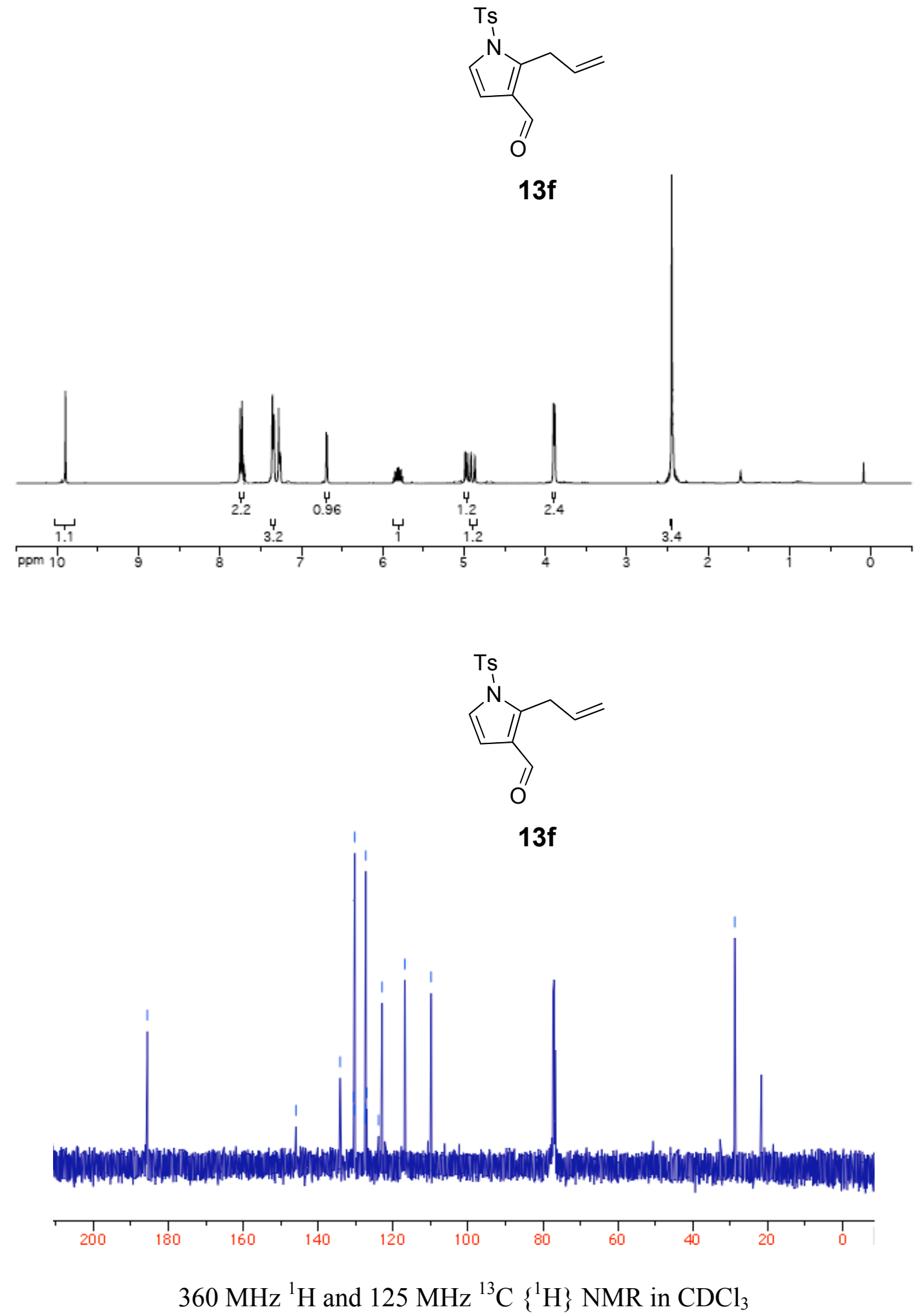

SI-94 

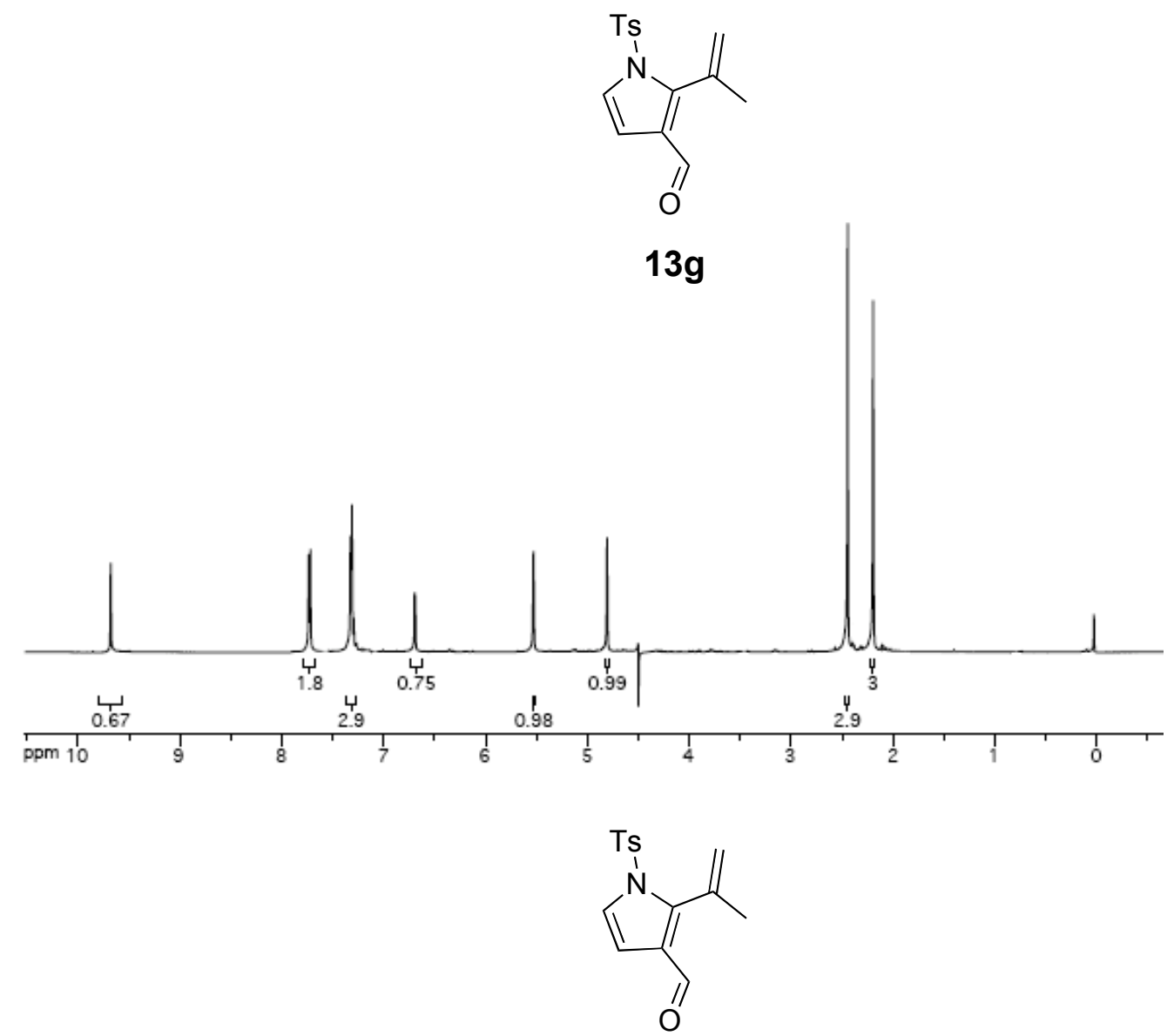

$13 \mathrm{~g}$
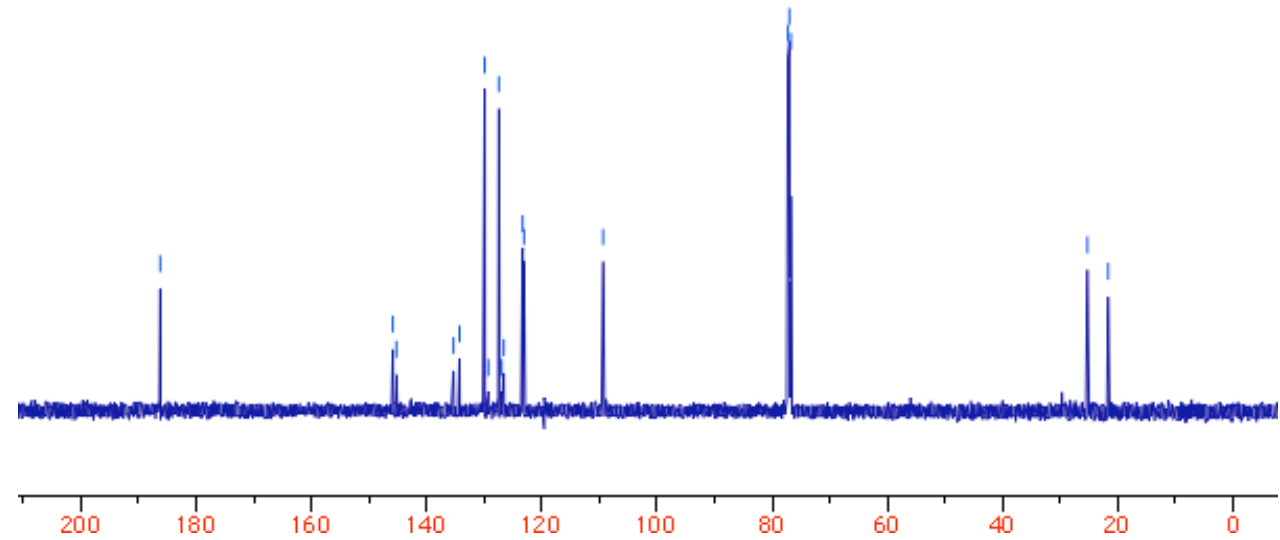

$500 \mathrm{MHz}{ }^{1} \mathrm{H}$ and $125 \mathrm{MHz}{ }^{13} \mathrm{C}\left\{{ }^{1} \mathrm{H}\right\}$ NMR in $\mathrm{CDCl}_{3}$ 